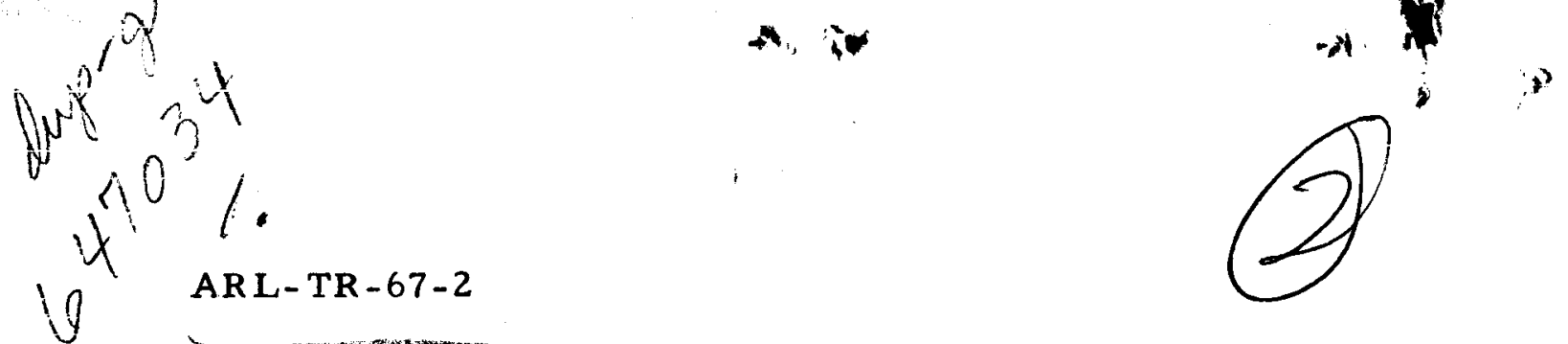

\title{
REPLICATION AND EXTENSION OF RAPID DECOMPRESSION OF CHIMPANZEES TO A NEAR VACUUM
}

Edited by Alfred G. Koestler

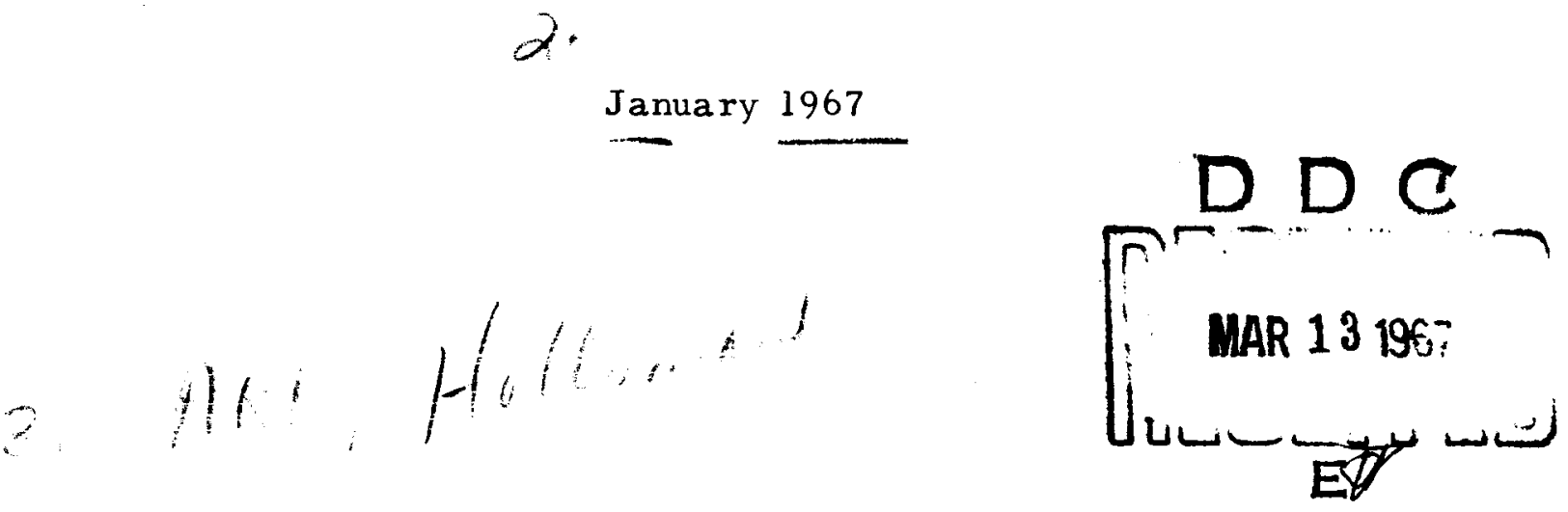

Distribution of this document is unlimited.
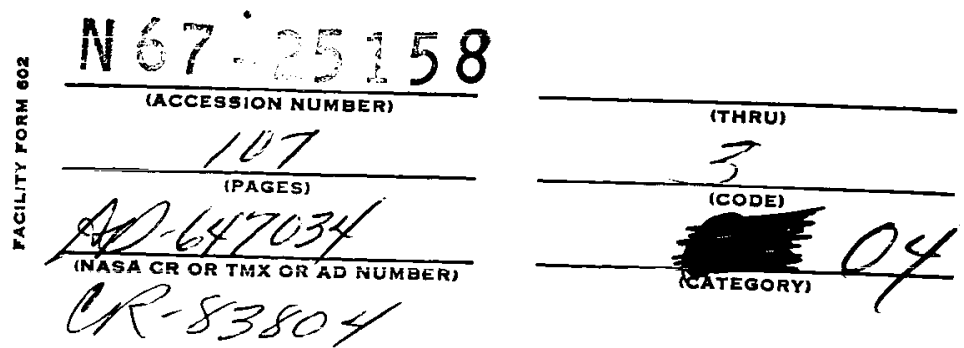

6571st Aeromedical Roscarch Laboratory

Aerospace Medical Division

Air Force Systems Command

Holloman Air Force Base, New Mexico 
The animals used in this study were handled in accordance with the "Guide for Laboratory Animal Facilities and Care" as promulgated by the National Academy of Sciences - National Research Council.

Certain of the animals used for this research were provided by the National Aeronautics and Space Administration under Order R-25.

This report may be reproduced to satisfy needs of U.S. Government agencies. No other reproduction is authorized except with permission of the 6571st Aeromedical Research Laboratory, Holloman AFB, NMex.

This report is made available for study with the understanding that proprietary interests in and relating thereto will not be impaired. In case of apparent conflict or any other questions between the Government's rights and those of others, notify the Judge Advocate, Air Force Systems Command, Andrews Air Force Base, Washington, D.C.

Do not return this copy. Retain or destroy. 


\section{REPLICATION AND EXTENSION OF RAPID DECOMPRESSION OF CHIMPANZEES TO A NEAR VACUUM}

Edited by Alfred G. Koestler

$$
\text { January } 1967
$$

Distribution of this document is unlimited. 


\section{FOR EWOR D}

This research was accomplished between 1 April 1965 and 31 August 1966 by the 6571 st Aeromedical Research Laboratory, Holloman Air Force Base, New Mexico, under Contract (T-39909G) with the Directorate of Medical Research and Operations, NASA Manned Spacecraft Center, Houston, Texas. Acknowledgement is made of contract monitorship by Dr. Wayland Hull and Miss Margaret Jackson of the Medical Research Directorate and of their continual interest in and enthusiam for this research.

The assistance of the following persons of the 6571st Aeromedical Research Laboratory is gratefully acknowledged: Lt Colonel Herbert $H$. Reynolds for his technical advice on experimental design, analysis of data and interpretation of the results; Lt Colonel James E. Prine for pathology support; Mr. John Phelps and A2C James Graham for experimental monitoring and data reduction; A2C Ronald Jeter for data reduction and TSgt Neil Catone and A2C Harry Wagner for their electronic support.

Special recognition is also due the following technical and administrative support personnel for their outstanding efforts throughout all phases of this program: $\mathrm{Mr}$. Bob Halferty and $\mathrm{Mr}$. Art Prell, cinematography; Mr. Bill Taylor, still photography; Mrs. Norma Jean Lacey, Miss Rosemary Holguin and Mrs. Sandra Gibson for the typing of the drafts and final copy of this report.

As a result of the findings in this research, a replication of the tests involving 180 and 210 seconds of exposure and an extension and replication of tests with 240 seconds of exposure to a near vacuum will begin in February 1967. This research will permit a more reliable statement of the limits of impairment and recovery which is needed for manned spaceflight programs.

\section{水水秋}

This report has been reviewed and is approved for publication.

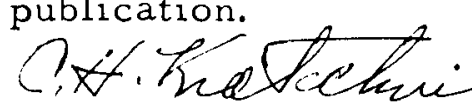

C. H. KRATOCHVIL, Lt Colonel, USAF, MC Commander 


\begin{abstract}
Nine chimpanzees were decompressed from $179 \mathrm{~mm}$. Hg (breathing 100 percent oxygen) to less than $2 \mathrm{~mm}$. $\mathrm{Hg}$ in .8 second and remained at this altitude from 90 to 210 seconds. After recompression with 100 percent oxygen to $179 \mathrm{~mm}$. Hg, the subjects were maintained at this pressure environment for 4 hours post decompression. Results of these tests, which were of replicatory nature, have substantiated previous findings that chimpanzees can survive sudden exposure to a near vacuum and recover within 4 hours to once again satisfactorily perform complex behavioral schedules on which they had had extensive training. One subject of questionable fitness expired following a 90second exposure to a near vacuum. ECG, respiration, and skin temperature were recorded as a standard procedure from all subjects, only two of which were instrumented for EEG. All subjects demonstrated tachycardia immediately following decompression which was regularily followed by a rather sudden bradycardia. There was an initial drop in skin temperature immediately after decompression with an ensuing gradual fall resulting in a total decrease of 1.7 to $2.0^{\circ} \mathrm{C}$. Visual inspection of the EEG as well as power spectral density computer analysis indicated the expected greater subcortical resistance to anoxia when compared to cortical responses. Evoked responses to stimulation of subcortical areas were used as indicators of excitability.
\end{abstract}


ABSTRACT

INTR ODUCTION

METHODOLOGY

Subjects

Apparatus

Performance Schedule

Procedure

Photographic Documentation

Statistical Approach

RESULTS

DISCUSSION

CONCLUSION

REFERENCES

APPENDIX I - Avoidance Performance Schedule for Rapid Decompression Studies

APPENDIX II - Veterinary Necropsy Protocol

APPENDIX III - Detailed Statistical Comparisons of

ABSTRACT

INTRODUCTION

METHODOLOGY

Apparatus

Procedure

RESULTS

65

Decompression

65

Recompression and Recovery

EEG Computer Analysis

DISCUSSION AND CONCLUSIONS 
SECTION III - CLINICAL EVALUATION

INTRODUCTION

97

CLINICAL EVALUATION

SECTION IV - PHYSICAL ENVIRONMENT

SUMMARY

101 
SECTION I

PERFORMANCE

Alfred G. Koestler

Louis M Barker, A IC, USAF

Comparative Psychology Division

6571st Aeromedical Research Laboratory Aerospace Medical Division

Air Force Systems Command

Holloman Air Force Base, New Mexico 


\section{ABSTRACT}

Nine chimpanzees were decompressed from $179 \mathrm{~mm} . \mathrm{Hg}$ (breathing 100 percent oxygen) to less than $2 \mathrm{~mm}$. Hg in .8 second and remained at this altitude from 90 to 210 seconds. After recompression with 100 percent oxygen to $179 \mathrm{~mm}$. $\mathrm{Hg}$, the subjects were maintained at this pressure environment for 4 hours post decompression. Results of these tests, which were of replicatory nature, have substantiated previous findings that chimpanzees can survive sudden exposure to a near vacuum and recover within 4 hours to once again satisfactorily perform complex behavioral schedules on which they had had extensive training. One subject of questionable fitness expired following a 90 -second exposure to a near vacuum. 


\section{INTRODUCTION}

In past official statements, personnel of the Directorate of Medical Research and Operations, NASA Manned Spacecraft Center, Houston, have posed the following questions $(1,2$,$) :$

1. What are the chances for survival for varying time exposures to a vacuum before recompression is initiated?

2. What emergency repressurization schedules should be planned for the vehicle cabin?

3. How soon will the crew member recover consciousness after varying periods of exposure?

4. How soon and how well will the crew member be able to carry out his duties after varying periods of exposure?

5. Will irrational behavior or sickness present any hazards to the completion of the mission?

Answers to these questions were partially provided in a report (3) by the 657 lst Aeromedical Research Laboratory, Holloman AFB, New Mexico when, in a series of experiments, nine chimpanzees were rapidly decompressed to a near vacuum (less than $2 \mathrm{~mm}$. $\mathrm{Hg}$ ). These subjects were exposed to this near vacuum for periods of 5 to 150 seconds. Results from these experiments showed that all subjects not only survived the exposures in excellent health but recovered within 4 hours after rapid decompression and were able to execute a complex be havioral schedule at a pre-exposure level of performance. Times of useful consciousness varied from 8.0 seconds to 29.7 seconds and the subjects were totally incapacitated for 0.42 minute to 38. 69 minutes, depending on the length of exposure to the near vacuum. From the behavioral data it was concluded that central nervous system damage was absent or negligible and would not hinder the subjects from performing adequately on tasks on which they had been previously trained. 
The purpose of this paper is to report on another series of nine decompression experiments with chimpanzees which were designed to replicate exposures to a near vacuum from 90 seconds to 150 seconds and to extend exposure times to near vacuum up to $3-1 / 2$ minutes (210 seconds).

\section{METHODOLOGY}

Subjects

Nine chimpanzees (five males and four females) from the chimpanzee colony at the 657 ist Aeromedical Research Laboratory at Holloman Air Force Base, New Mexico, were as signed to this project. Their approximate ages (determined by dental eruption) and weights (on the day of decompression) are summarized in Table $\mathrm{I}$.

Apparatus

The experimental apparatus consisted of an environmental system, behavioral programming and recording equipment, and a subject restraint couch with a performance panel. These systems are described briefly below but a detailed description may be found in Reference 3 .

\section{A. Environmental System}

During experimentation, subjects were maintained in an environmental (decompression) chamber, 76.2 by 121.9 by 121.9 centimeters, containing a volume of 1.132 cubic meters.

Atmospheric conditions (pressure, gas composition, temperature, and relative humidity) inside the chamber were monitored and controlled by a coupled life support system.

The decompression chamber was connected via a 45.7 $\mathrm{cm}$. diameter decompression valve to a 117.51 cubic meter volume vacuum system. With the chamber at $179 \mathrm{~mm}$. Hg and the parasitic system at approximately 140 micron $\mathrm{Hg}$. the resultant initial pressure equilibrium after decompression (approximately 1 second) was less than $2 \mathrm{~mm}$. $\mathrm{Hg}$. 


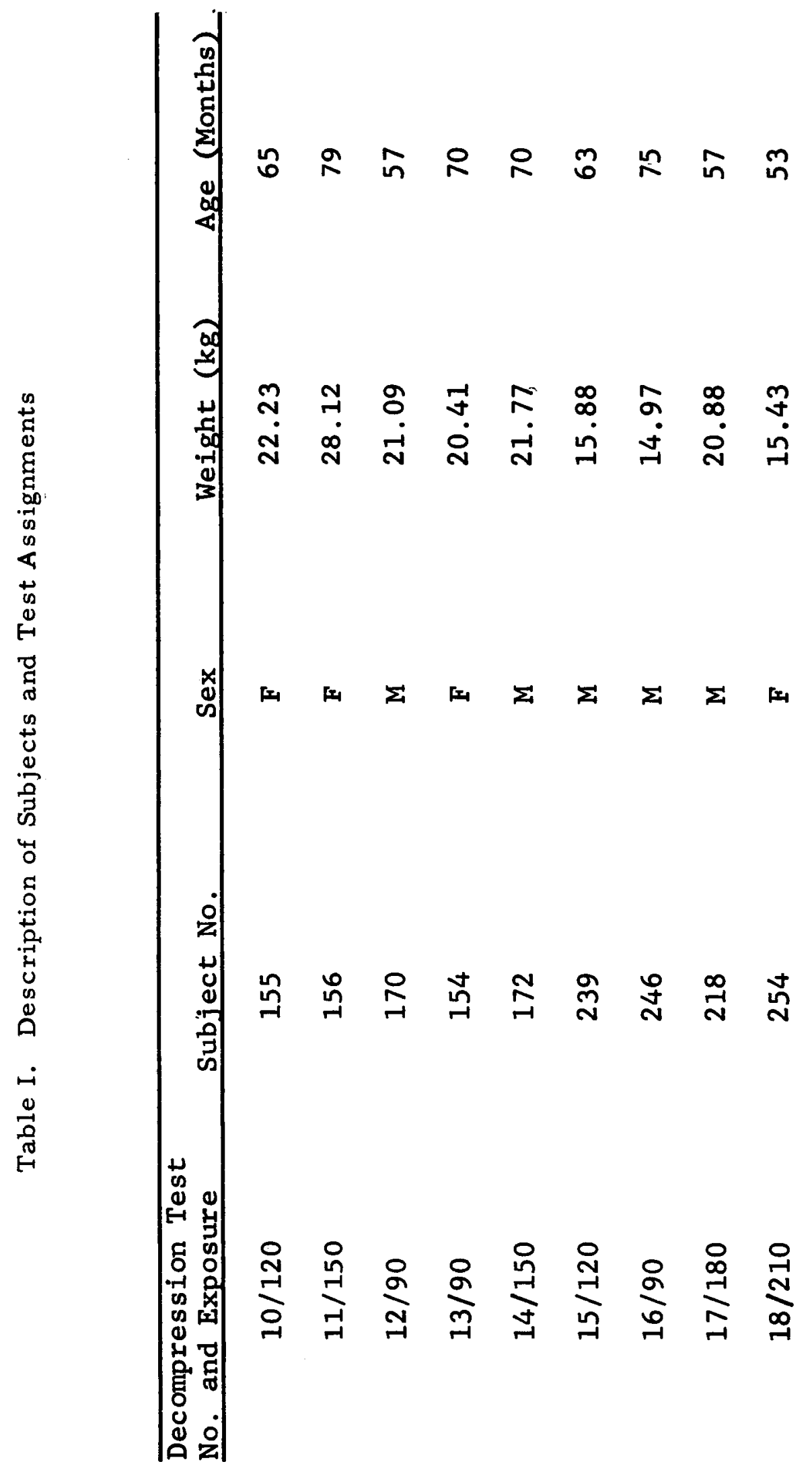


A schematic of the chamber, valve, and vacuum tanks is presented in Figure 1. Also evident in the schematic is a liquid nitrogen coil shroud covering the entrance to the first vacuum tank. This super-cooled coil condensed moisture as it left the decompression chamber and assisted in maintaining a near vacuum during the decompression period.

B. Behavioral Programming and Recording Equipment

Training programming equipment consisted of commercially available relay systems 1,2 , while the experimental programming equipment was of the solid state variety ${ }^{3}$. Besides read-out counters, digital print-out counters recorded reaction times to within one-tenth of a second, while cumulative type recorders reflected rates of response. As a back-up system, an eight-channel oscillograph recorded reaction times, responses, reinforcements, and IRIG - C time code.

$\overline{\mathrm{I}_{\text {Grayson Stadler }}}$ Co., West Concord, Mass.

${ }^{2}$ Foringer and Co., Inc., Rockville, Md.

${ }^{3}$ BRS Electronics Inc., 5451 Holland Drive, Beltsville, Md. 


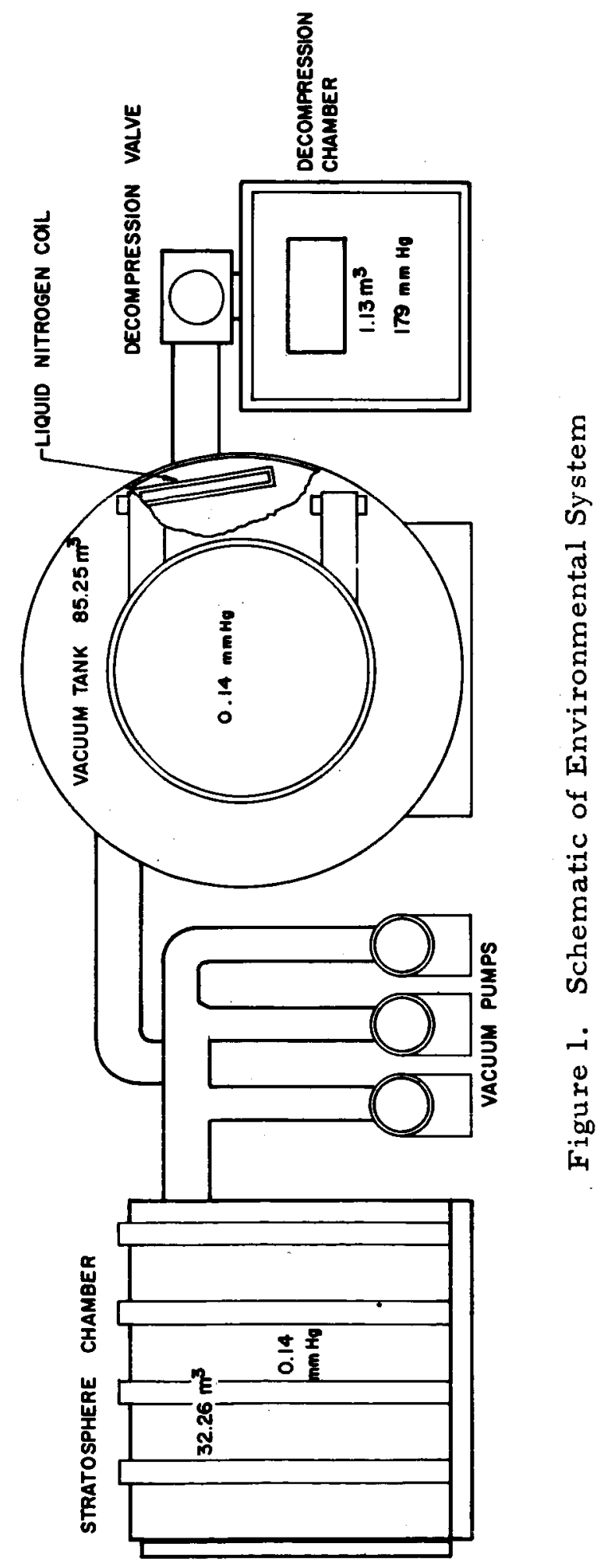




\section{Performance Panel and Restraint Couch}

The performance panel consisted of 10 visual and auditory stimulus displays and corresponding response manipulanda which were located within easy reach of the subject. The performance unit also contained automatic food pellet dispensers and a water reservoir. The panel was removable from a form-fitted fiberglass couch which kept the subject's thighs perpendicular to its back as shown in Figure 2. The subjects were restrained in the couch with straps from a loosely fitting net restraint suit which also protected physiological sensors (EKG, respiration, cardiotachometer, and skin temperature).

During those experiments which provided for neurophysiological recordings, a well ventilated plexiglass shield was mounted over the subject's head. This shield permitted excellent visibility and an opportunity for feeding, yet prevented the subject from tampering with the EEG electrodes and EEG cables.

Performance Schedule

A standard 22-minute performance module, previously described in detail in Reference 3, was used on all decompression experiments.

The first 12 minutes of the performance module constituted the avoidance phase, i. e., the subject performed tasks in order to avoid delivery of a mild electric shock. It consisted of a continuous motor task and superimposed reaction time tasks. The continuous avoidance (CA) task (4) covered the entire period and required the subject to depress a lever at least once every 5 seconds. The following dependent variables were measured: average lever presses per minute and an efficiency measure based on the ratio of the number of shocks avoided versus the total possible number of shocks (144) the subject could receive.

Concurrent with CA the subject was conditioned to respond to three reaction time tasks: auditory monitoring (AM), visual monitoring (VM), and discrete avoidance (DA). AM required the subject to depress a pushbutton within $I$ second of 


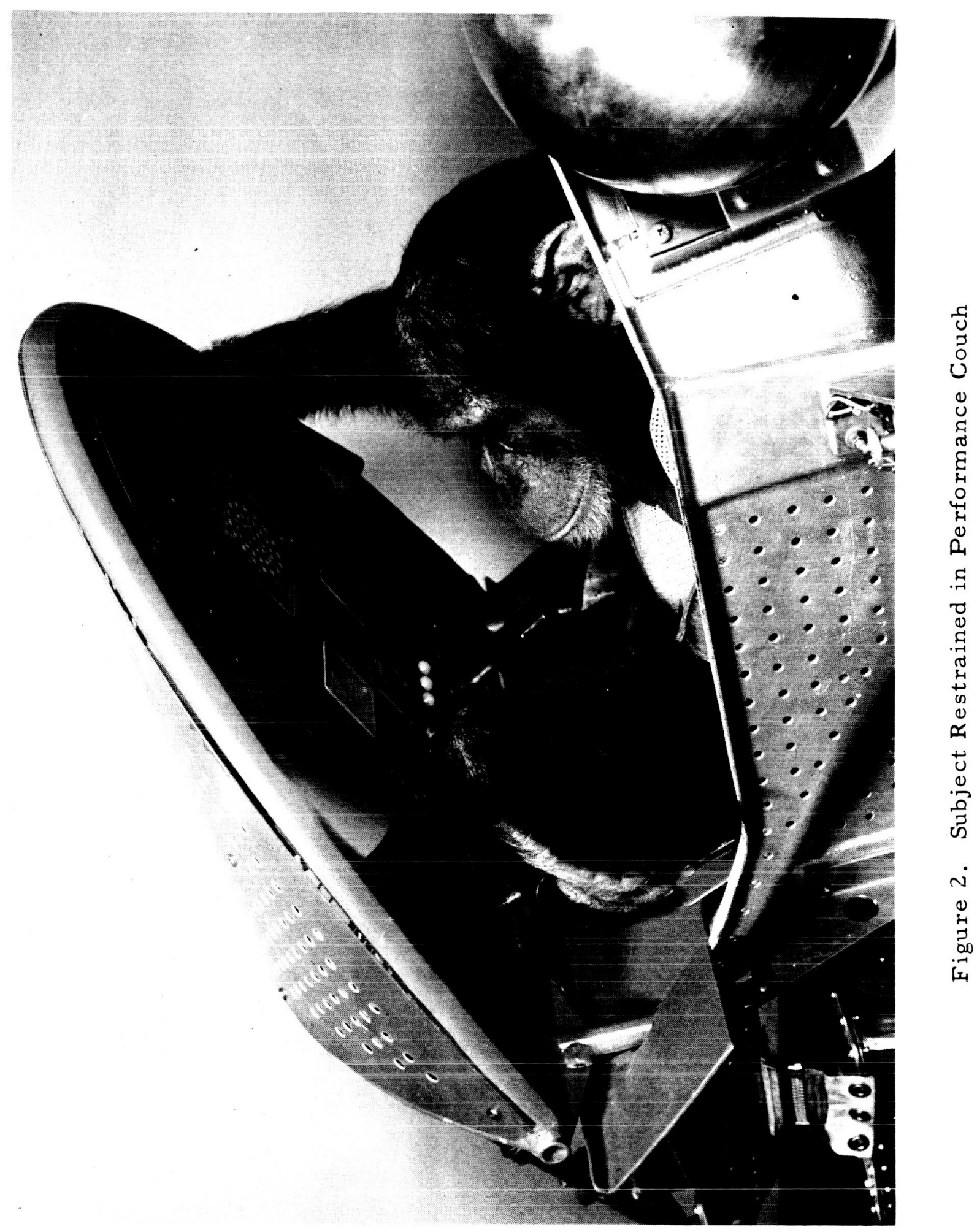


the onset of a $60 \mathrm{db}, 1000 \mathrm{c} . \mathrm{p} . \mathrm{s}$. tone. Reaction time tasks to visual cues required the subject to either depress a lever (DA) or push a response plate (VM) within l second of the onset of respective visual stimuli. These discrete events occurred eithe $r$ alone or in conjunction with another discrete stimulus e. g. a VM stimulus occurred paired with an AM or a DA cue, while the subject was also attending to the CA task. A temporal sequence of the avoidance program events is presented in Appendix I. The measured parameters of all discrete events (77) consisted of response latencies determined in tenths of seconds and of an efficiency precentage measure derived from the ratio of number of correct responses versus the total number of presentations.

The last 10 minutes of the performance module was an "oddity" task which was designed to evaluate discrimination efficiency and choice response latency. This program required the subject to select the "odd" symbol of three geometric symbols presented by pressing a corresponding response plate. The procedure was corrective (wrong choices were repeated). Successful choices were reinforced by the avoidance of electric shock and an opportunity to select food or water. Oddity problems were separated by 20 seconds and the subject was allowed 10 seconds for each choice.

Following the oddity task, a rest period of 13 minutes was provided before a new performance module was cycled.

Procedure

\section{A. Training}

Each decompression subject underwent intensive training on all tasks of the performance schedule. Training was initiated in a restraint chair (Fig. 3) and was continued in a restraint couch to acquaint each subject with a reclining body position, a restraint suit, and the new location of the performance panel (Fig. 2).

\section{B. Baseline}

Two days before an actual decompression study, baseline data were gathered. 


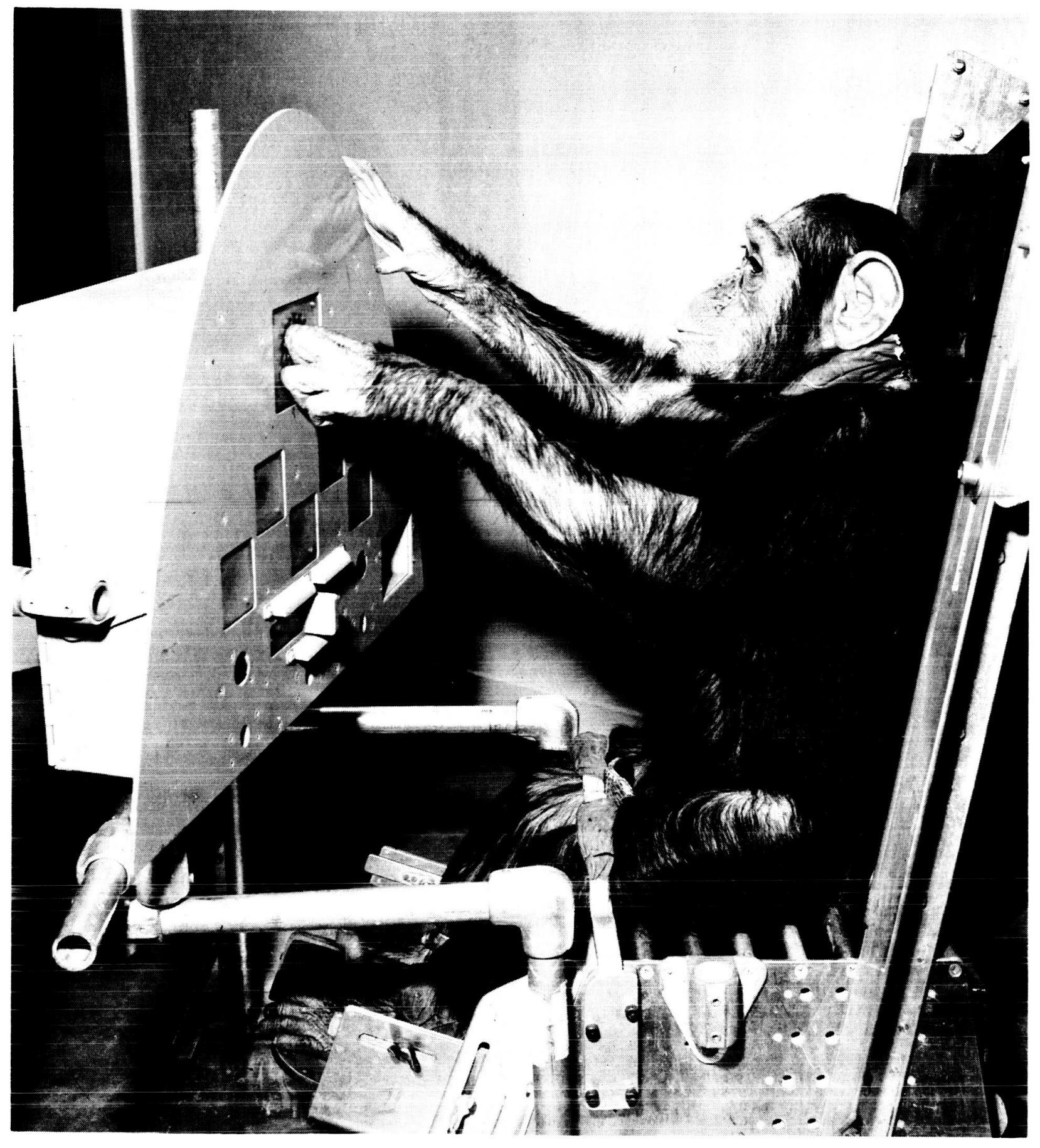

Figure 3. Subject Seated in a Training Chair 
At 0700 hours of the baseline day the subject was given a brief physical examination (a thorough examination was administered four days previously). After physiological sensors were attached, the subject was then secured in the restraint couch and transported to the chamber area. By 0830 hours the subject was placed into the decompression chamber and following behavioral, physiological, and environmental instrument checks, the chamber door was sealed. Purging with dry, bottled oxygen began with the sealing of the chamber door and the attainment of a 95 percent $\mathrm{O}_{2}$ concentration in the chamber marked the beginning of the denitrogenation period which continued for 180 minutes with maximum attainable $\mathrm{O}_{2}$ concentration (100 percent). Ambient pressure (660 mm. Hg ) was maintained in the chamber during this time.

Thirty minutes, and again at two hours after the onset of denitrogenation, a complete performance module was presented to the subject.

Ascent to $179 \mathrm{~mm}$. Hg ( 100 percent $\left.\mathrm{O}_{2}\right)$ began at the termination of the denitrogenation period. This reduction in pressure was accomplished in an average of 13 minutes. A complete performance module was presented 10 minutes after the attainment of $179 \mathrm{~mm}$. $\mathrm{Hg}$ and was followed by a 13-minute rest. A "sham decompression" was inserted into the second performance module after attainment of 179 $\mathrm{mm}$. Hg. The exact point of the sham decompression was determined by the performance module (see Appendix I). Following the sham decompression the avoidance portion of the performance module was recycled and presented to the subject (separated by one minute rest breaks) twice in succession. A normal work-rest sequence ( 22 minutes of performance and 13 minutes rest) was then pursued for 4 hours after the sham decompression. For studies which had extended exposure times to the near vacuum ( 180 seconds and 210 seconds) the post sham RD time was expanded to 8 hours in the expectation of longer recovery periods. During these extended baseline days, I hour of rest was inserted at 4 hours and 6 hours post sham RD.

At the end of this period the subject was then recompressed to ambient pressure with air. After removal from the chamber, the subject was transported to the Veterinary Division. There, all physiological sensors were removed and a brief physical examination was performed. The subject was placed into a metabolic cage to collect urine and feces samples. The time between the baseline test and the actual decompression test was used to rest the subject. 
Physiological recordings began simultaneously with the closing of the decompression chamber and were repeated as often as the attending physiologist considered necessary for sampling purposes of baseline data. However, continuous recording was accomplished immediately prior to, during, and subsequent to the sham decompression.

\section{Experimental}

On the day of the decompression test the procedure described under "baseline" was followed with the following exceptions:

The sham decompression was substituted by the actual decompression. Decompression from $179 \mathrm{~mm}$. Hg $(100$ percent oxygen) to less than $2 \mathrm{~mm} \mathrm{Hg}$ was accomplished on the average in 0.8 seconds while recompression from the near vacuum to $179 \mathrm{~mm}$. $\mathrm{Hg}$ (with 100 percent oxygen) was always accomplished in 30 seconds. Exposure time to near vacuum was predetermined and was measured from the onset of de compression to the onset of recompression.

The negative reinforcement device was switched off 30 seconds after the subject made the last appropriate response to a meaningful stimulus and was reactivated when the attending physiologist indicated sufficient physiological and neurological recovery by the subject.

Following recompression, the avoidance portion of the performance module was recycled until the subject made the first appropriate response to a meaningful stimulus, thus ending the time of total behavioral impairment. The particular program module during which the subject made its first response following decompression was then presented in total (avoidance and oddity) and the nominal work-rest sequence ( see performance schedule) was continued for a minimum of 4 hours post decompression or until the subject had again regained a pre-exposure level or performance. A schematic of the test profile is presented in Figure 4. 


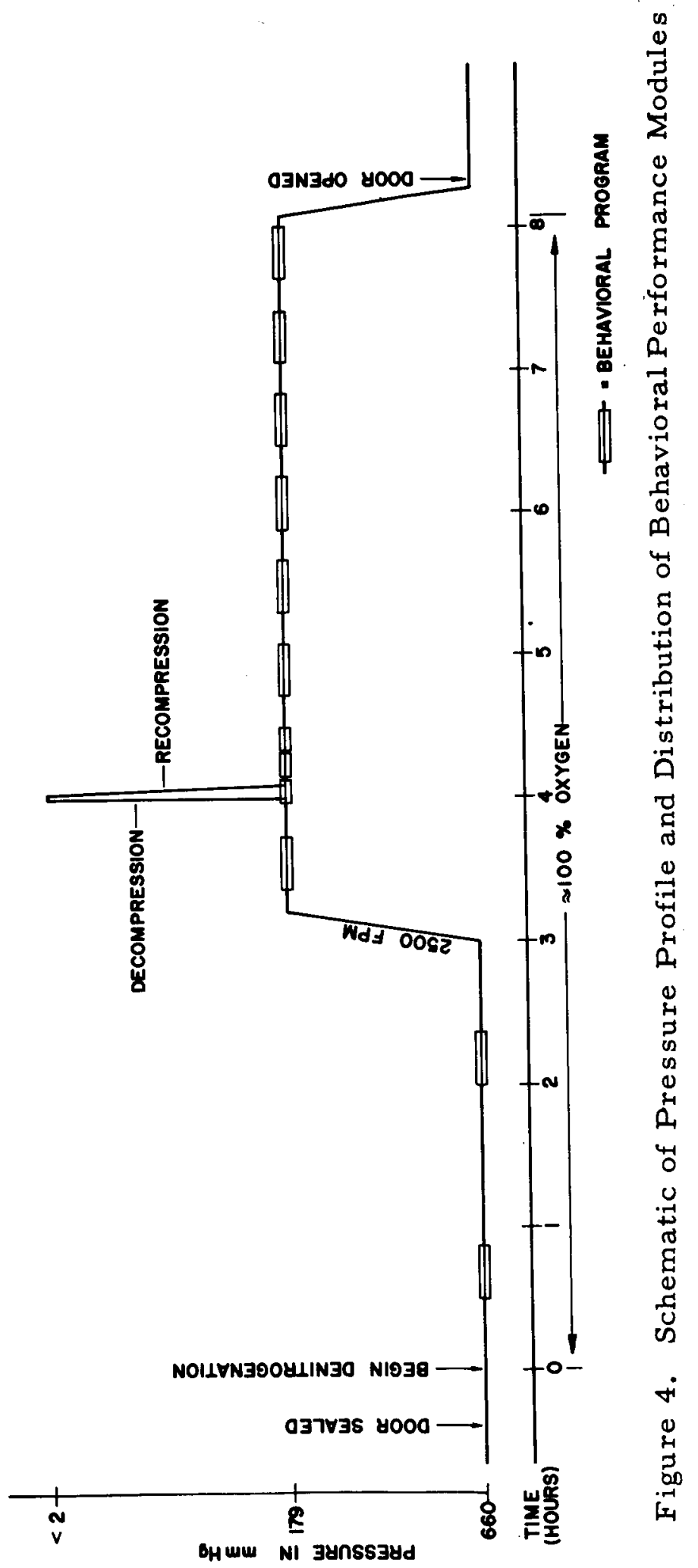


Photographic Documentation

Black and white still pictures were taken of the subject during the experimental conditions. The pictures included one photograph every 15 seconds starting with decompression and ending with completed recompression.

A 100 foot color film with a 48 frames/second exposure rate began 5 seconds prior to decompression and continued until the film was exhausted. A second color film ( $1200 \mathrm{feet}$ ) with a 24 frames/second exposure rate began 30 seconds prior to decompression and $\mathrm{r}$ an for approximately 10 minutes. The camera was restarted when the subject showed signs of recovery and continued until the film was exhausted.

Stat istical Approach

\section{A. Definitions}

1. "Baseline data" included all behavioral meas ures recorded during baseline sessions and the data obtained on the experimental day before RD occurred.

2. "Experimental data" included all behavioral measures beginning with the first appropriate responses to a meaningful stimulus following the period of total impairment and ending with the removal of the subject from the experimental environment.

3. "Time of useful consciousness (TUC)" encompassed the time elapsed between the onset of RD and the last appropriate response to a meaningful stimulus immediately föllowing $R \mathbf{D}$.

4. "Time of total impairment (TTI)" described the time elapsed between the end of TUC and the first appropriate response to a meaningful stimulus following TUC.

5. "Total behavioral recovery (TBR)" represented the time elapsed between the onset of RD and the point in time when the last behavioral measure had returned to or crossed the respective lower baseline limit. In the case where oddity reaction time was the last performance measure 
to return, the experimental data had to fall within the lower and upper baseline limits to be considered recovered. The point in time for $T B R$ was determined by the first correct responses in the module whose respective mean fell beyond the lower baseline limit.

6. Baseline and experimental ranges were composed of performance module means rather than individual responses.

B. Data Analysis

For each decompression experiment, total reaction times (RTt) were divided into single reaction time (RTs) responses and paired reaction time (RTp) responses. Each data group was tested for significance of difference between the baseline mean and the corresponding experimental mean. Means were based on all baseline and all experimental responses rather than on performance module means.

For each decompression experiment, efficiency measures on all performance variables were tested for significance of difference between the baseline and the experimental means (computed from performance module means).

For each decompression experiment, a performance module-by-module comparison was made between baseline and experimental reaction time means to illustrate impairment and recovery of these measures for different exposure times.

For all decompression experiments, product moment correlation coefficients as well as a correlation ratio (eta) were computed between the temporal variables ( $T$ TI and TBR) and exposure time to a near vacuum. These data were also combined with previous findings to arrive at more reliable statistics. 


\section{RESULTS}

A total of nine decompression experiments were conducted with exposures to a near vacuum ranging from 90 seconds to 210 seconds (in 30-second increments). Eight subjects survived the experimental conditions in excellent physical health and were able to perform a complex behavioral schedule at a pre-exposure level of performance within 4 hours of decompression. One subject (No. 170, RD 12/90) expired during the exposure to near vacuum. A complete necropsy report and a summary of the histological findings on subject 170 is presented in Appendix. II.

A summary of the effects of rapid decompression to a near vacuum on behavior is presented in Table II, and Figure 5. Representative recordings of continuous motor response rates at the various exposure times show impairment and total recovery of this task during and following decompression (Fig. 6 and 7 ).

Detailed results of statistical comparisons of overall baseline and experimental performance as well as a performance module-by-module comparison of the reaction time tasks for each decompression can be found in Appendix III.

\section{A. General Observations}

After removal from the chamber, subjects appeared to be fatigued but displayed very little change in their responses to handlers and the routines of post-decompression examinations. All subjects were quite dehydrated, drank large amounts of water and generally showed good appetites. On the average all subjects lost 250 to 800 grams of weight as a result of the decompression and the 10-hour confinement in the chamber. The penis of each male subject showed distinct swelling, which subsided after 24 hours.

B. 90-Second Exposure to a Near Vacuum

$$
\text { 1. Subject } 154-\text { RD 13/90 }
$$

From the onset of decompression, the subject responded to the behavioral tasks for 6.5 seconds (TUC), then was incapacitated for 11.63 minutes (TTI), and recovered after 199 minutes following recompression to within baseline limits of performance (TBR). 


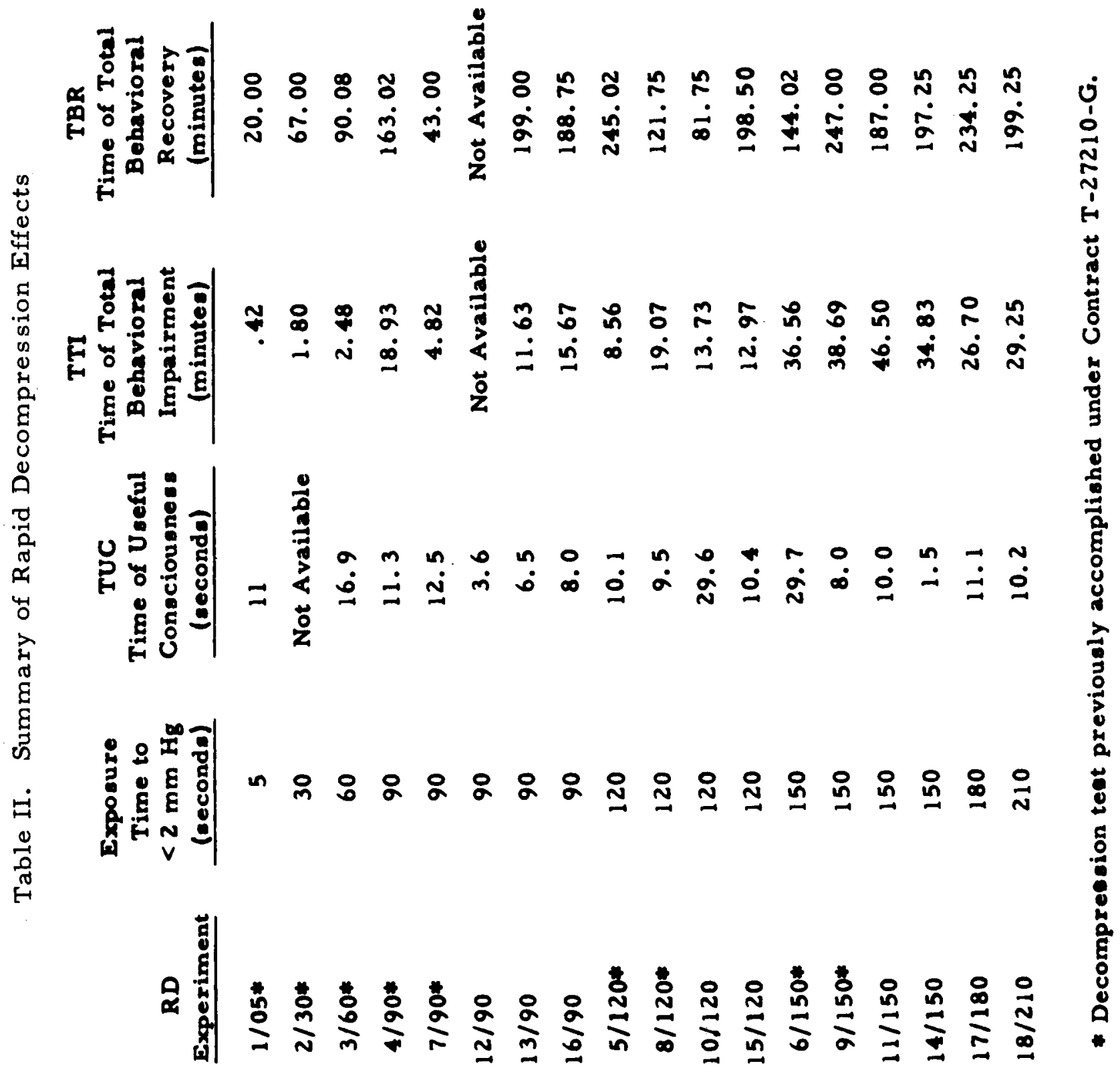




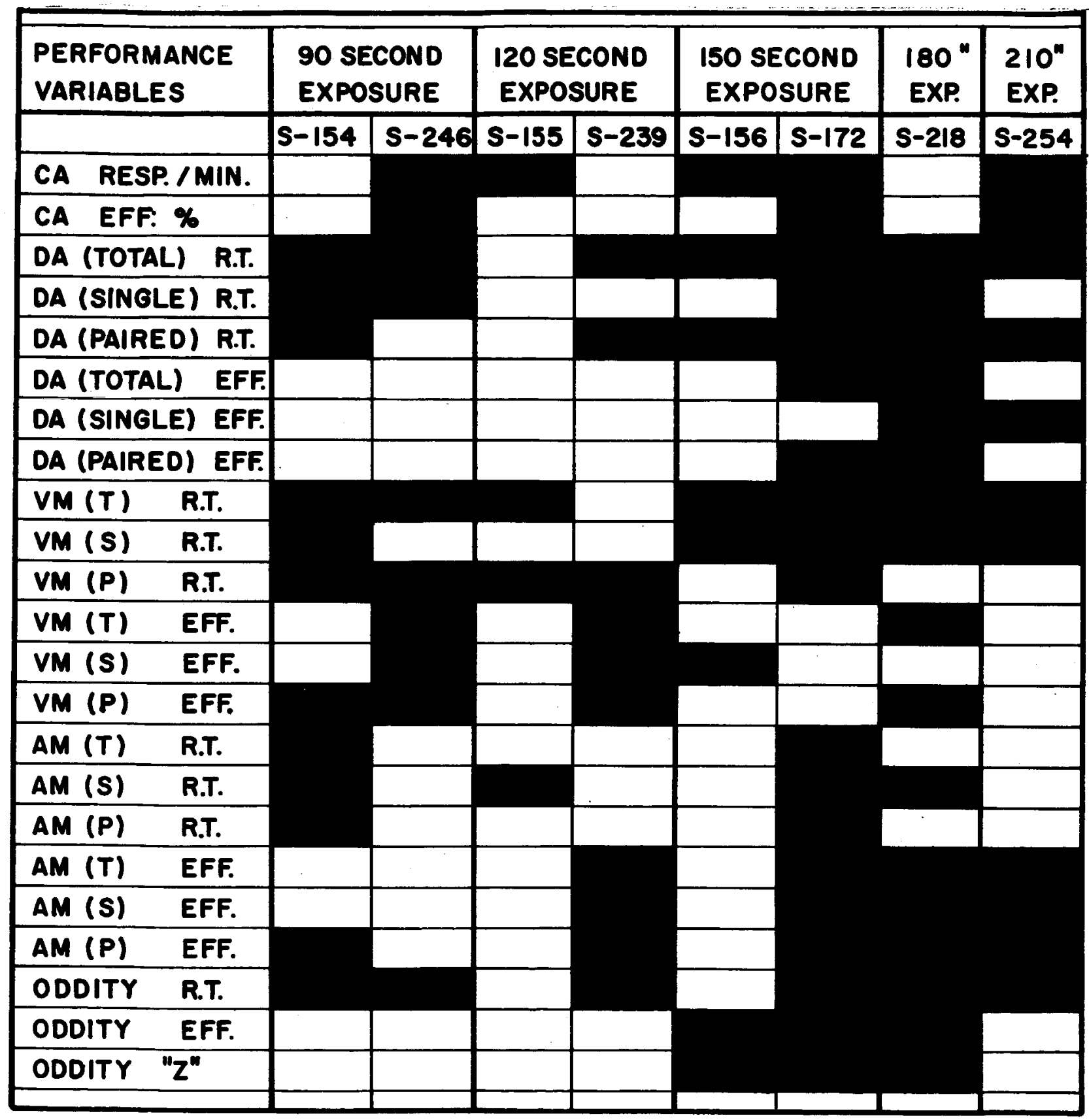

SIGNIFICANT DECREMENT FOLLOWING DECOMPRESSION

Figure 5. Summary of Significant Behavioral Decrements 

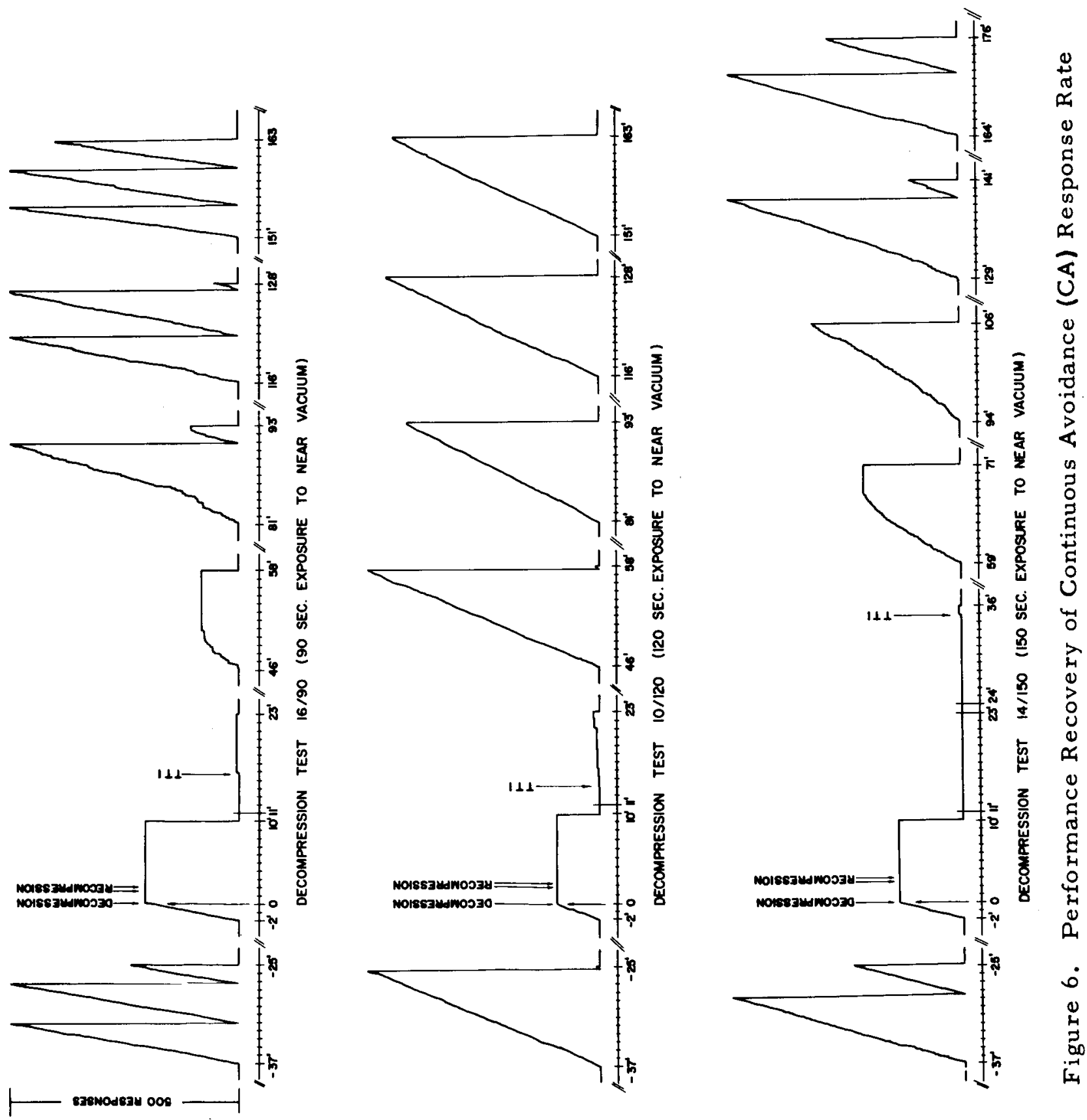

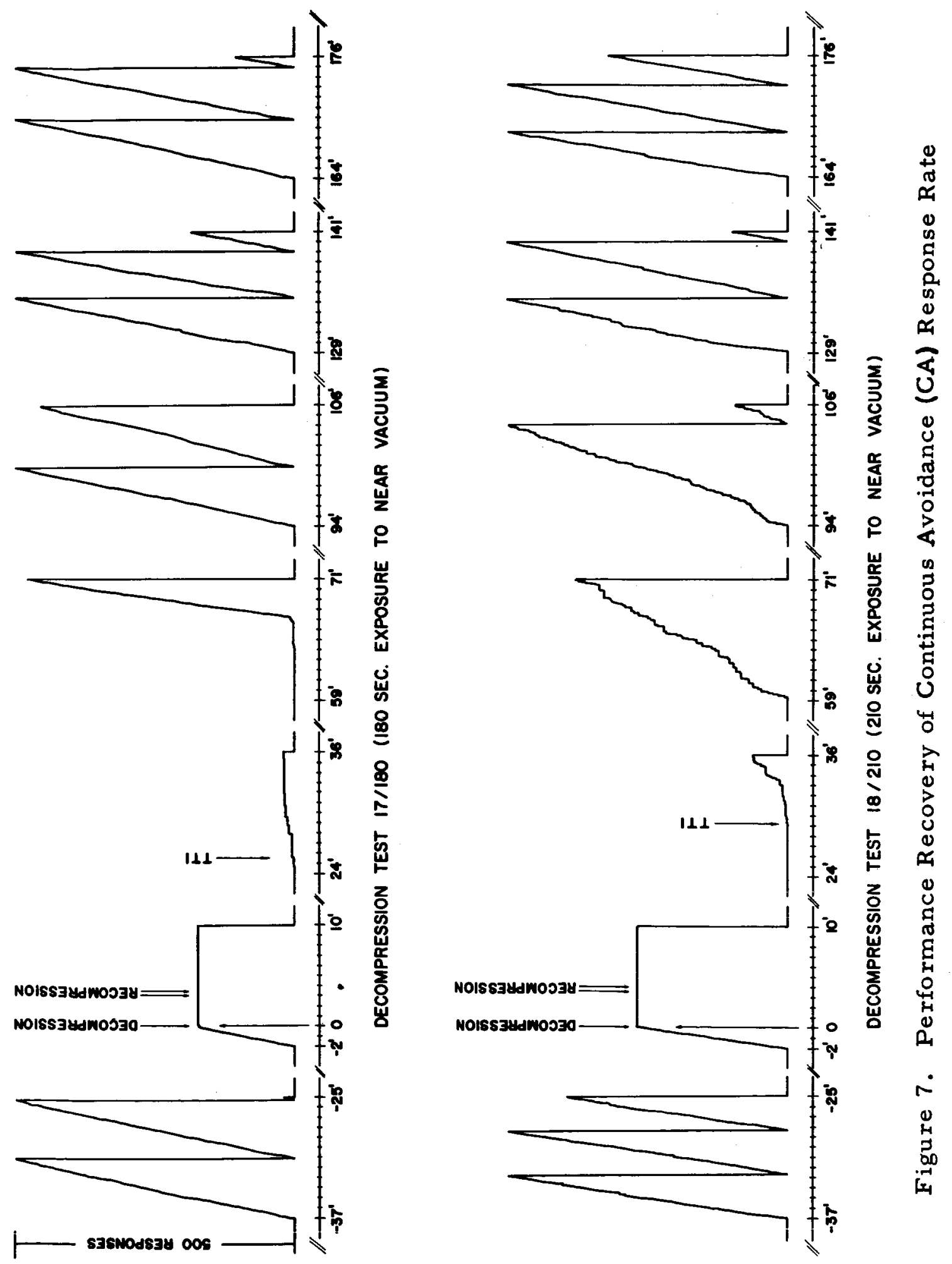
In a comparison based on overall baseline and experimental means, 13 performance measures out of a total of 23 were significantly affected after decompression. Reaction times to visual stimuli of pushbutton responses (VM) and of lever press responses (DA) were significantly slower after decompression as a result of significant decrements in response to single and paired cues. However, the only response efficiencies adversely affected were those associated with paired pushbutton responses (VMp). Reaction times of single as well as paired pushbutton responses to auditory cues before decompression showed significant impairments, while only paired responses showed a significant reduction in response efficiency after decompression. Reaction times to the choice discrimination task (oddity) were significantly longer even though discrimination efficiency did not change significantly. Continuous motor task variables (response rate and response efficiency) were not adversely affected by the experimental conditions.

\section{Subject $246-$ RD $16 / 90$}

This subject attended to the behavioral task for 8. 0 seconds after decompression (TUC) and was totally impaired for 15.67 minutes. Total behavioral recovery occurred 188.75 minutes following decompression.

Comparison of pre-experimental and experimental performance reveals that 10 out of 23 performance measures were significantly depressed following decompression. CA responses dropped markedly in response rate and efficiency. Reaction times to DA cues showed an overall decrement attributable to the increase in time it took the subject to attend to single DA stimuli. Efficiencies on this task were not affected. Total VM reaction time was significantly slower during the experimental sessions, due to a significant increase in response latency to paired VM cues. The overall VM efficiency was significantly reduced as a result of a drop in efficiency to both paired and single visual cues.

Experimental auditory measures were lost because of equipment failure and could not be analysed.

Reaction times to the discrimination task (oddity) were on the average significantly slower than baseline measures but discrimination efficiency was not affected. 


\section{120-Second Exposure to a Near Vacuum}

\section{Subject $155-\mathrm{RD} 10 / 120$}

Subject 155 responded for 29.6 seconds following decompression (TUC), was unable to respond for 13.73 minutes (TTI), and recovered completely after 81.75 minutes measured from the onset of the decompression.

Only four recorded behavioral variables ( out of 23) showed a significant decrement during the experimental period when compared with baseline performance.

Response rate on the continuous avoidance task (CA) was significantly lowered but not enough to reduce the subject's effectiveness in avoiding electric shock.

Visual monitoring reaction times to paired stimuli were extended significantly to bring about a significant decrement in the overall VM reaction time.

Response latencies to single auditory cues slowed markedly during the experimental sessions but not sufficiently to influence the overall AM reaction time.

\section{Subject $239-\mathrm{RD} \mathrm{15/120}$}

After 10.4 seconds following decompression (TUC) the subject was unable to respond to the behavioral program for 12.97 minutes (TTI) and needed 198.5 minutes to achieve complete behavioral recovery (TBR).

Continuous motor performance was not adversely affected by the experimental condition. Overall DA reaction times were significantly slower after decompression because of significant increase in response latency to paired stimuli. Efficiencies on this task were not affected.

VM response latencies to paired cues showed a significant decrement; however, the decrement was not large enough to influence overall VM reaction times. All VM efficiencies were significantly lowered after decompression. 
AM reaction times were not affected, but all efficiencies on this task were significantly lowered.

The subject was able to discriminate on the oddity task with equal efficiency after decompression, yet its reaction times to the oddity problems were significantly slower.

Of 23 measured variables only 10 were significantly lowered by the experimental conditions.

D. 150-Second Exposure to a Near Vacuum

1. Subject $156-$ RD $11 / 150$

After 10 seconds following decompression (TUC) the subject was incapacitated for 46.50 minutes (TTI), but recovered to within baseline limits of performance 187.00 minutes following decompression (TBR). Eight of 23 response variables were significantly depressed as a result of the exposure to a near vacuum.

Response rate on the continuous motor task (CA) dropped an average of 10 lever presses per minute, a significant reduction which did not affect the subject's efficiency to avoid electric shock.

Overall DA response latency was increased after decompression because the subject took longer to respond to paired DA stimuli.

Reaction times for pushbutton responses to single visual cues (VM-single) was so significantly slower that it was reflected in a significant decrement of the overall visual monitoring (VM-total) response latency. The response efficiency to this particular portion of the behavioral program was also significantly reduced, however not enough to bring about an overall VM efficiency reduction.

Reaction times and efficiencies to the auditory stimuli were not affected by the experimental condition. 
Even though response latency to the visual dis crimination task was not affected, efficiency in selecting the "odd" symbol was significantly reduced.

\section{Subject 172 - RD 14/150}

The subject lost its ability to respond to the behavioral task 1.5 seconds after decompression (TUC), was totally impaired for 34.83 minutes (TTI) but regained a level of performance equal to its baseline performance after 197.25 minutes following RD (TBR).

Only 4 measures of the 23 variables were not affected by the exposure to a near vacuum; all others reflected a significant reduction in performance immediately following decompression.

The unaffected variables were response efficiencies to single DA cues and single, paired, and combined VM stimuli.

\section{E. 180-Second Exposure to a Near Vacuum}

$$
\text { Subject } 218-\text { RD } 17 / 180
$$

After decompression the subject was totally incapacitated for 26.70 minutes (TTI) following a time of useful consciousness of 11.10 seconds. Within 234.25 minutes after $R D$ the subject was again performing on a baseline level.

With the exception of the measures on the continuous avoidance task, reaction time measures to paired VM cues, single and combined AM stimuli, and the efficiency measure on the visual monitoring task to single stimuli (VM-single), all experimental mean performance measures displayed a significant decrement when compared to respective overall baseline means.

F. 210-Second Exposure to a Near Vacuum

$$
\text { Subject } 254-\text { RD } 18 / 210
$$

This subject responded to the behavioral program for 10.20 seconds following decompression and was totaliy 
impaired for 29.25 minutes. The subject showed complete behavioral recovery 199.25 minutes after onset of decompression.

Response rate and response efficiency on the continuous avoidance task (CA) were significantly reduced. Overall reaction times for lever presses to visual stimuli (DA) showed a significant decrement due to a marked increase in DA-paired response latency. Efficiency to DA-single stimuli was significantly lowered after RD.

Overall VM response latency was significantly longer brought about by a significant slowing of reaction time for pushbutton responses to single visual cues (VMs).

Auditory reaction times were not affected; however, impairment was sufficient to significantly lower all response efficiencies to auditory cues.

The subject was able to discriminate on the oddity task not significantly different after decompression but took significantly more time to make selections.

A total of 11 out of 23 response variables showed a significant impairment after decompression when compared to baseline performance.

\section{DISCUSSION}

After exposure to a near vacuum, experimental subjects showed a statistically significant impairment on 4 to 19 (the range) behavioral measures. It is important to note that each subject had recovered sufficiently within 4 hours of decompression to respond on all behavioral measures within its respective baseline limits. Responses immediately following decompression were impaired to a point below the respective baseline average and reduced the experimental performance means, thus bringing about the statistical differences--but responses towards the end of the 4 -hour period were within the subject's normal pre-exposure limits, demonstrating behavioral recovery. 
The performance variables most consistently affected by the exposure to a near vacuum, regardless of length of exposure, were pushbutton reaction times to visual cues (VM) and DA lever. press reaction times to visual cues (7 out of 8 subjects). Response latencies of pushbutton responses to auditory cues (AM) were least affected by the experimental conditions ( 2 out of 8 subjects).

During the longer exposures to near vacuum (150 to 210 seconds), reaction times to visual cues, regardless of the type of response, showed a consistent decrement after decompression ( 4 out of 4 subjects). Only one subject showed a reaction time decrement to auditory cues; however, response efficiencies to the auditory tasks were reduced significantly on 3 out of 4 subjects. At these longer exposure times it became evident that a trade-off was taking place in almost all subjects. For tasks involving visual cues subjects were successful in attending to stimulus presentations at the expense of quick reaction times, while auditory response reaction time was maintained but fewer successful responses were made. In essence, it may be said that following decompression the chimpanzee can respond to most visual signals but does so slower than before decompression. On the other hand, he fails to respond to more auditory than visual signals, but when he does respond to an auditory signal, he responds as fast as he did before he was decompressed.

It is also interesting to note that for these longer durations ( 150 to 210 seconds) the decrement in reaction time of lever presses to visual cues (DA) is consistently attributable to the pairing of this response with other responses (VM or $A M$ ). Contrary to this phenomenon, pushbutton (VM) reaction time decrements occur principally when only a single response is required, i.e., not paired with other responses. On the average, response rates on the continuous motor task (CA) were depressed on all exposures, with 3 out of 4 subjects showing a significant reduction when the time at near vacuum was 150 to 210 seconds.

One subject, No. 218, RD 17/180, was placed in the chamber again approximately 6 weeks following its decompression and was exposed to the baseline procedure previously described. Comparison of the behavioral samples taken at baseline ( 2 days before the 180-second exposure) and during the follow-up study (54 days after exposure to a near vacuum) showed a general decrement of behavior which was not evident during follow-up studies. 
performed with subjects exposed to shorter durations at vacuum. CA response rate, reaction times to auditory cues, DA cues as well as the efficiencies to all discrete events showed significant decrements. However, reaction times to the oddity problems were significantly improved with discrimination efficiency on this task remaining unchanged from its baseline (pre-exposure) value. Even though response rate on CA was lowered it did not impair the efficiency on this task which could mean that the subject was able to adjust its behavior and still be successful at a lowered work output. These data may be indicative of some residual behavioral impairment following a 3-minute exposure to a near vacuum.

A product-moment correlation between exposure times to a near vacuum and the time of total behavioral impairments, using data points. gathered during this and the previous series of decompressions, produced a Pearson $r$ of . 78 (Fig. 8). Visual inspection of the distribution pointed out a marked and consistent deviation from linearity at the 150-second exposure time. A curvilinear correlation analysis supported this with an eta $(\eta)$ of .96 and a statistically significant deviation from linearity $(F=3.59 ; \mathrm{df}=7,8 ; \mathrm{p}<.05)$. The data from the current series of decompressions did not vary markedly from the prediction based on the first series of nine cases suggesting the reliability of the total findings.

Product-moment correlation between exposure time and the time of total behavioral recovery produced a Pearson $r$ of . 70 (Fig. 9). Here data points were not as clustered as in the correlation of impairment times with exposure times but the small change of the prediction based on 17 cases compared to the prediction based on the first series of nine decompressions also lent credence to the overall reliability of these data.

In spite of the fact that results of these decompressions substantiated previous findings (3), new results became evident. After exposure to a.near vacuum up to 150 seconds, it was postulated that longer exposures (180, 210 seconds) would probably follow a linear, if not exponential function. Thus, the time of total behavioral impairment (TTI) and the time for total behavioral recovery (TBR) should be of increasingly longer 


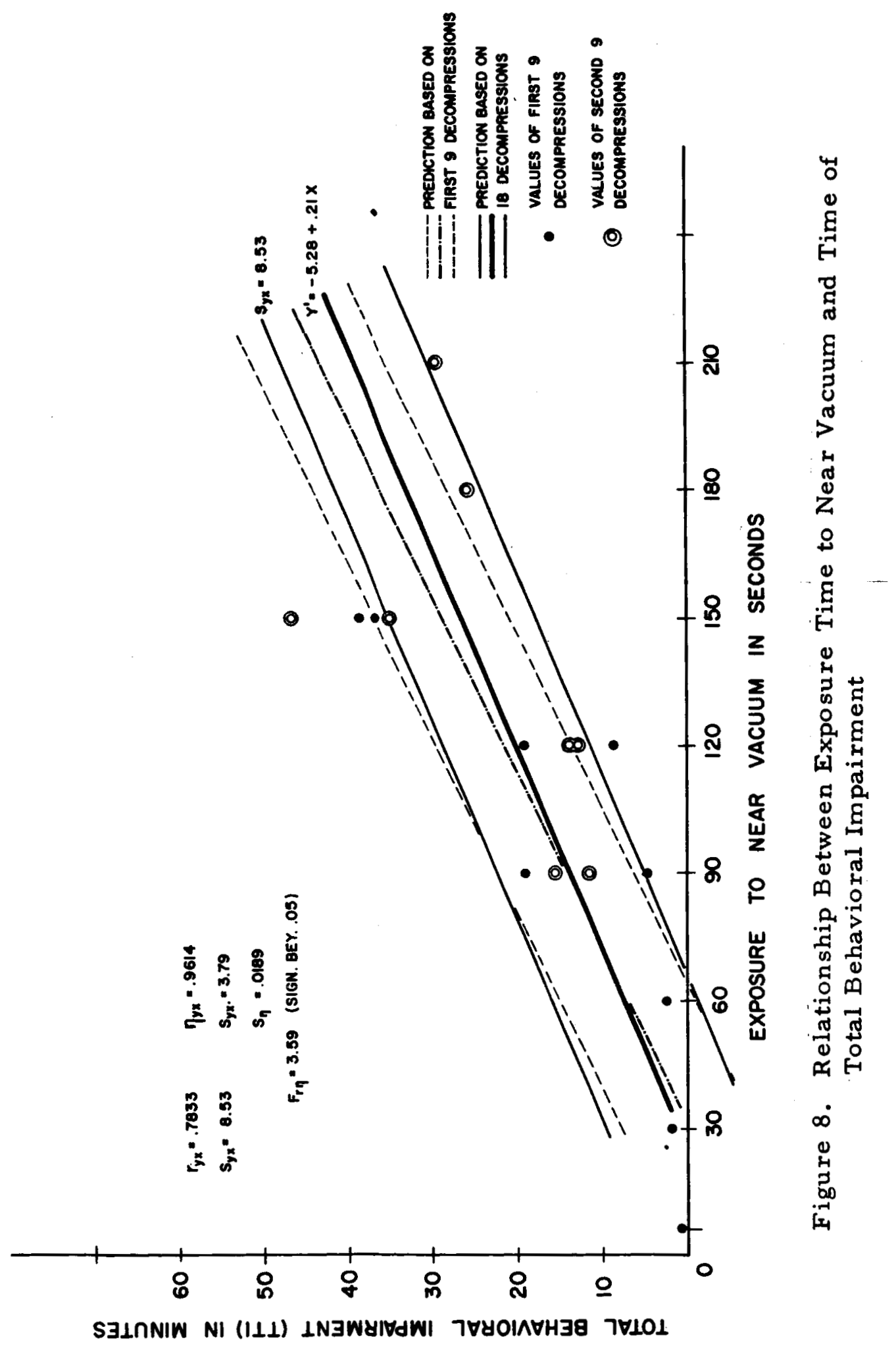




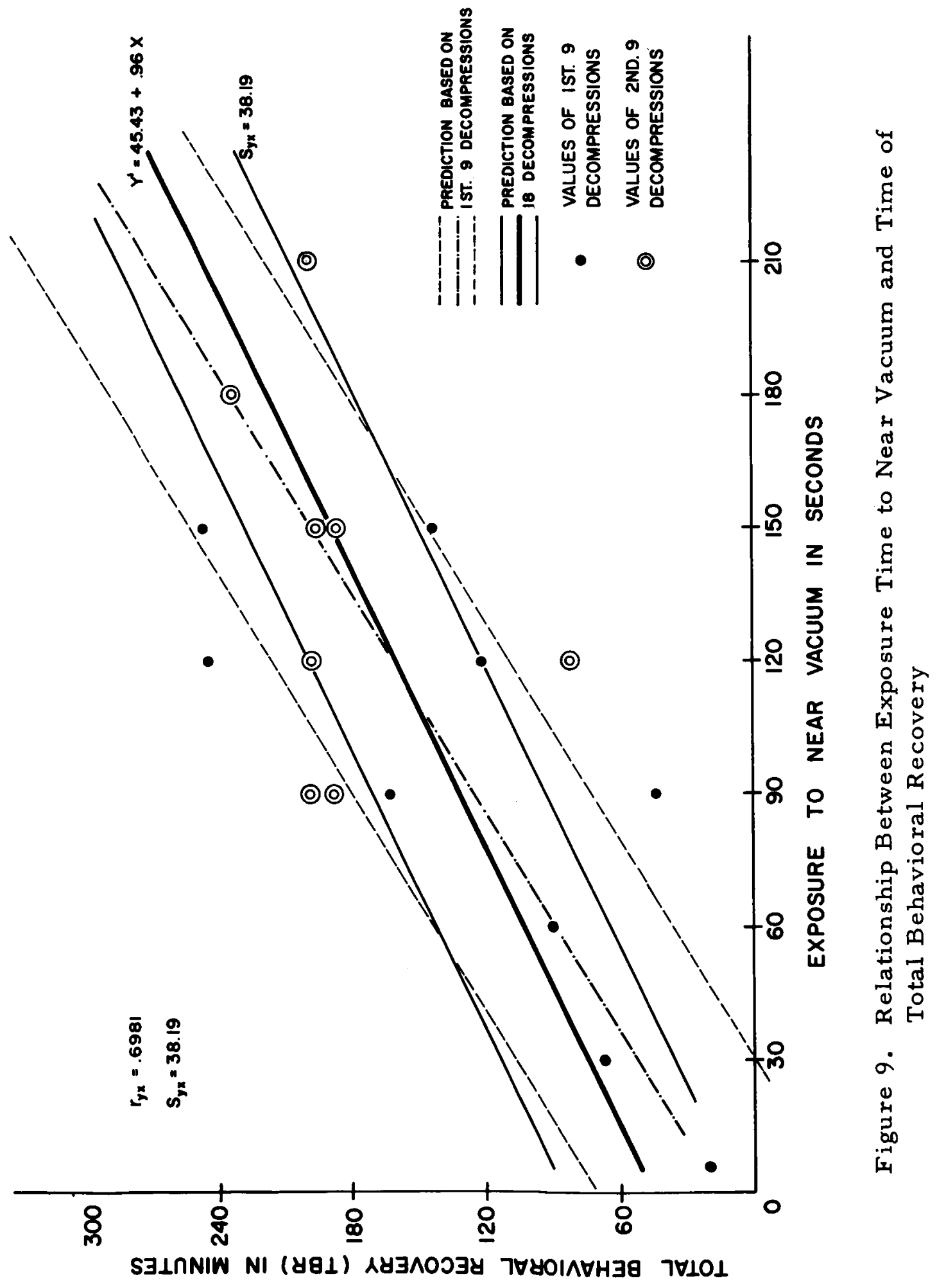


duration. However, both subjects (No. 218, and No. 254) exposed to 180 and 210 seconds, respectively, showed faster recovery from total impairment than any subject exposed to 150 seconds of a near vacuum. In addition, they reached total behavioral recovery as soon as the average subject exposed to a near vacuum for 150 seconds. As may be seen from Figure 5, the 210 -second exposure subject had fewer significant decrements on the behavioral schedule than subjects exposed for 150 or 180 seconds. Whether this response is unique to this one subject must be determined by replicating the long-exposure experiments.

\section{CONCLUSION}

The results from nine decompression experiments of a replicatory nature have substantiated previous findings that chimpanzees can survive sudden exposures to near vacuum for up to 3-1/2 minutes and recover within 4 hours to once again satisfactorily perform complex behavioral schedules on which they have had extensive training. However, as encouraging as these results may be--unless the subject is in perfect health-decompressinn to a near vacuum, regardless of length of exposure, can pose a major threat to life. This was exemplified in the one instance in which a subject of questionable fitness (See Appendix II.) expired following a 90-second exposure while 17 other completely fit subjects experienced no damage when exposed to the near vacuum for up to 210 seconds. 



\section{REFERENCES}

1. John Billingham, "Survival After Decompression to a Vacuum", Presentation at the Aerospace Medical Association, Miami, Florida, May 1964.

2. Personal communication with Dr. Wayland Hull, Margaret Jackson, Directorate, Medical Résearch and Operations, NASA, MSC, Houston, Texas.

3. Alfred G. Koestler, Ed., The Effect on the Chimpanzee of Rapid Decompression to a Near Vacuum, NASA CR 329, Nov. 1965.

4. Sidman, M., "Avoidance Conditioning with Brief Shock and No Exteroceptive Warning Signal." Science, 118: 157-158, 1953. 


\section{A PPENDIX I}

Avoidance Performance Schedule for

Rapid Decompression Studies

\begin{tabular}{|c|c|c|c|c|}
\hline Time & $\begin{array}{c}\text { Continuous avoidance } \\
\text { (5'" R-S interval) }\end{array}$ & $\begin{array}{c}\text { Discrete } \\
\text { avoidance }\end{array}$ & $\begin{array}{c}\text { Visual } \\
\text { monitoring } \\
\text { (2 stimuli) } \\
\end{array}$ & $\begin{array}{c}\text { Auditory } \\
\text { monitoring }\end{array}$ \\
\hline-2 & Begin & & & \\
\hline$-1^{\prime} 45^{\prime \prime}$ & & & & $\mathbf{x}$ \\
\hline$-1 ' 15^{\prime \prime}$ & & $\mathbf{x}$ & & \\
\hline$-\quad 45^{\prime \prime}$ & & & $x_{2}$ & \\
\hline$-\quad 30 \prime 1$ & & $\mathbf{x}$ & & $x$ \\
\hline$-\quad 15^{\prime \prime}$ & & & $x_{1}$ & \\
\hline 0 & Decompression & $\mathbf{x}$ & & $\mathbf{x}$ \\
\hline$+2 \prime \prime$ & & & & $\mathbf{x}$ \\
\hline$+4^{\prime \prime}$ & & & $x a$ & $\mathbf{x}$ \\
\hline$+6 \prime \prime$ & & & $x_{1}$ & \\
\hline$+8 \prime \prime$ & & $x$ & & \\
\hline $10^{\prime \prime}$ & & $\mathbf{x}$ & $x_{2}$ & \\
\hline $12 \prime \prime$ & & $x$ & $\mathbf{x}_{1}$ & \\
\hline $14 \prime \prime$ & & & & $x$ \\
\hline $30 " 1$ & & $\mathbf{x}$ & & \\
\hline $45^{\prime \prime}$ & & & $x_{1}$ & $\mathbf{x}$ \\
\hline $60 " 1$ & & & & $x$ \\
\hline $1: 15^{\prime \prime}$ & & & $x_{a}$ & \\
\hline $1 ' 30 \prime \prime$ & & $\mathbf{x}$ & & $\mathbf{x}$ \\
\hline
\end{tabular}


Visual

Continuous avoidance Discrete monitoring Auditory

Time (5"R-S interval) Avoidance (2 stimuli) monitoring

$2^{\prime} 0^{\prime \prime}$

$\mathbf{x}_{1}$

2'15'

$\mathbf{x}$

2'30"'

$\mathbf{x}$

2'45'

$3^{\prime} 0^{\prime \prime}$

$\mathbf{x}$

4'30'

$5^{\prime} 0^{\prime \prime}$

$\mathbf{x}$

$5 ' 30^{\prime \prime}$

$x_{1}$

5'45'

$\mathbf{x}$

6'0'1

$\mathbf{x}$

7 '0'

$\mathbf{x}$

$\mathbf{x}_{1}$

$\mathbf{x}$

7'30'I

$\mathbf{x}_{1}$

$\mathbf{x}_{2}$

$\mathbf{x}$

$8^{\prime} 15^{\prime \prime}$

$\mathbf{x}_{\mathbf{z}}$

813011

$\mathbf{x}$

$8^{\prime} 45^{\prime \prime}$

$\mathbf{x}_{1}$

9'0"'

9'30'1

$\mathbf{x}$

$\mathbf{x}$

9'45'

$\mathbf{x}$

$\mathbf{x}$

$\mathbf{x}$

$10^{\prime} 00^{\prime \prime}$ end

$\mathbf{x}_{1}$ 


\title{
APPENDIX II
}

\section{VETERINARY NECROPSY PROTOCOL}

\author{
No. N35-65 \\ 31 August 1965
}

Identification: Chimpanzee No. 170, male, weighing approximately $45 \mathrm{lbs}$.; measuring, crown to rump $54 \mathrm{~cm}$., chest circumference $62 \mathrm{~cm}$.

Experimental Procedure: This animal was utilized in a rapid decompression run. The decompression test was identified by a serial number 12/90. The animal died post-decompression with EKG indication of cardiac fibrillation.

Time of Death: $\quad$ Approximately 1415 hours.

Time of Necropsy: $\quad 1445$ hours.

Primary Incision: The subcutaneous tissues appeared to be most dry. The cut surfaces of subcutaneous vessels exuded little or no blood. Exploration of the abdominal and thoracic cavities revealed the various viscera to be in normal position. A small zone of adhesion was recognized in the the lower abdomen between the large intestine and the lower right abdominal wall. Multiple adhesions were recognized along the left abdominal wall from the spleen down to, but not entering, the pelvic cavity.

Respiratory System: Exploration of the nares, pharynx and trachea revealed no significant gross changes. The diaphragmatic lobes of the lung adjacent to the aortic diaphragmatic hiatus were rather dark red in color. The remaining portions of the lung were light pink in color. The left lung weighed 65 gms; the right lung $74 \mathrm{gms}$. Multiple slices through the lung revealed these darkened areas to be confined to the superficial portion of the lung, penetrating perhaps a distance of less than $1 \mathrm{~mm}$. The specific point should be made that at the time of opening the abdomen, the diaphragm was recognized to rise quite well into the thoracic cavity. Subsequent to removing the lung and trachea from the thoracic cavity, a Tygon tubing was 
inserted into the trachea and a small quantity of air inflated the lungs. No apparent leak could be recognized.

Cardiovascular System: Several small fibrinous tabs were recognized over the epicardical surface of the heart. These apparently represented older adhesions for no attachment to the pericardial sac could be recognized. Multiple slices along the coronary vessels failed to reveal any indication of stenosis. Intermittent air bubbles were recognized in the coronary vessels. There was a very good probability that these air bubbles arose, not from the rapid decompression, but rather from the severance of the main stem vessels and subsequent aspiration of air into the cardiovascular system. The heart still was capable of mechanical response to stimulation.

Digestive System: No changes were recognized in the mouth, esophagus, or stomach. The midsection of the small intestine presented a mucosal surface that was moderately reddened. No changes were recognized in the lower portion of the small intestine or large intestine.

Liver: The liver was very dark in color weighing $590 \mathrm{gms}$. Multiple slices through the liver failed to reveal any significant gross changes.

Spleen: The spleen weighed 49 gms. No gross change was recognized.

Endocrine System: No gross change was recognized in the pituitary, thyroids or adrenals.

Weights on Tissues:

\begin{tabular}{|c|c|}
\hline $\begin{array}{l}\text { Left adrenal } \\
\text { Right adrenal }\end{array}$ & $\begin{array}{l}-\quad 3 \mathrm{gms} . \\
-\quad 2 . \mathrm{gms}\end{array}$ \\
\hline Pancreas & $26 \mathrm{gms}$ \\
\hline Thyroids & not weighed \\
\hline Pituitary & - not weighed \\
\hline
\end{tabular}

Urinary System: The left kidney weighed 84 gms; the right kidney 77 gms. The capsule of each stripped with ease. Slices through the kidneys revealed no indication of gross pathology. Tissue was collected from this organ for submission to an investigator at the National Institutes of Health. 
Reproductive System: The testes were of equal size and were approximated to weigh 4 gms each. No gross change was recognized.

Central Nervous System: The brain was exposed in the conventional manner. Multiple air emboli were recognized in the meningeal vessels (Fig 10).

Gross Diagnosis: Probable myocardial fibrillation.

Comment: The paucity of lesions throughout this case suggested the heart may have been the factor responsible for death. The small epicardial adhesions or fibrin tabs may have placed the heart in such a position as to be more susceptible to additional irritation. The possibility existed that the air bubbles in the meningeal.vessels could have been introduced at the time of removing the skull cap, however, this probability seemed rather small.

\section{MICROSCOPIC FINDINGS}

Kidney: Occasional small bits of debris were recognized in Bowman's space. A single nidus of leukocytic infiltration was recognized surrounding a collecting tubule near the cortical medullary junction. A second bloc of kidney revealed a rather severe leukocytic infiltration, predominantly lymphocytes, along one of the smaller branches of the arcuate artery: A small nidus near the arcuate contained a considerable number of eosinophils.

Heart: The quantity of fibrous tissue components within the epicardium was modestly increased; penetrating into the superficial portion of the myocardium were prominent blood vessels surrounded by infiltrates of leukocytes, predominantly neutrophils (Fig. 11). This type of infiltration was limited to a very small portion of the myocardium. Adjacent to one of the smaller penetrating arterioles was found a bit of fibrinoid degeneration of the connective tissue elements. The individual myocardial fibers exhibited no loss of cross striations. 


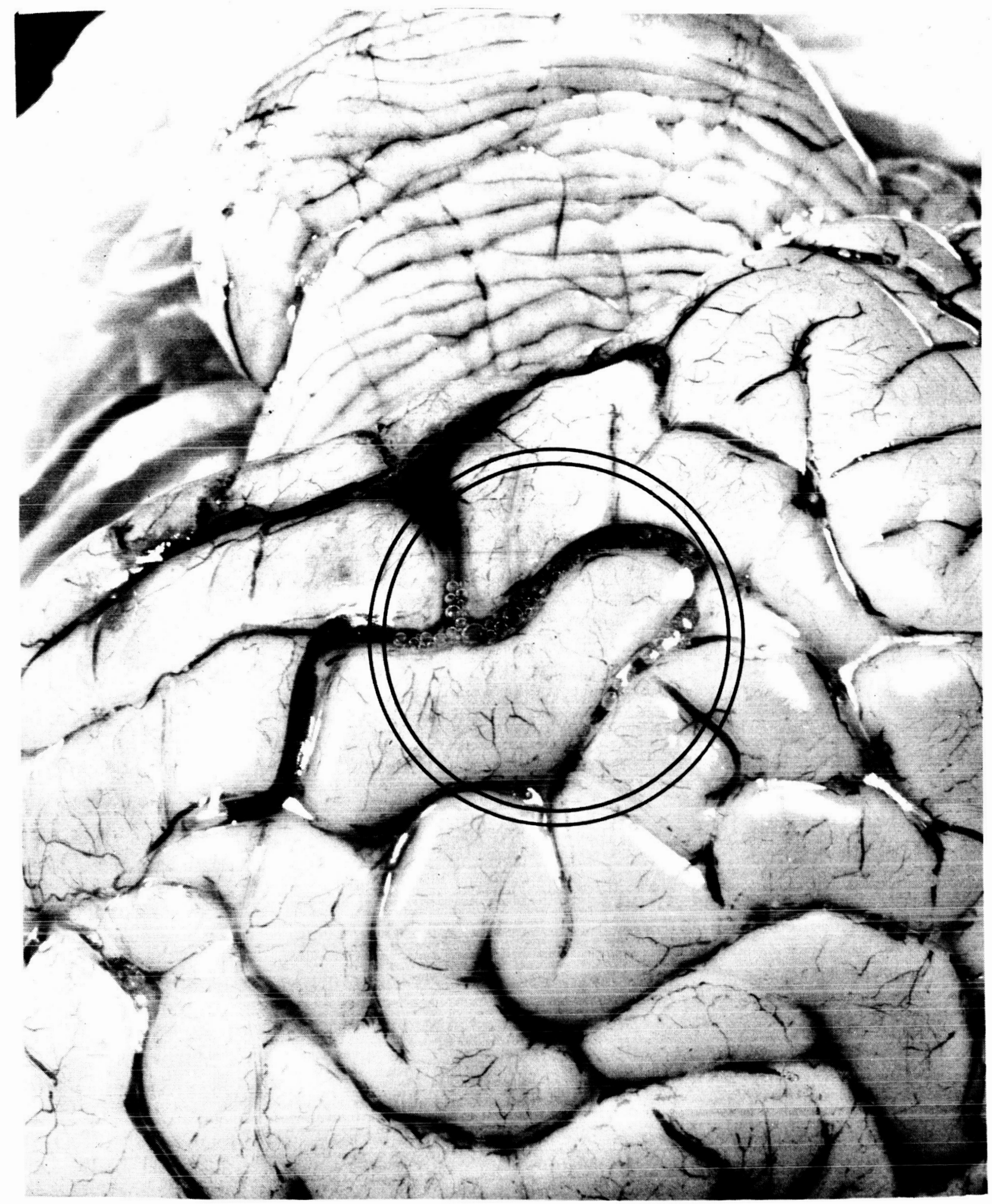

Figure 10. Brain, Showing Multiple Air Emboli in Cerebral Vessels 


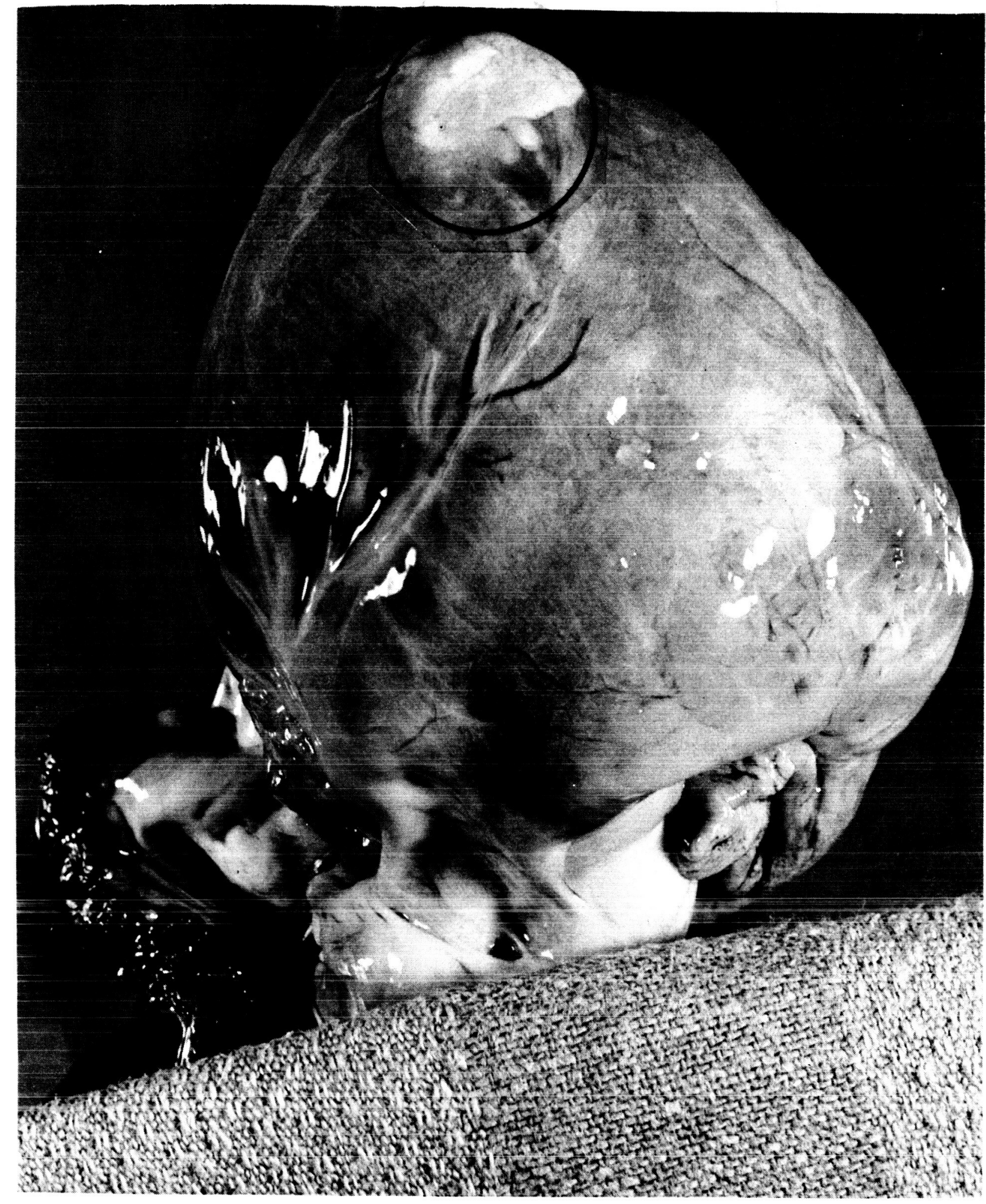

Figure 11. Heart, Showing Fibrinous Tab on Epicardial Surface 
An occasional myocardial nucleus was observed to be considerably enlarged with division of the chromatin material into two dense, cigar-shaped bodies. Other areas of the epicardium contained abundant fat cells which were partially collapsed.

Liver: Occasional small zones of focal necrosis involving hepatic cord cells were recognized. These were often infiltrated by mature, dark staining lymphocytes.

Lung: Because this case represented one of the few opportunities to examine the lung immediately post rapid decompression, careful evaluation was made of the smaller bronchioles, aleolar ducts and alveoli. No indication of disruption or hemorrhage into any of these areas was found.

Microscopic study of the remaining tissues in this case including skin, pancreas, urinary bladder, small intestine, stomach, testes, lymph nodes, adrenal, spleen, phineal; thyroid and pituitary failed to disclose any changes considered to be of pathological significance.

Microscopic Diagnoses:

Inflammatory thickening of the epicardium

Interstitial nephritis, chronic, kidney

Focal necrosis with lymphocytic infiltration, liver

Comment: The cause of death in this case was attributed to a failure in the conducting mechanism in the myocardium. The absence of significant morphological changes in the myocardium may be attributed to the very short interval between the failure of the conducting mechanism and the time of death. Also, the interval between death and necropsy precluded any alterations of postmortem nature. These factors precluded documentation by microscopic examination of the myocardial tissues. The alterations observed in the kidney and liver were of academic interest and probably did not have any influence in regard to the general health of this animal. 
Photomicrographs will be prepared of the lung to support the negative findings associated with rapid decompression.

James R. Prine

Lt Colonel, USAF, VC

Veterinary-Pathologist 


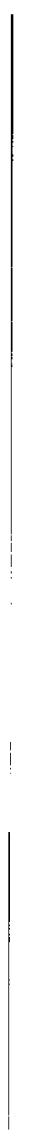




\section{APPENDIX III}

DETAILED STATISTICAL COMPARISONS OF BEHAVIORAL DATA 


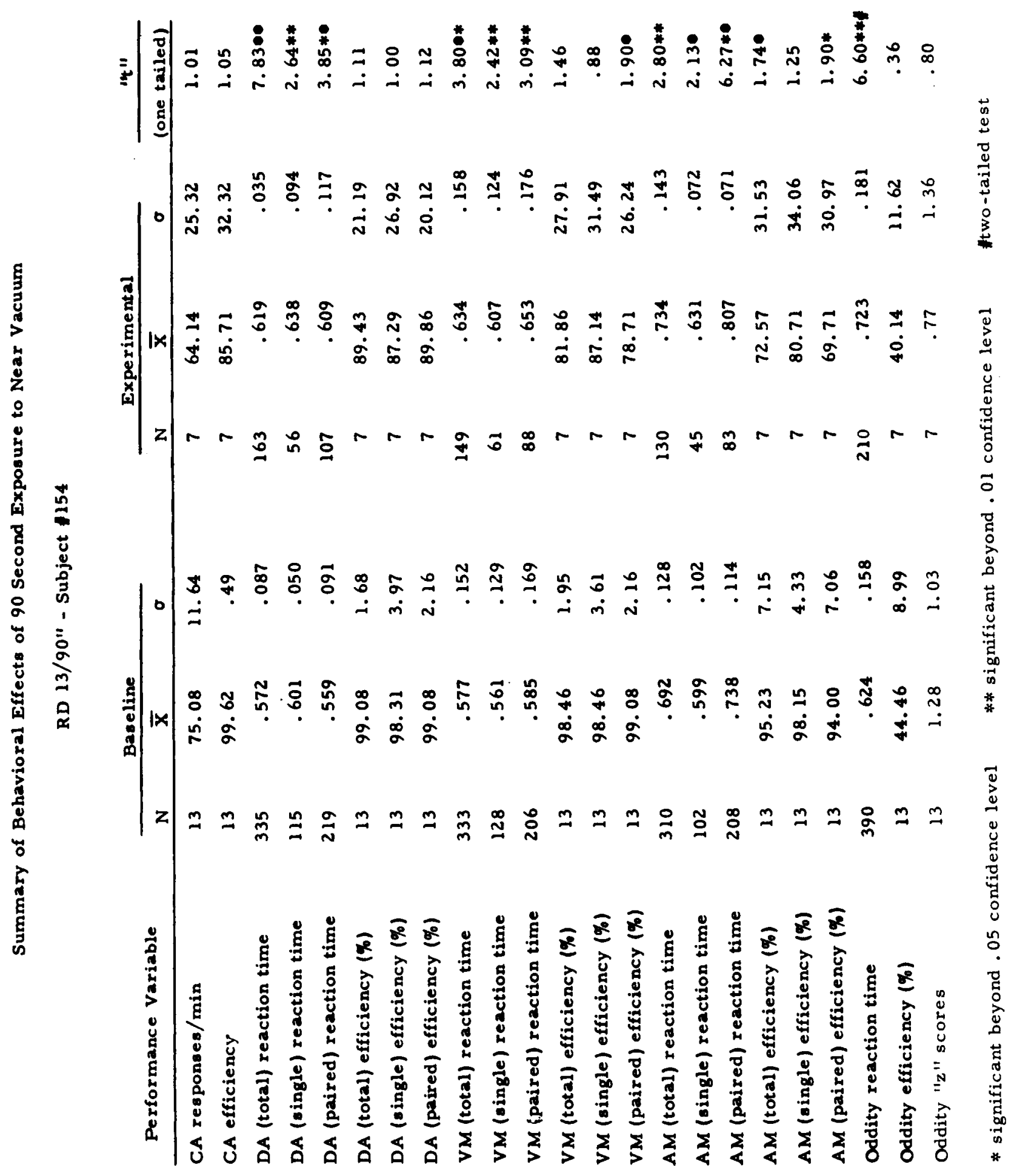




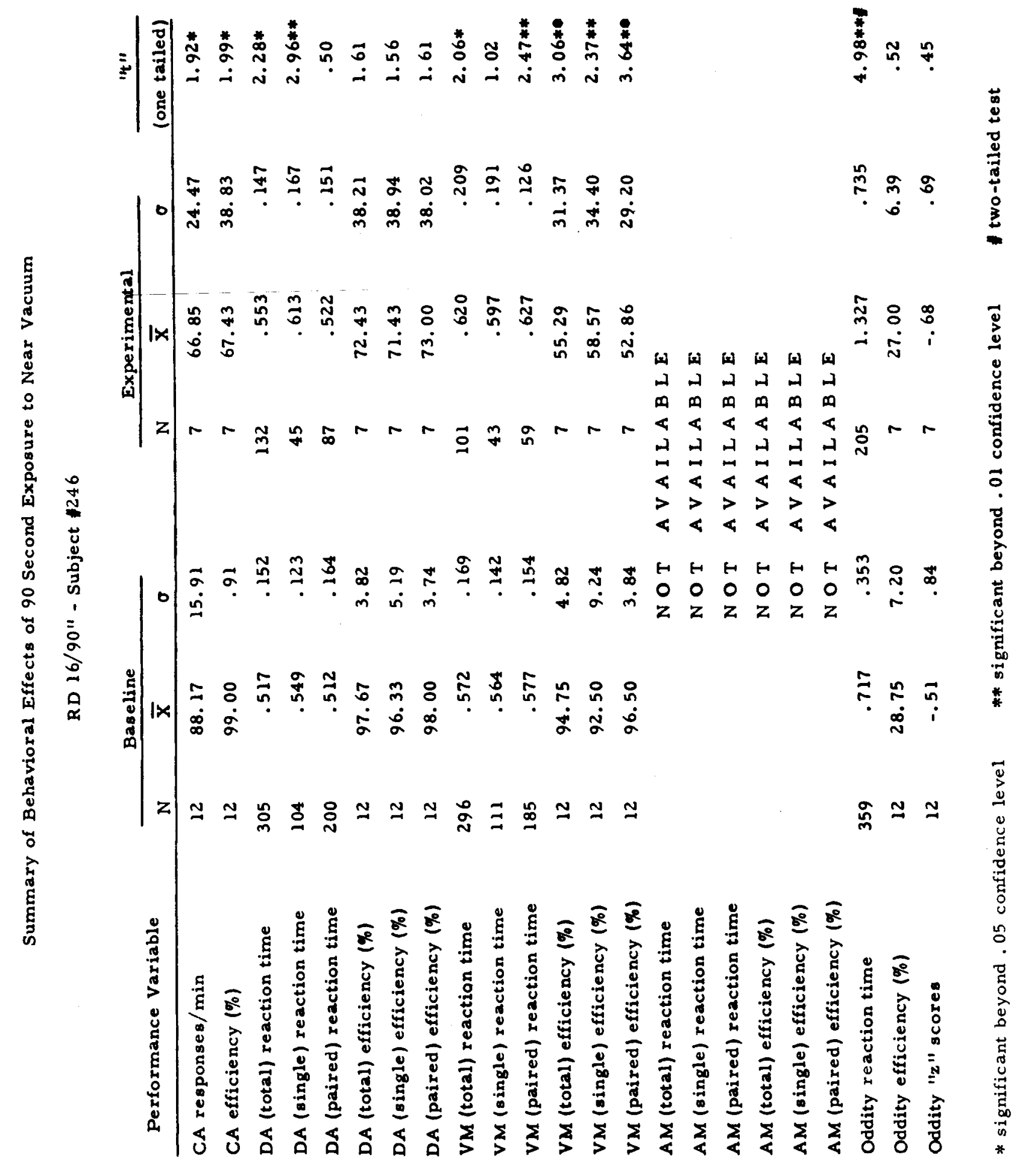




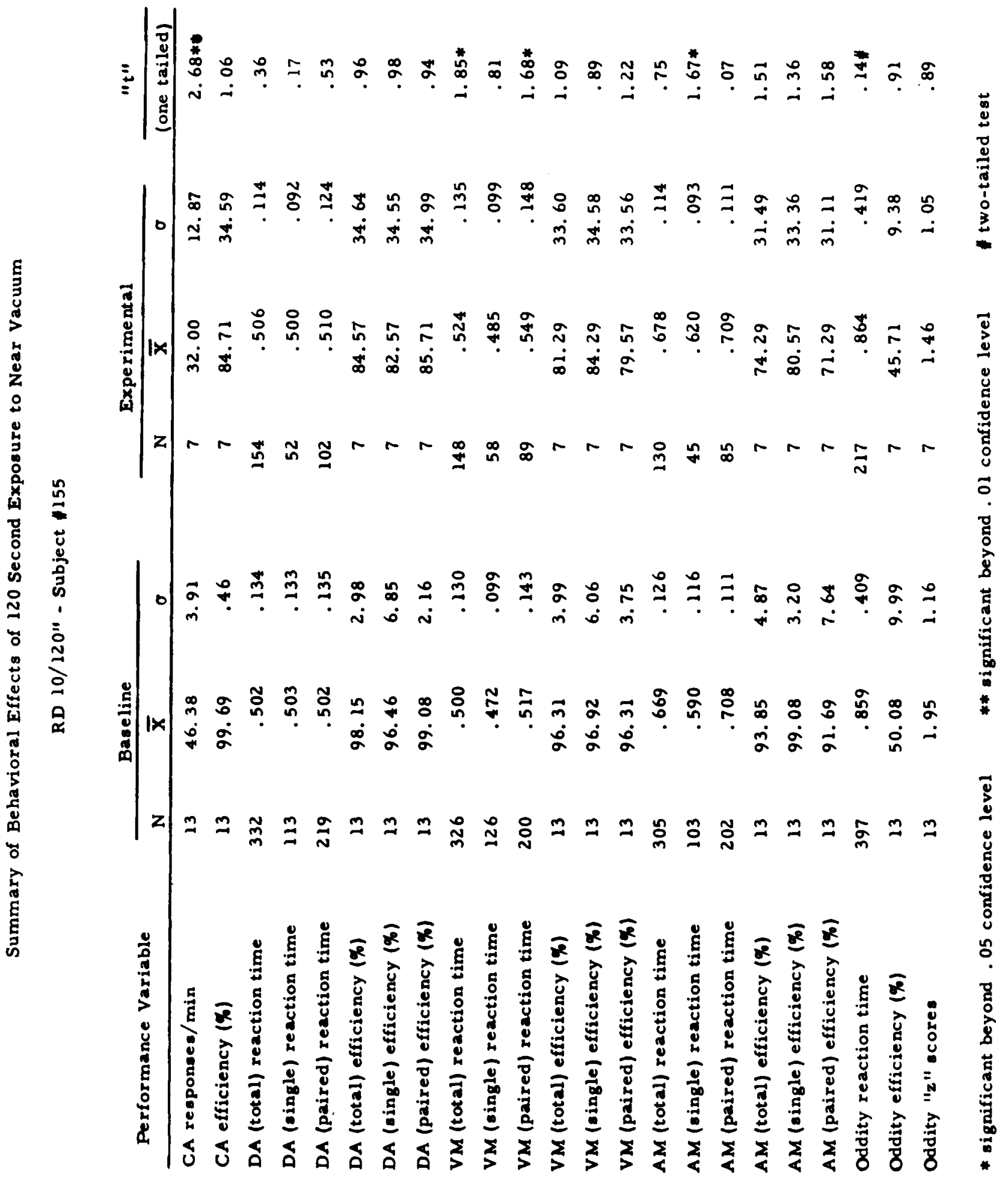




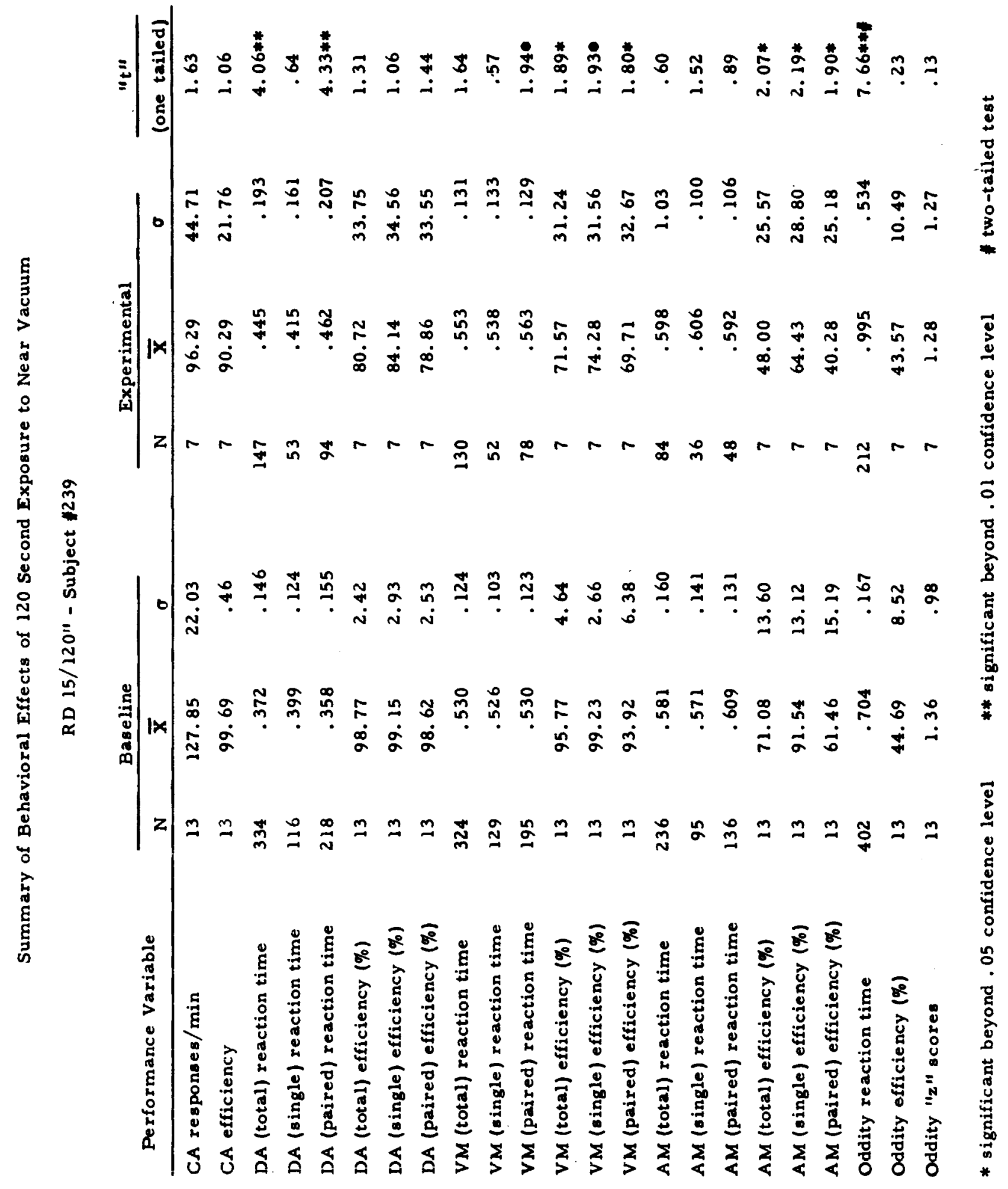




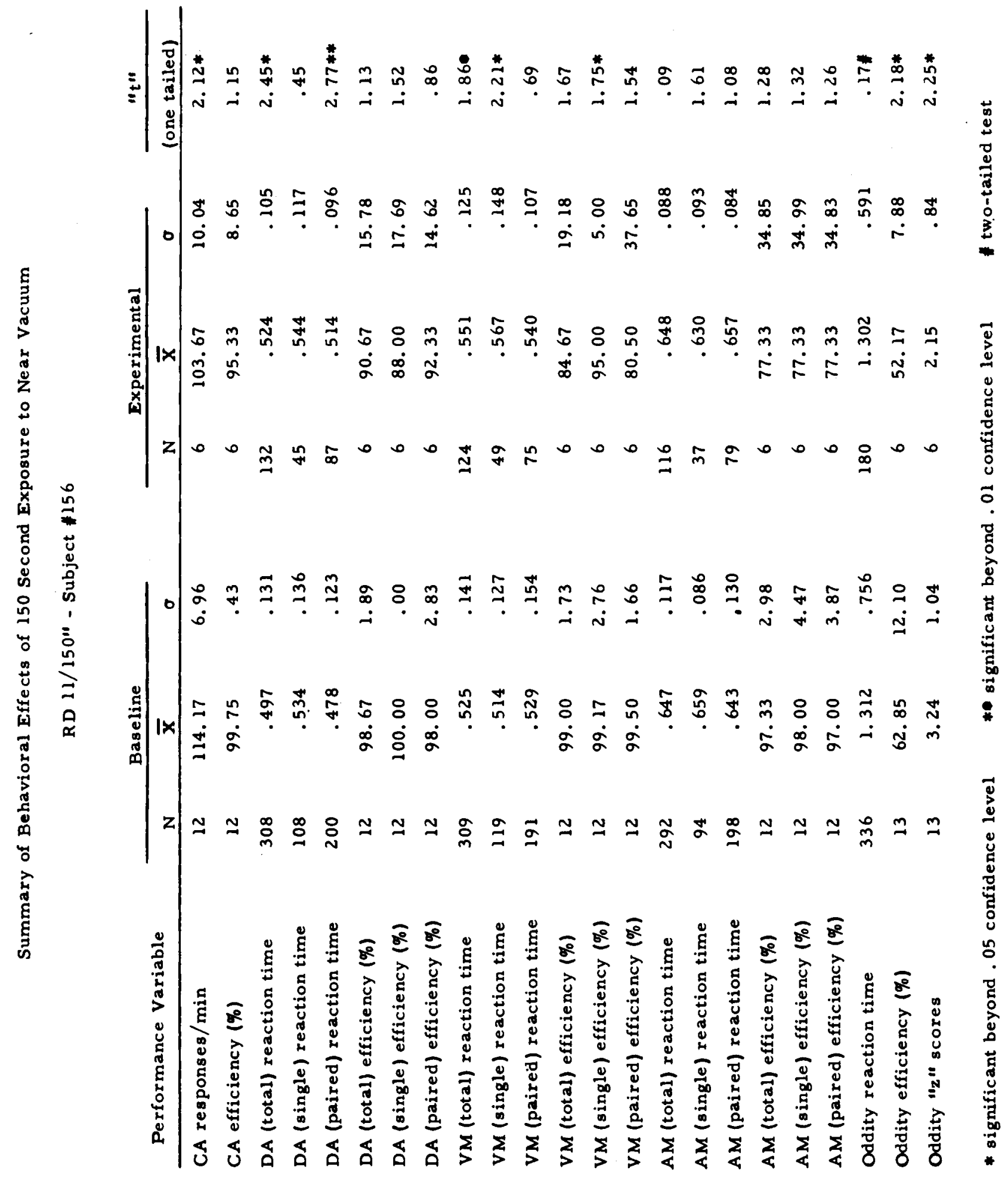




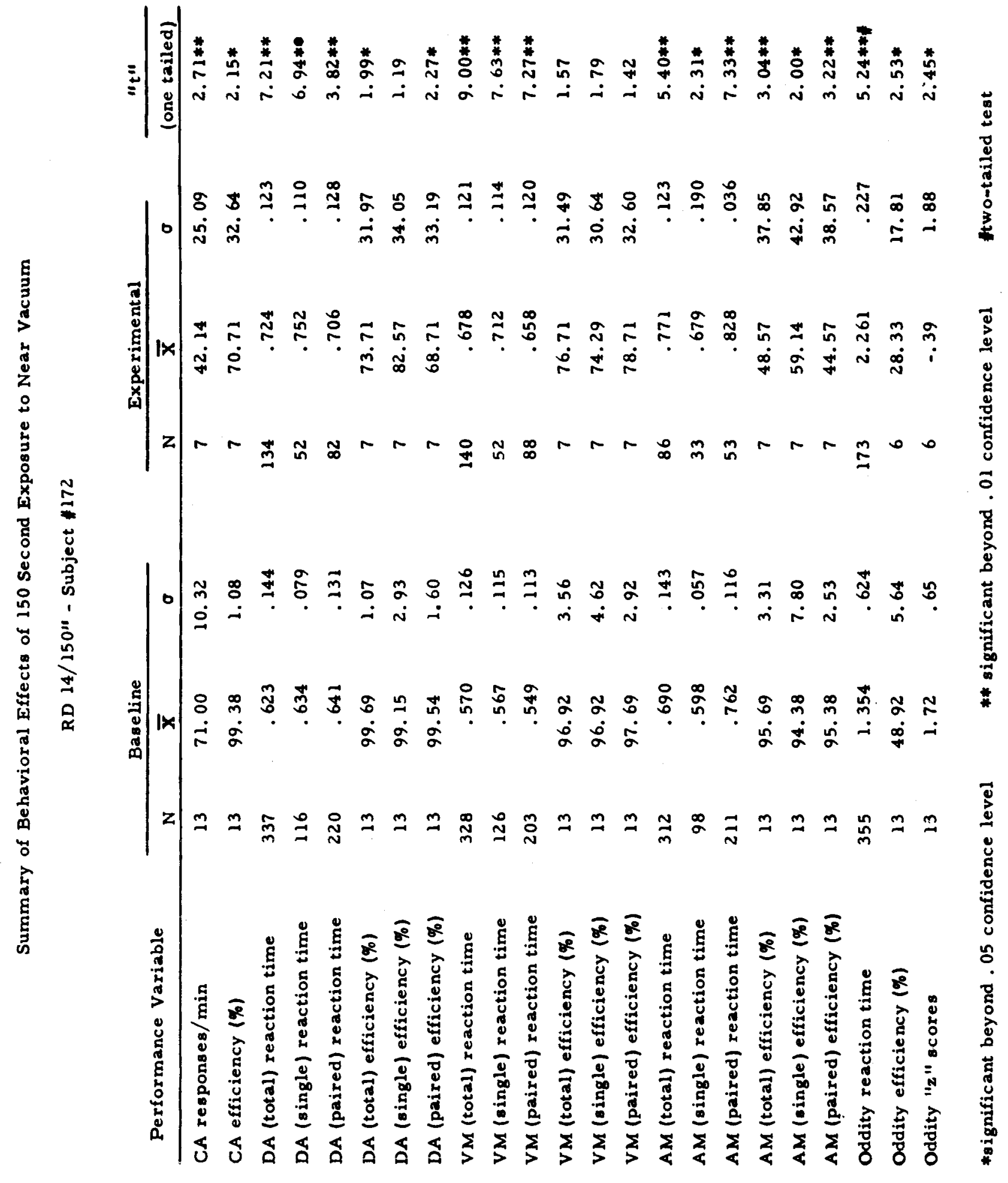




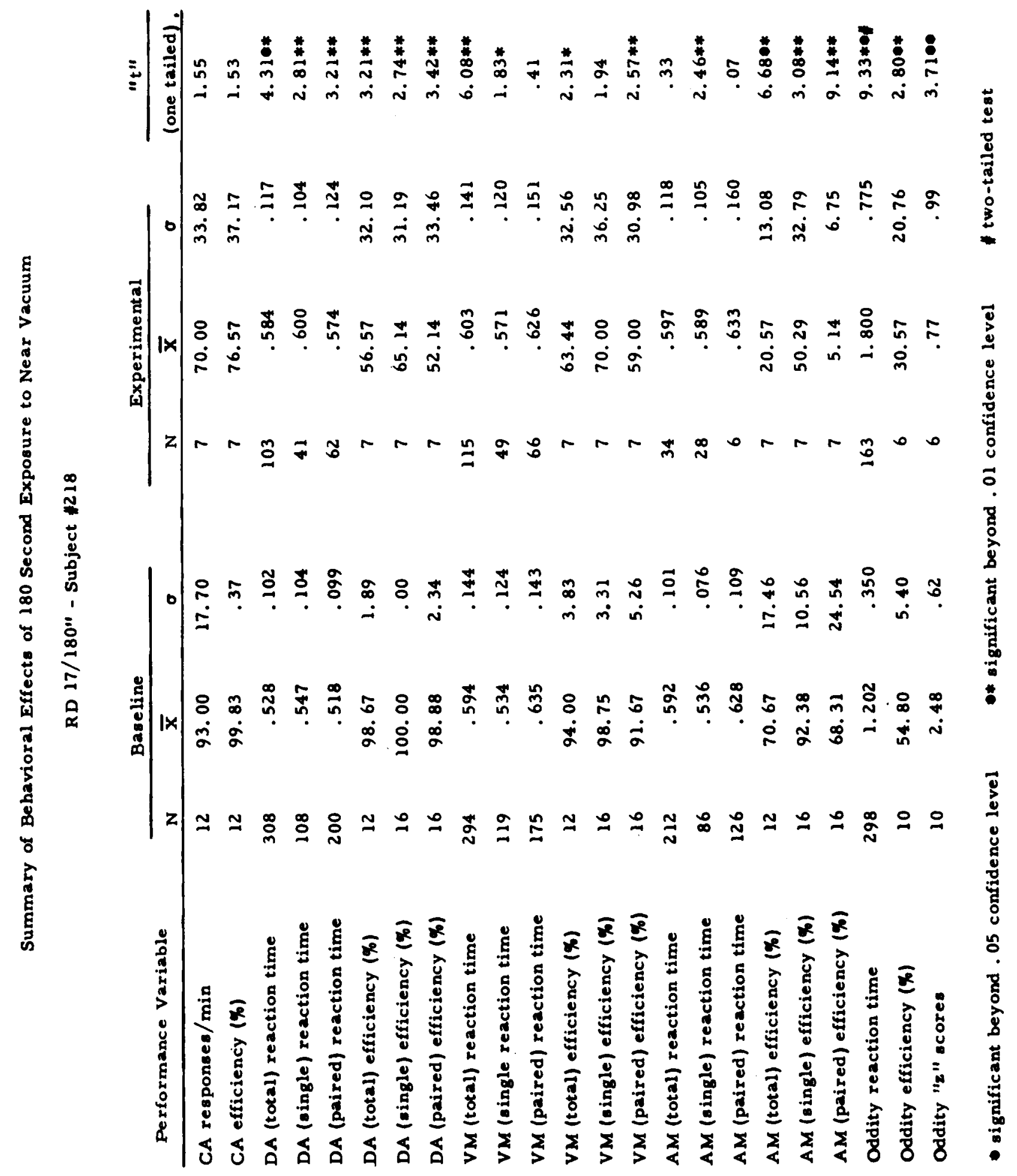




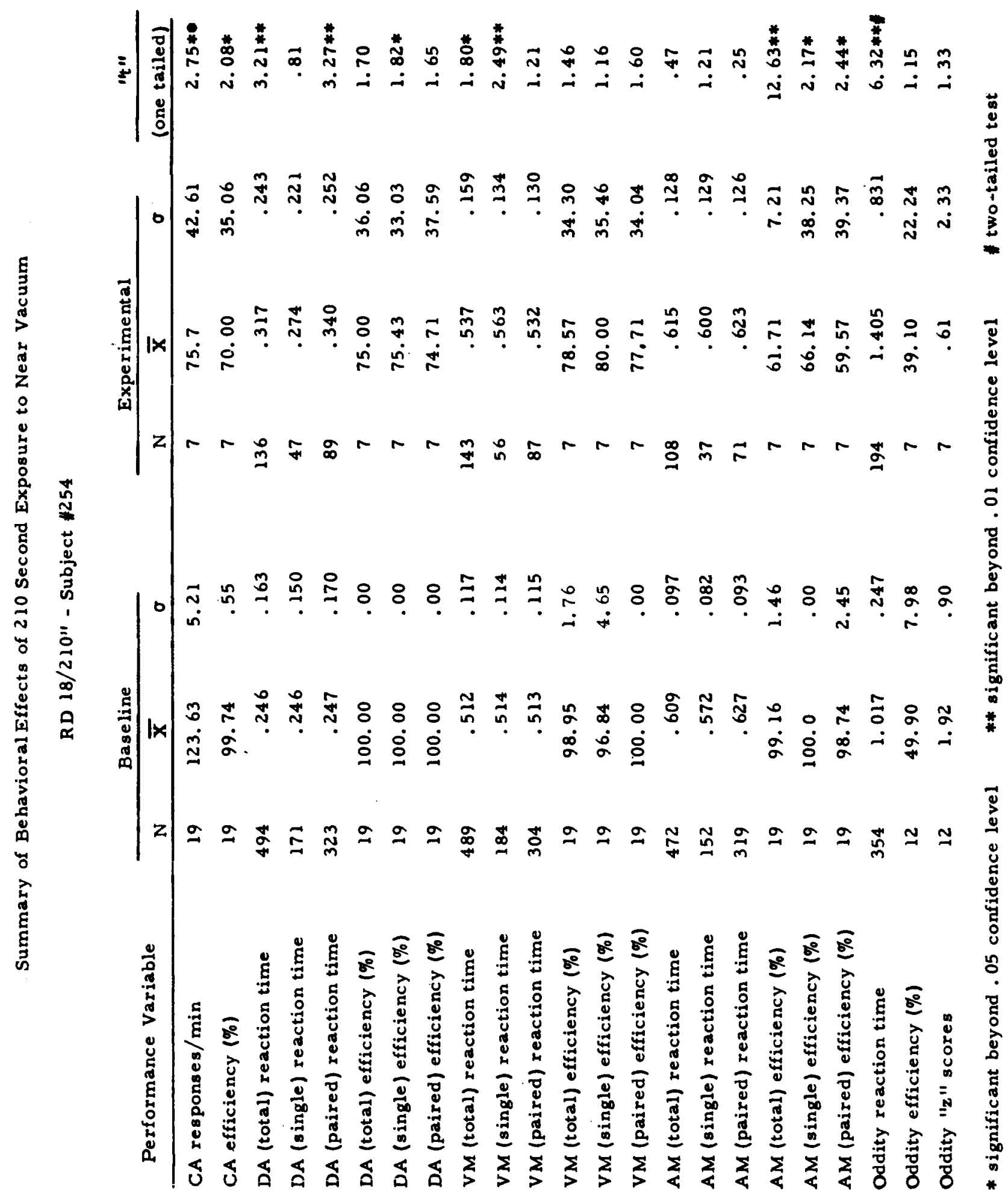




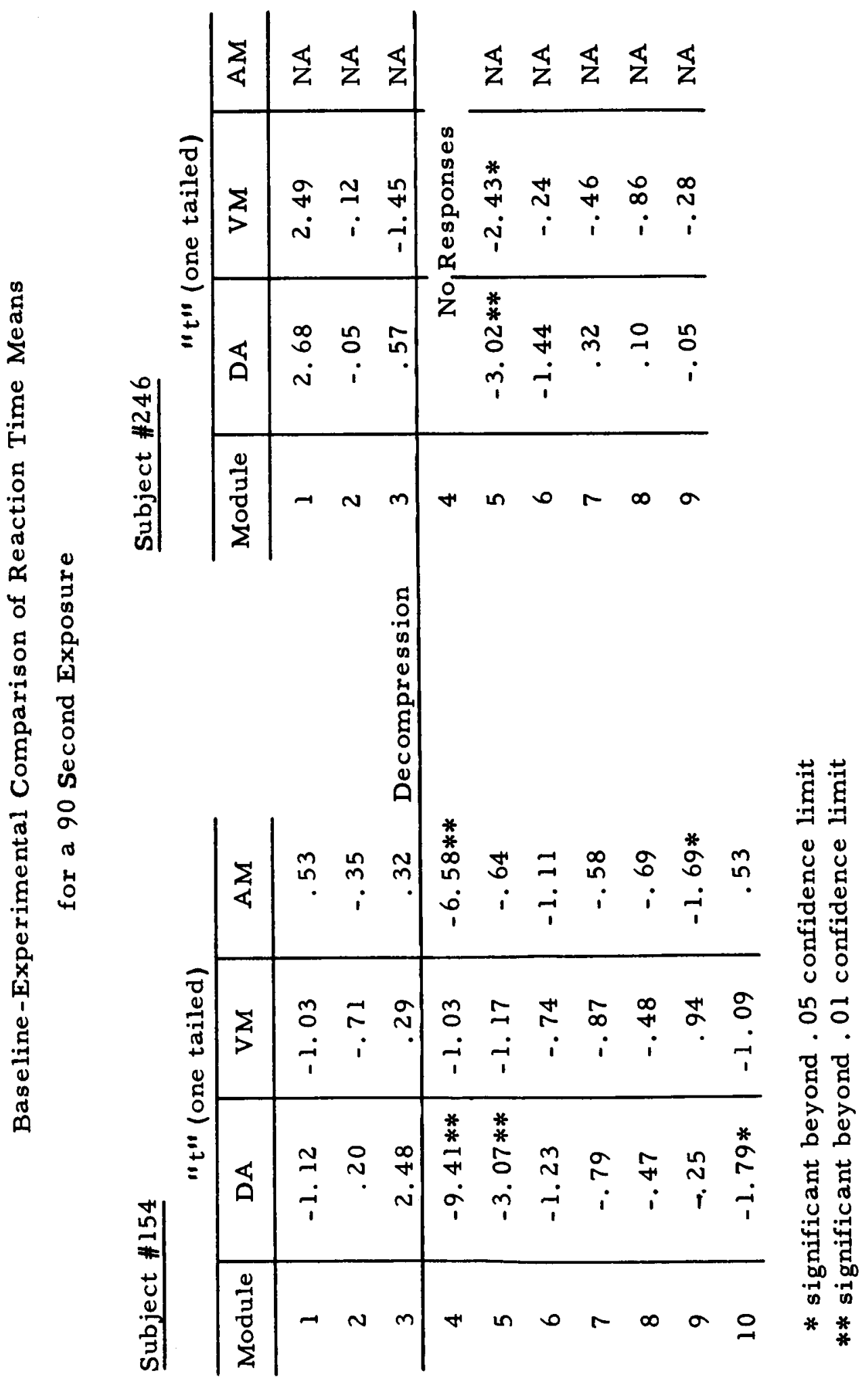




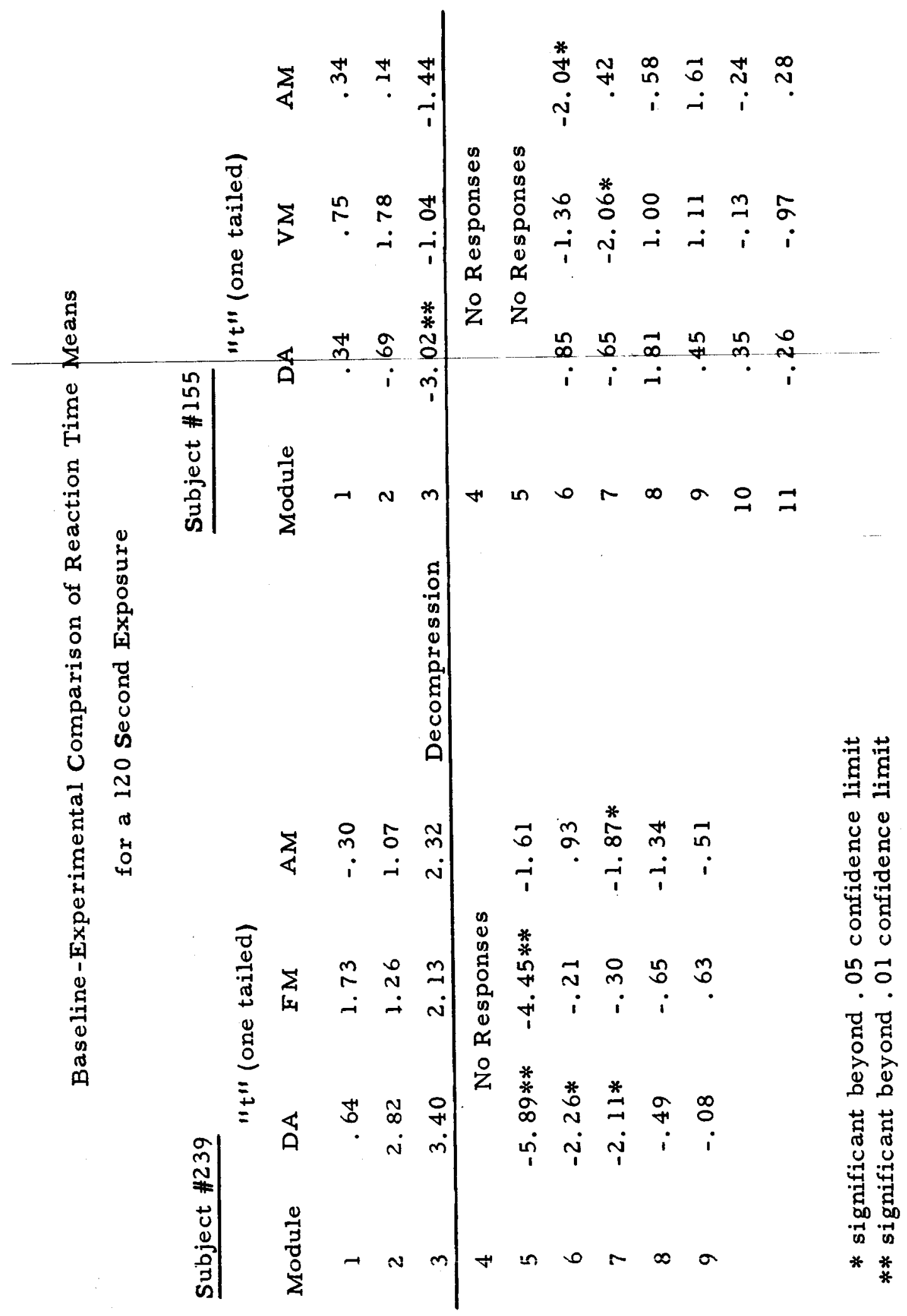




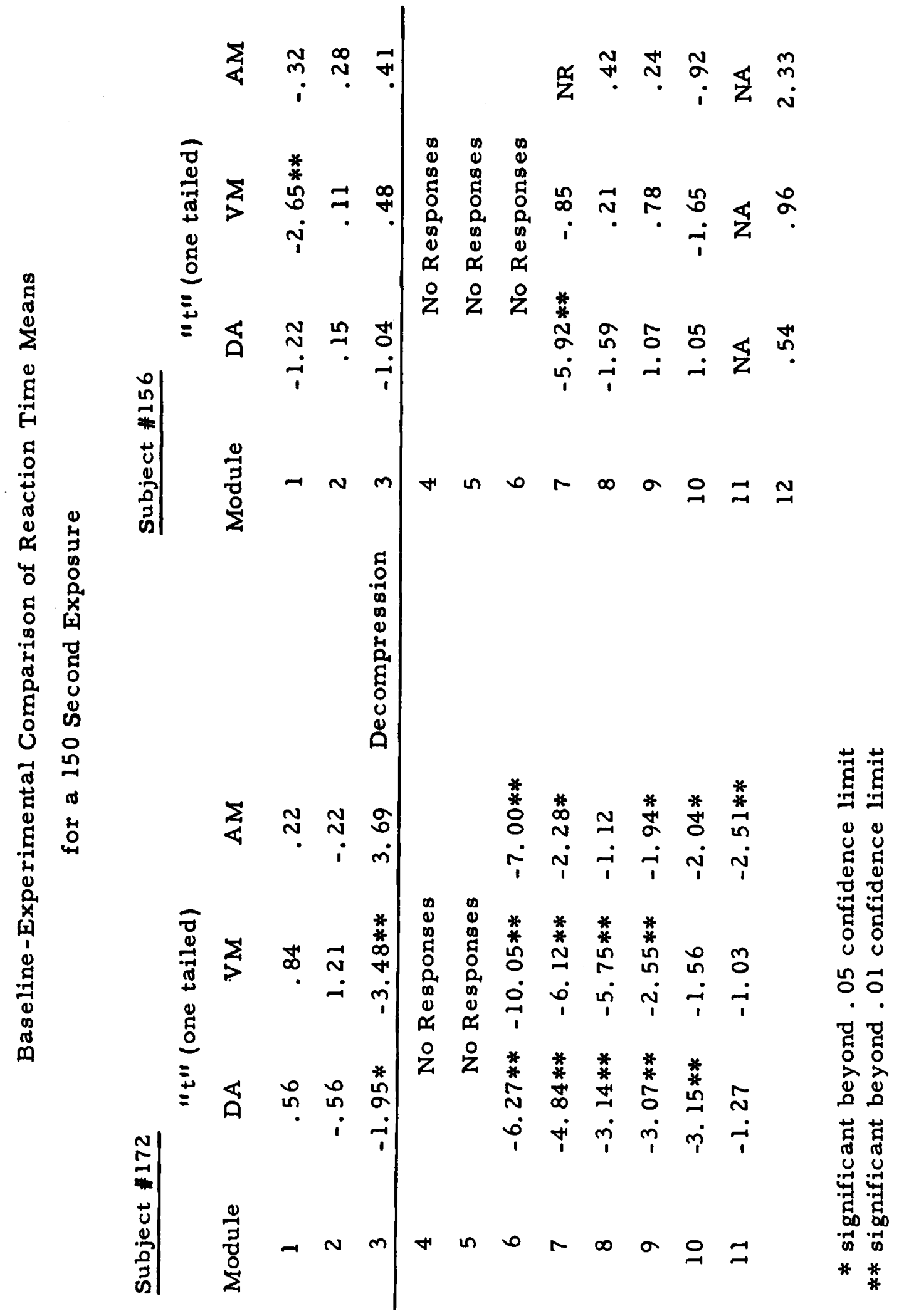




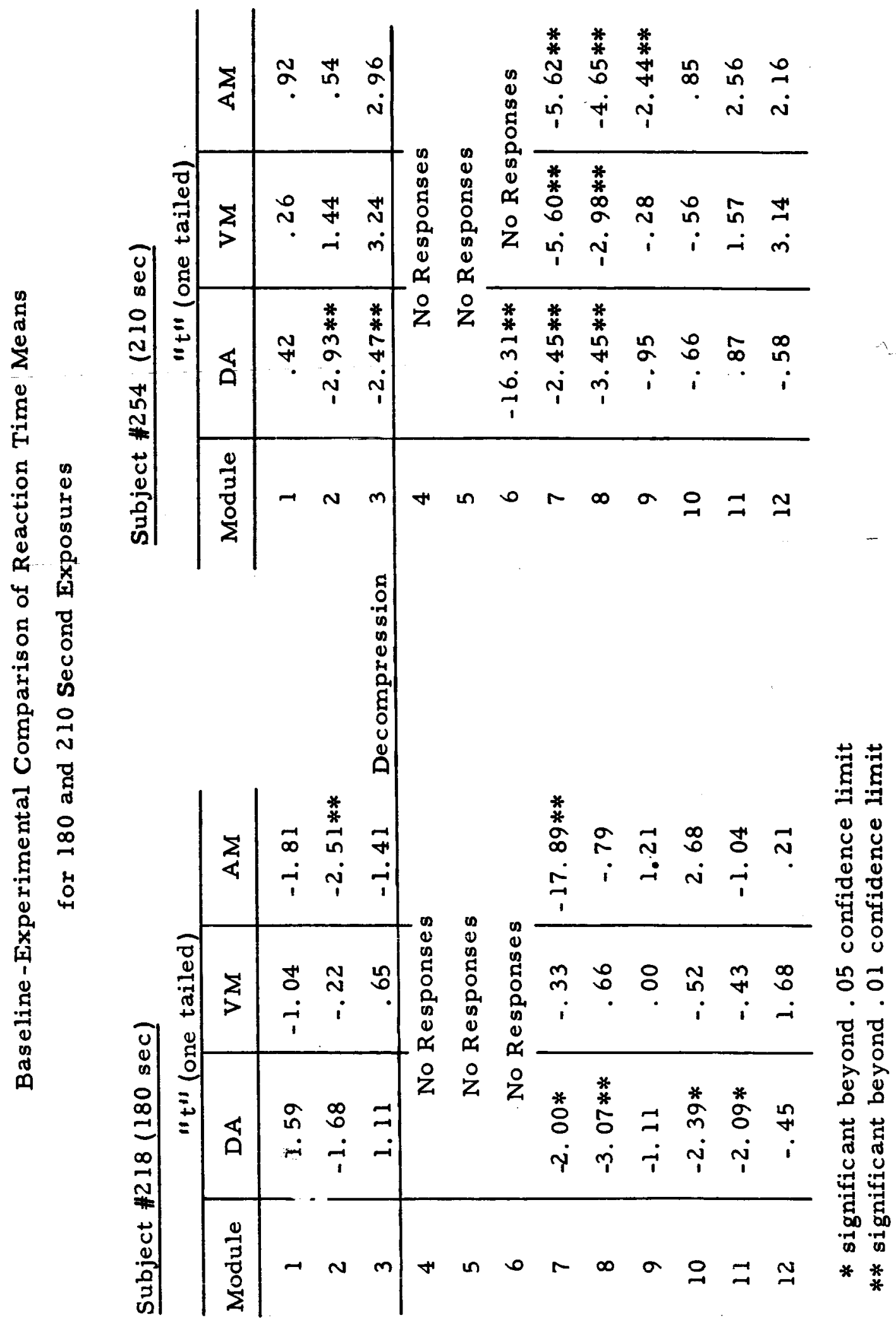




\section{SECTION II}

\section{Physiology and Neurophysiology}

Martin Reite, Captain, USAF, MC

Loyd Stephens, lst Lt, USAF

\section{Edward Bixler}

John M. Rhodes, Ph. D., Associate Profess or University of New Mexico

Neurophysiology Section

Bio Effects Division

6571 st Aeromedical Research Laboratory

Holloman Air Force Base, New Mexico 


\section{ACKNOW LEDGEMENTS}

The assistance of the following persons is gratefully acknowledged:

Charles Clark

Don Lentz
Senior Electronics Engineer

Senior Electronics Technician 


\begin{abstract}
Rapid decompression (RD) to a near vacuum in nine chimpanzees was associated with a pronounced tachycardia, which was regularly followed by a rather sudden bradycardia beginning 15 to 20 seconds post RD, with maximum slowing at 40 to 60 seconds post RD. Two animals exhibited ventricular tachycardia, one progressing to ventricular fibrillation and death. Both had higher than normal pre-RD rates, with greater than normal variability.
\end{abstract}

One subject (RD 17/180) was chronically implanted with depth electrodes in the amygdalae, uncus, hippocampus, and reticular formation, and with skull screws in the frontal, temporai, and parieto-occipital regions. Time of decompression was 180 seconds. Time of useful consciousness (TUC) was 11.1 seconds followed at 45 seconds by cortical electrical silence, and by subcortical silence at 75 seconds, during which evoked responses from cortex and amygdala to centrum medianum stimulation disappeared. Following recompression definite electrical activity, consisting of symmetrical paroxysmal bursts, was first noted in the limbic structures at 90 seconds. With recovery fast activity returned to uncus and hippocampus, foliowed by the amygdala and reticular formation. Cortical fast activity was the last to return, and preceded recovery of function on the psychomotor program. Two months after RDa mild organic residual was manifested by a slight performance decrement and by subtle behavioral changes.

There is suggestive evidence that circulation stops during decompression, which, along with a degree of hypothermia, may represent a survival enhancing factor. 


.




\section{INTRODUCTION}

Previous work ( 1 ) on the effect of rapid decompression on the chimpanzee has shown that this species can survive exposures to pressures of less than $2 \mathrm{~mm}$. Hg for periods up to $2-1 / 2$ minutes without evidence of central nervous system damage as measured by performance on a behavioral program, and that return to normal performance occurs within 4 hours. The electroencephalogram, recorded from skull screws, progressed to electrical silence during decompression periods of 30 seconds and over, and the time to recovery of normal activity was related to the length of decompression. Cortical fast activity returned before the animal began to work the psychomotor program, and return to baseline level of performance was preceded by the EEG returning to normal. An initial tachycardia at the onset of decompression was followed by respiratory arrest and an ensuing bradycardia prior to recompression. There was no obvious relationship between either heart rate or respiration and cortical electrical activity or performance ability (2).

The present series of nine chimpanzees all had EKG, respiration, and skin temperature recorded, but only two were instrumented for EEG. One of the EEG records (RD 11/150) was unusable because of technical difficulties. The other record ( $R D 17 / 180$ ) is the first from an implanted animal, and considerable effort was expended in solving the various technical and recording problems. EKG, respiration, and temperature data will be presented for all animals in the present: series;, and the EEG results from $R D$ 17/180, which is a prototype of the experimental setup for the next series of animals, will be presented in detail.

\section{METHODOLOGY}

The decompression profile and psychomotor performance programs are presented in detail in Section 1 . Decompression times ranged from 90 to 210 seconds. Eight animals survived and recovered; one animal succumbed to ventricular fibrillation during decompression and will be discussed separately (RD 12/90). 
EKG leads, $\mathrm{CuSO}_{4}$ band respiration sensors and skin temperature thermistors were of the same type as described by Stephens, et al. (2) in the previous study. EKG was recorded between the sternum and fifth lumbar vertebra, and skin temperature from the inner mid-thigh region. These measures, with a cardiotachometer, were recorded on an 8-channel Sanborn Model 350 recorder during all decompressions.

Animal No. 218 , used in RD 17/180, was implanted with chronic subcortical electrodes and skull screws several months prior to RD. Electrodes were bipolar pairs of 29-gauge stainless steel tubing, epoxy varnished, bared one-half $\mathrm{mm}$. at the tip, with an interelectrode distance of approximately $1 \mathrm{~mm}$. Subcortical locations included the amygdalae, uncus, hippocampi, mesencephalic reticular formation, and nucleus centrum medianum. Stainless steel screws were placed in the skull overlying the frontal, central, parietal, and occipital cortex. Following the implantation, the animal was trained on the performance program described in Section 1 , and baseline EEG recordings were obtained during wakefulness and sleep.

\section{Procedure}

Eight channels of EEG were recorded on a 10-channel Grass Model 6 electroencephalograph. Areas recorded were the left centro-parietal cortex, left parieto-occipital cortex, right centro-occipital cortex, right amygdaga, left uncus, left hippocampus; left amygdala, and mesencephalic reticular formation. Seven channels of electroencephalographic data were also recorded on magnetic tape for later analysis.

Average evoked responses to stimulation of the Right $\mathrm{N}$ Centrum medianum (N. $\mathrm{Cm}$ ) were recorded from the right centro-occipital cortex and the right amygdala. A Nuclear Chicago Constant Current Stimulator was used to produce 0.5 $m$ amp symmetrical biphasic pulses $0.1 \mathrm{msec}$ in duration separated by $0.1 \mathrm{msec}$, delivered at 1 per second. Twenty stimuli were averaged with a Nuclear Chicago Data Retrieval Computer, using the Grass Model 6 preamplifiers, giving a frequency response to $5 \mathrm{KH}_{\mathrm{z}}$.

Selected epochs of the EEG were subjected to computer analysis using spectral analysis techniques. 


\section{RESULTS}

\section{A. DECOMPRESSION}

1. Electrocardiogram

The pre-RD heart rate was determined by taking a reading from the cardiotachometer every 30 seconds for the 10 minutes immediately following the start of the last complete program prior to $R D$ and for the 10 minutes immediately preceding $R D$.

During decompression and for 10 minutes following recompression the rate was determined by taking a direct reading from the cardiotachometer at 5-second intervals. The data were normalized by conversion to standard or $\mathbf{Z}$ scores to minimize subject variability.

All subjects demonstrated a tachycardia immediately following decompression which was regularly followed by a rather sudden bradycardia beginning 15 to 20 seconds post RD, with maximum slowing 40 to 60 seconds post RD (Fig. 1). A gradual increase in rate was seen until recompression, and in the longer decompressions the rate had returned to normal baseline limits by the time of recompression.

Because of the non-standard lead configuration and possible intrathoracic organ displacement at decompression, no EKG interpretation was made other than rate and obvious alterations in rhythm.

In general, a sinus rhythm persisted during decompression, although premature ventricular contractions (PVC's) were frequently noted, and occasionally related to the length of decompression.

The subject in RD 12/90 had the normal pattern of post RD tachycardia followed by bradycardia until 85 seconds post RD ( 5 seconds before recompression in this case) at which time irregular ectopic beats were noted which progressed to ventricular tachycardia in 63 seconds and ventricular fibrillation 7 seconds later. Fibrillation persisted and no attempt at resusitation was made. 


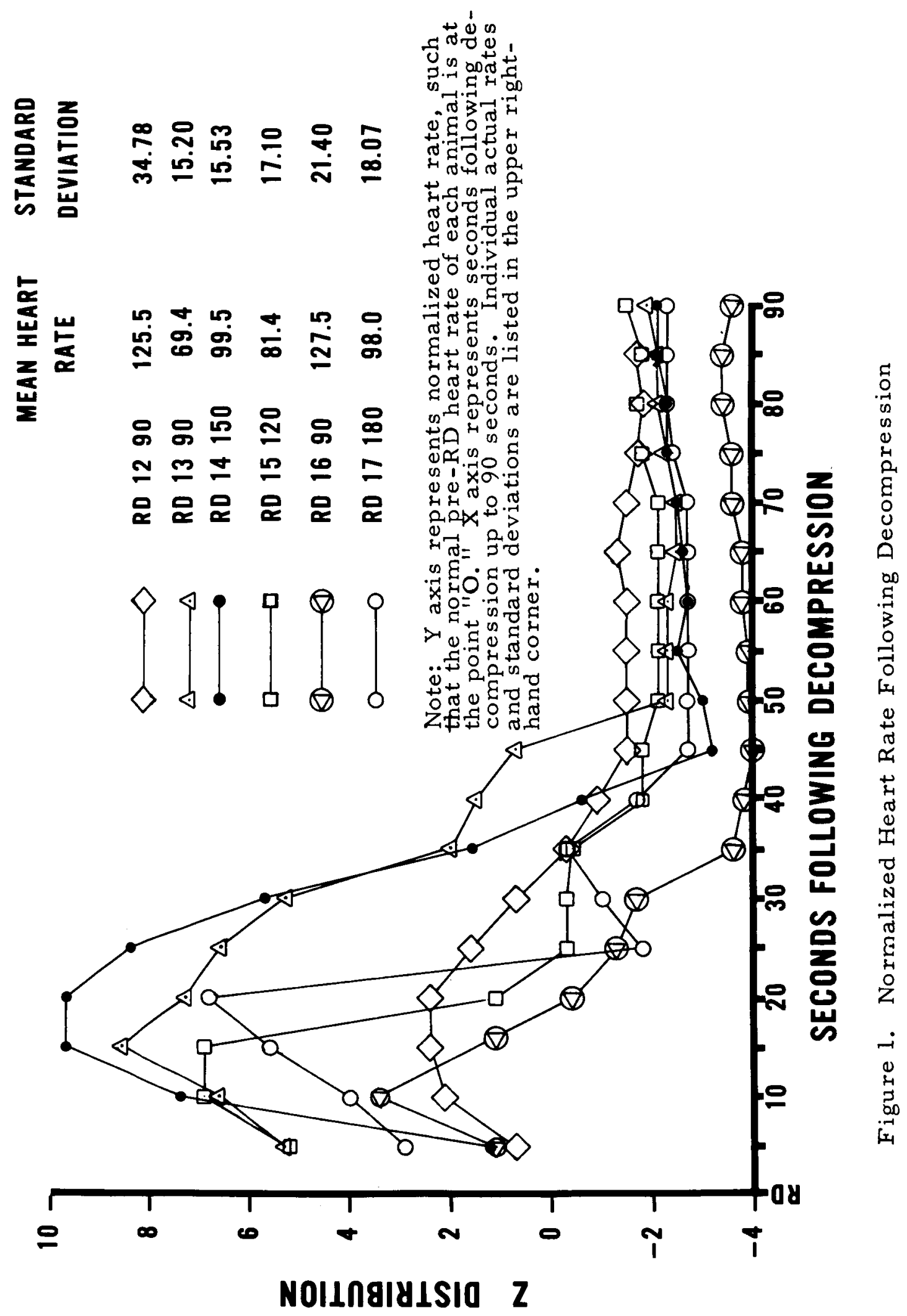


In RD $16 / 90$ the subject developed a bigeminal rhythm which progressed to ventricular tachycardia in 115 seconds. Ventricular tachycardia persisted for 25 seconds reaching a rate of 300 beats per minute before spontaneously converting to a normal sinus rhythm. Recovery was otherwise uneventful.

\section{Skin temperature}

From the time the subject entered the chamber until the time of $R D$ there was on the average a 0.5 to $1.0^{\circ} \mathrm{C}$ rise in skin temperature. At decompression there was an average initial drop in skin temperature of 0.4 to $1.1^{\circ} \mathrm{C}$ during the first 30 to 40 seconds. Temperature continued to fall at a slower rate for as long as 110 seconds post RD, resulting in a total decrease of 1.7 to $2.0^{\circ} \mathrm{C}$. After reaching the lowest level, a gradual rise begins at about .03 to $.11^{\circ} \mathrm{C}$ per minute which persists through recompression.

\section{Respiration}

The respiration sensor continues to respond for from 35 to 65 seconds post $R D$, but actual respiratory movements caunot be clearly separated from other body movements producing displacement of the sensor.

\section{EEG, RD $17 / 180$}

The normal electroencephalogram of the alert animal is illustrated in Figure 2. At the moment of decompression, 1308: 01 hours, and for a period of approximately 30 seconds thereafter, the record is partially obscured by violent pen excursion, at least some of which is caused by movement artifact. Electromyogram (EMG) artifact occurs in the cortical channels during the first minute post RD. Cortical slowing can be seen at $\mathrm{RD}+12$ seconds, proceeding through delta frequencies to electrical silence at $\mathrm{RD}+45$ seconds. The time of useful consciousness (TUC), defined as that time which elapsed between the onset of decompression and the last correct response to a meaningful stimulus before unconsciousness occurs, was 11 . 1 seconds, and corresponds to los s of cortical fast activity. At $R D+23$ seconds what may be seizure activity is noted briefly in the cortical record, although a behavioral seizure was not observed (Fig. 3). 


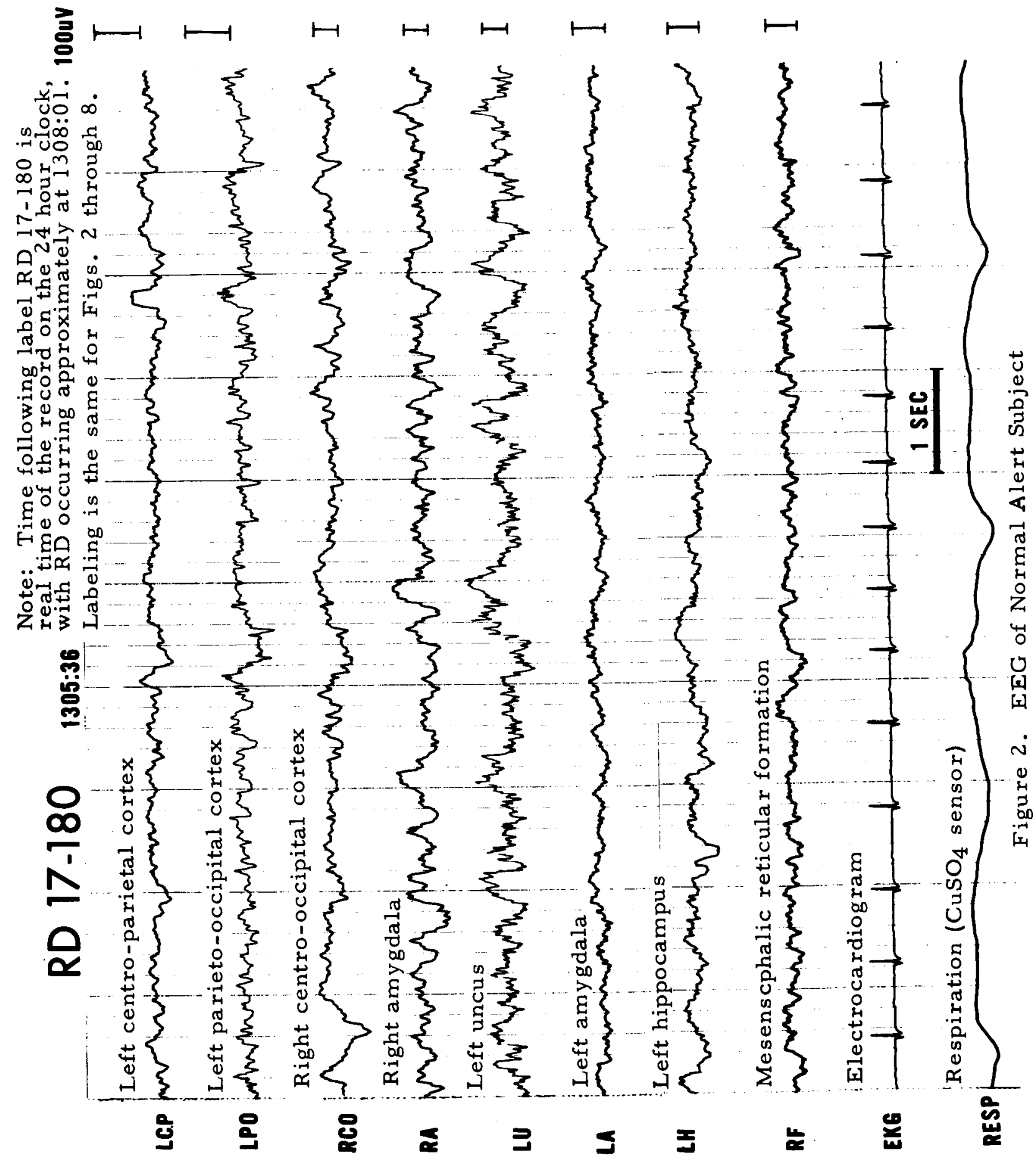




\section{RD 17-180 1308:24}

100uv
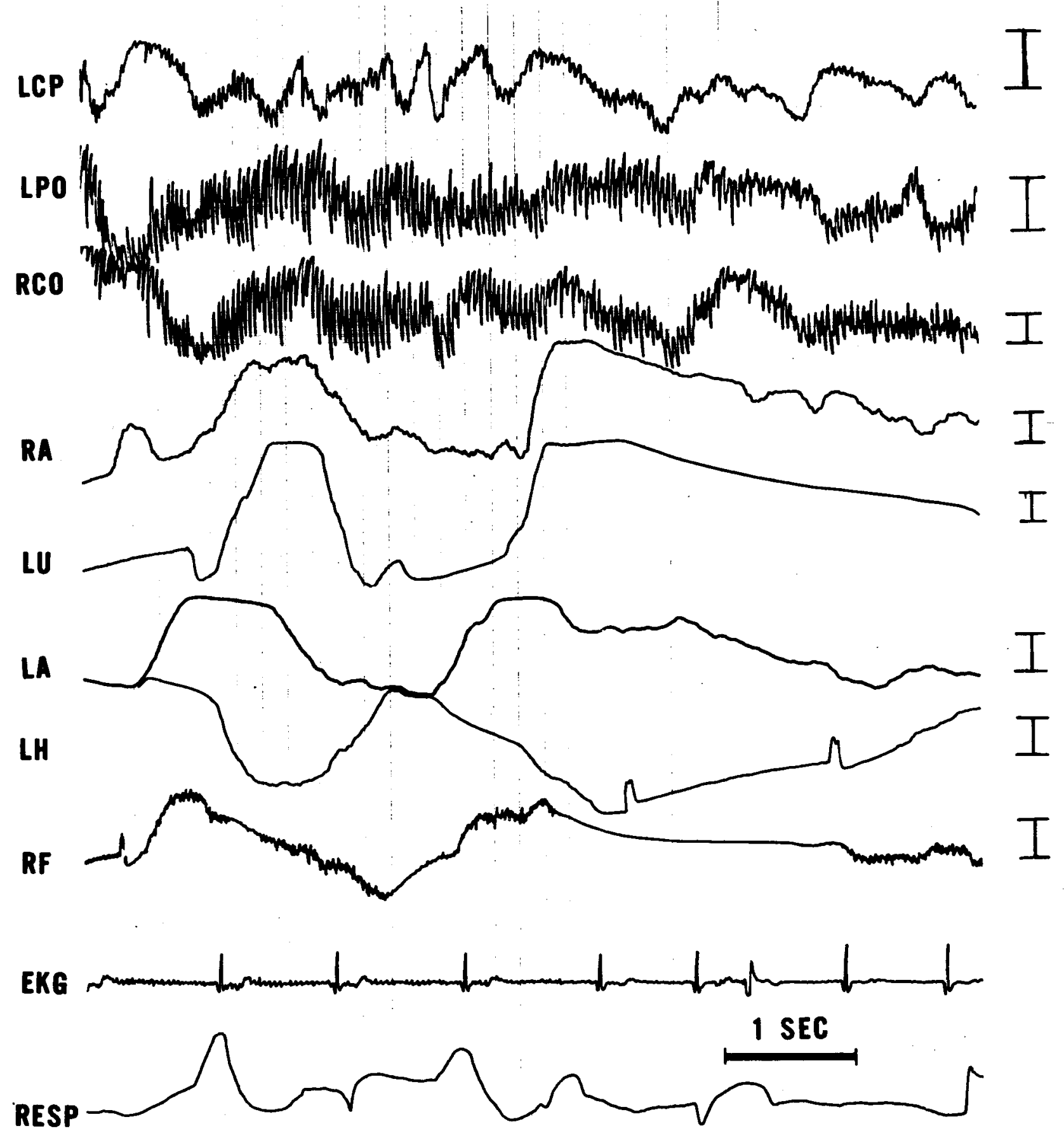

Figure 3. Possible Seizure Activity Following Decompression 
The subcortical record continues to display very slow and low amplitude activity following cortical electrical silence, although it, too, with the exception of the reticular formation, proceeds to electrical silence by $R D+75$ seconds. The reticular formation continues to show rhythmical slow wave activity throughout the period of decompression that is time locked to the EKG ( Fig. 4).

\section{B. RECOMPRESSION AND RECOVERY}

\section{EKG}

During recompression the heart rate rapidly returns to normal and sometimes higher than normal rates. The rate remains within normal limits after 1 to $1-1 / 2$ minutes following recompression. Shocks delivered as part of the psychomotor program following recovery increase the rate to rates at the highest normal limits or slightly above in most subjects.

\section{Skin temperature}

The progressive rise of 0.3 to $.11^{\circ} \mathrm{C}$ continues during and following recompression until pre-decompression values are reached about 30 to 40 minutes following recompression.

\section{Respiration}

Respiratory movements begin about 40 to 75 seconds following the onset of recompression with progressive increase in $r$ ate and depth for a varying number of minutes, followed by a return to normal levels.

\section{EEG, RD $17 / 180$}

Recompression starts at $R D+3$ minutes, and is complete at $\mathrm{RD}+3-1 / 2$ minutes. Slow activity begins to return to the subcortical leads shortly after the onset of recompression, before a pressure of $179 \mathrm{~mm}$. $\mathrm{Hg}$ is reached. This activity is time locked to the EKG and may represent pulse artifact.

The first prominent EEG activity occurs at $\mathrm{RD}+4$ minutes and 55 seconds (Fig. 5) and consists of paroxysmal bursts in the limbic structures. Fast activity returns first 


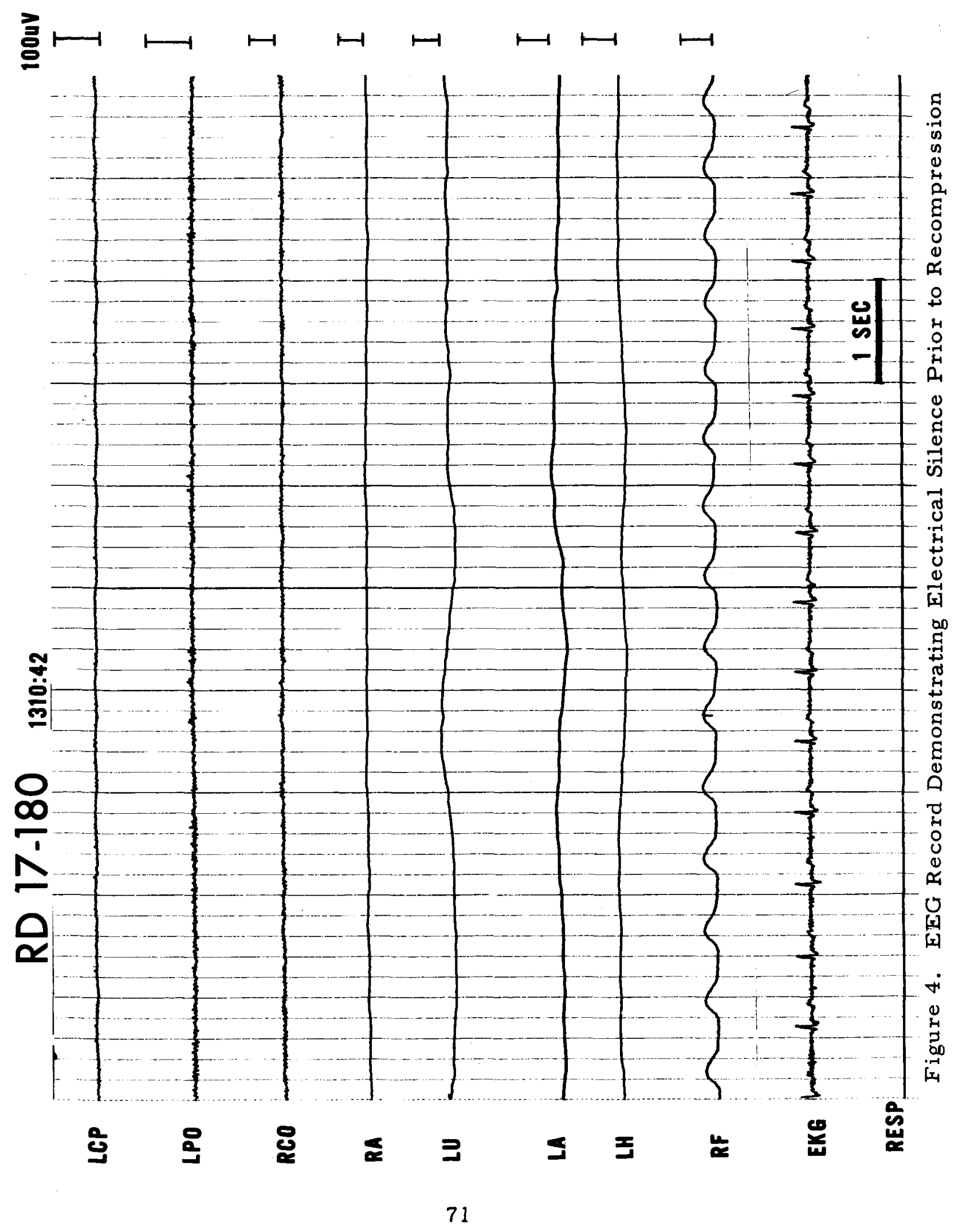




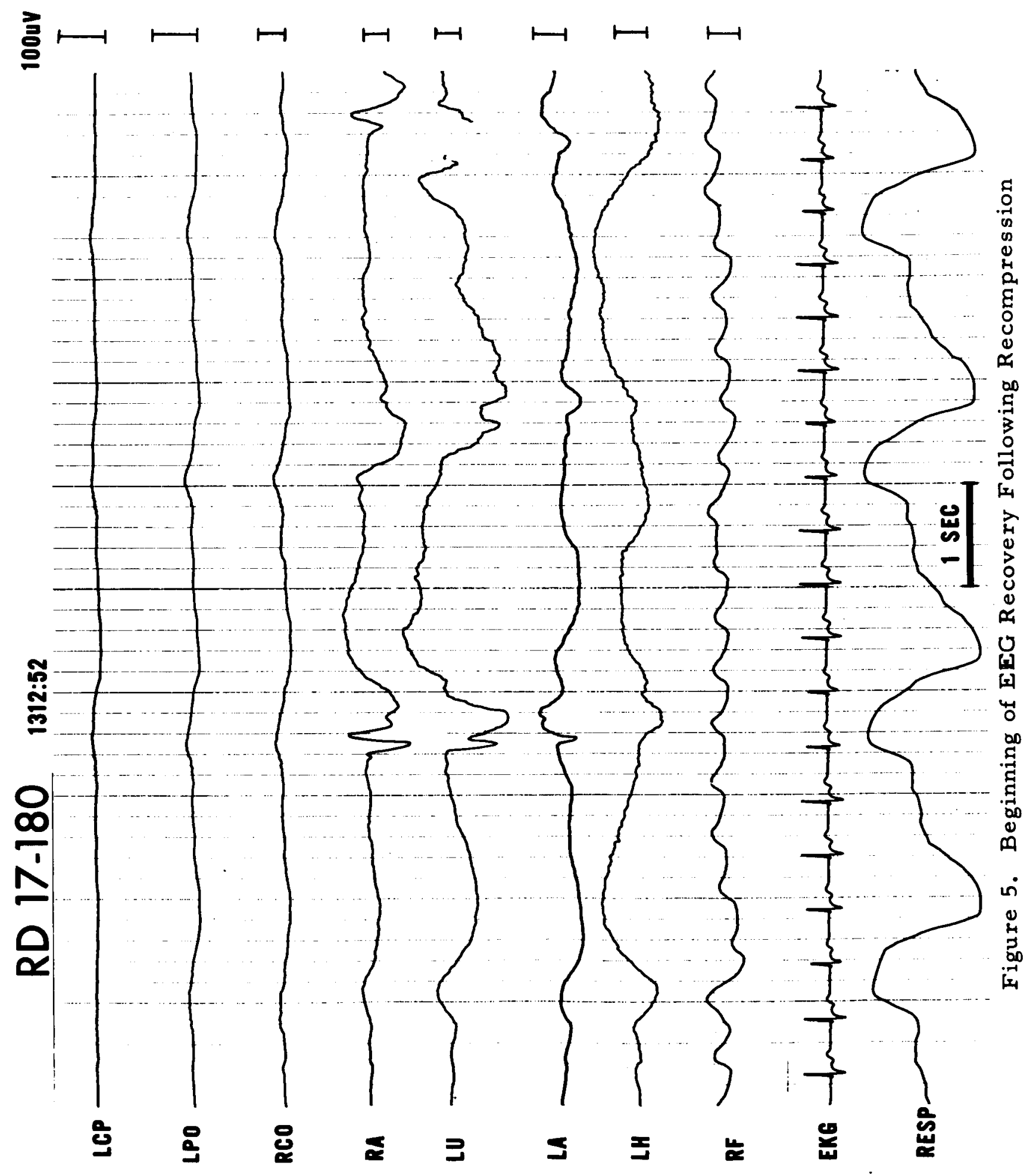


to the uncus and hippocampus, then to the amygdala, and considerably later to the reticular formation. The cortex remains essentially silent during the first several minutes of subcortical recovery (Fig. 6). Slow cortical activity begins at about $R D+7$ minutes. The first evidence of fast cortical activity is seen at RD + 7-1/2 minutes, and consists of short bursts of very low voltage activity at about $18 \mathrm{c} . \mathrm{p} . \mathrm{s}$., which occurs simultaneously with short bursts of the same frequency activity in the reticular formation (Fig. 7). At RD + 9 minutes the central cortical leads contain paroxysmal components related to respiration (Fig. 8), which Cooper (3) feels are similar to waves noted in the human EEG during recovery from hypothermia.

The end of the time of total impairment (TTI), defined as that time from the end of the TUC to the time of the first response made to a meaningful stimulus, occurred at 26 minutes 42 seconds after the end of the TUC. At this time limbic structures showed nearly normal activity, whereas the cortex and reticular formation still contained more slow activity than normally.

By RD + 1 hour the EEG contained some cortical slow activity and slightly less fast activity in the reticular formation compared to the pre-RD record, and visual monitoring reaction time and oddity reaction time had returned to baseline levels. The continuous avoidance (CA) lever presses returned to normal by RD + I hour 34 minutes, by which time the EEG was normal to visual inspection. In the previous study the EEG had been found to return to normal before the CA lever presses reached baseline-levels, and again this was the case.

Follow-up EEGs were obtained at 10 days and 6 weeks post RD which were normal to visual inspection. The animal's performance at 6 weeks post RD was slightly but significantly poorer than pre-RD performance. During the several months immediately post RD the animal had been noted by his handlers, and others who had worked extensively with him, to be unusually irritable and generally hyperactive as compared to his pre-RD status. He remained this way for about 3 months, following which his behavior was indistinguishable from pre-RD behavior. 


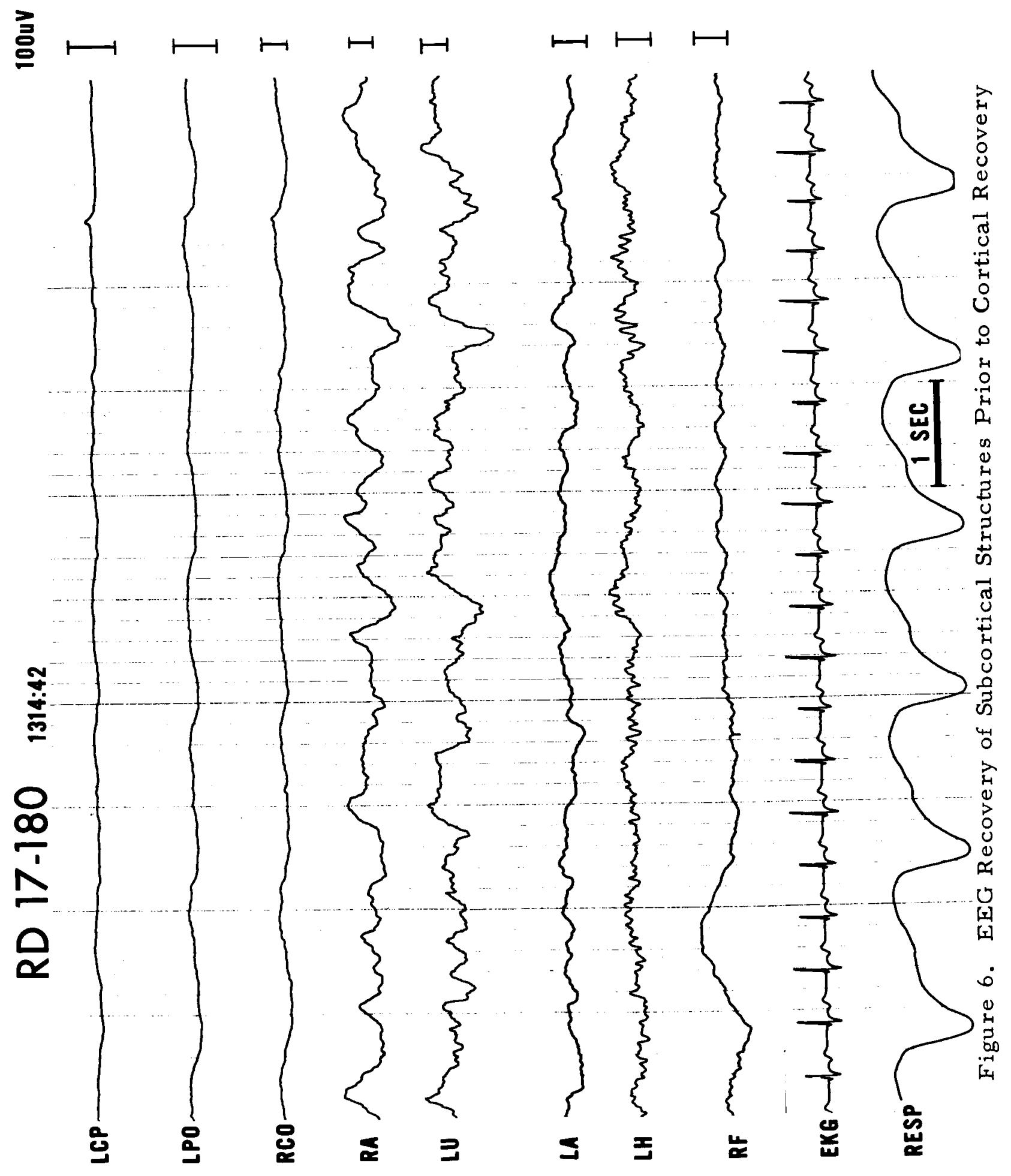



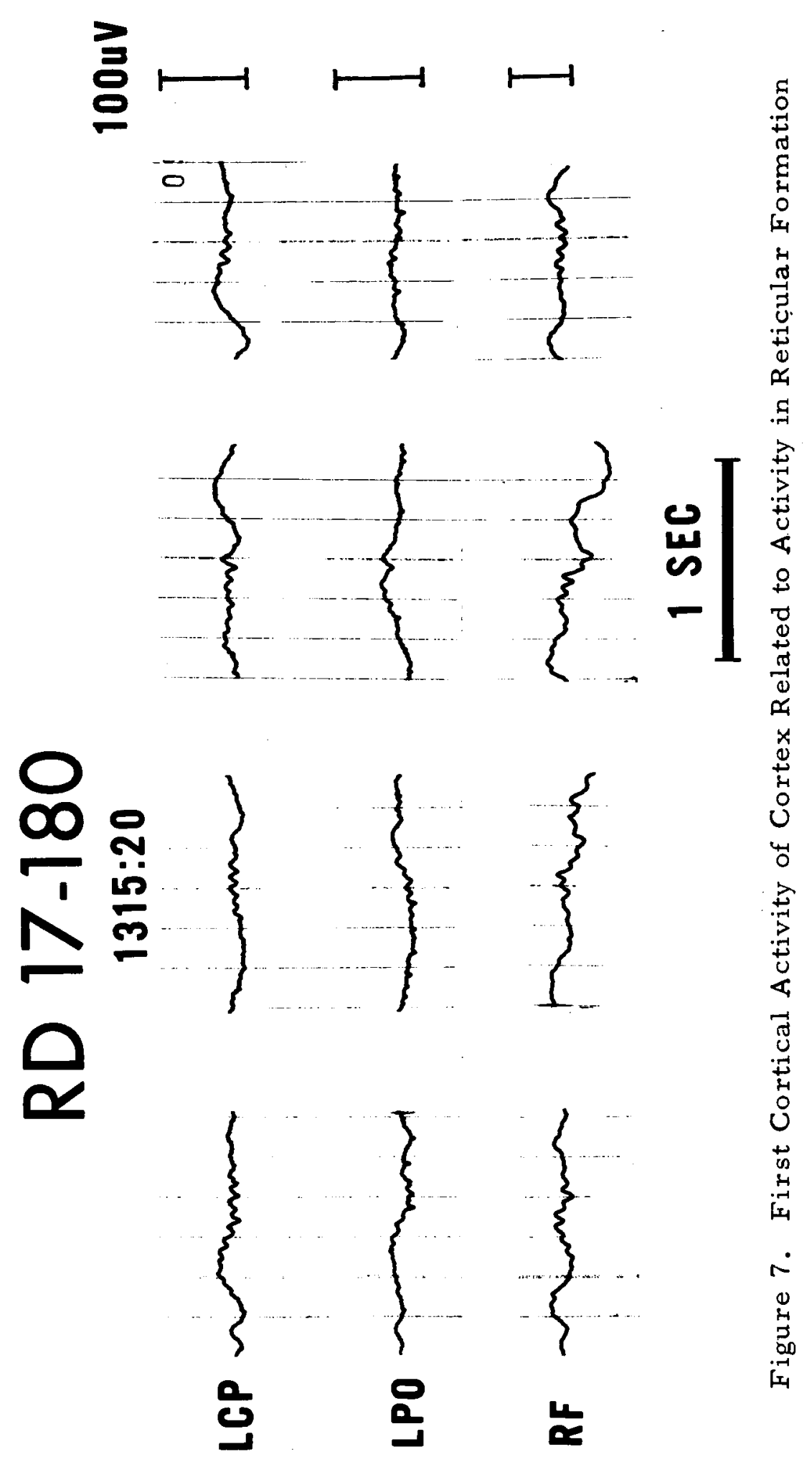


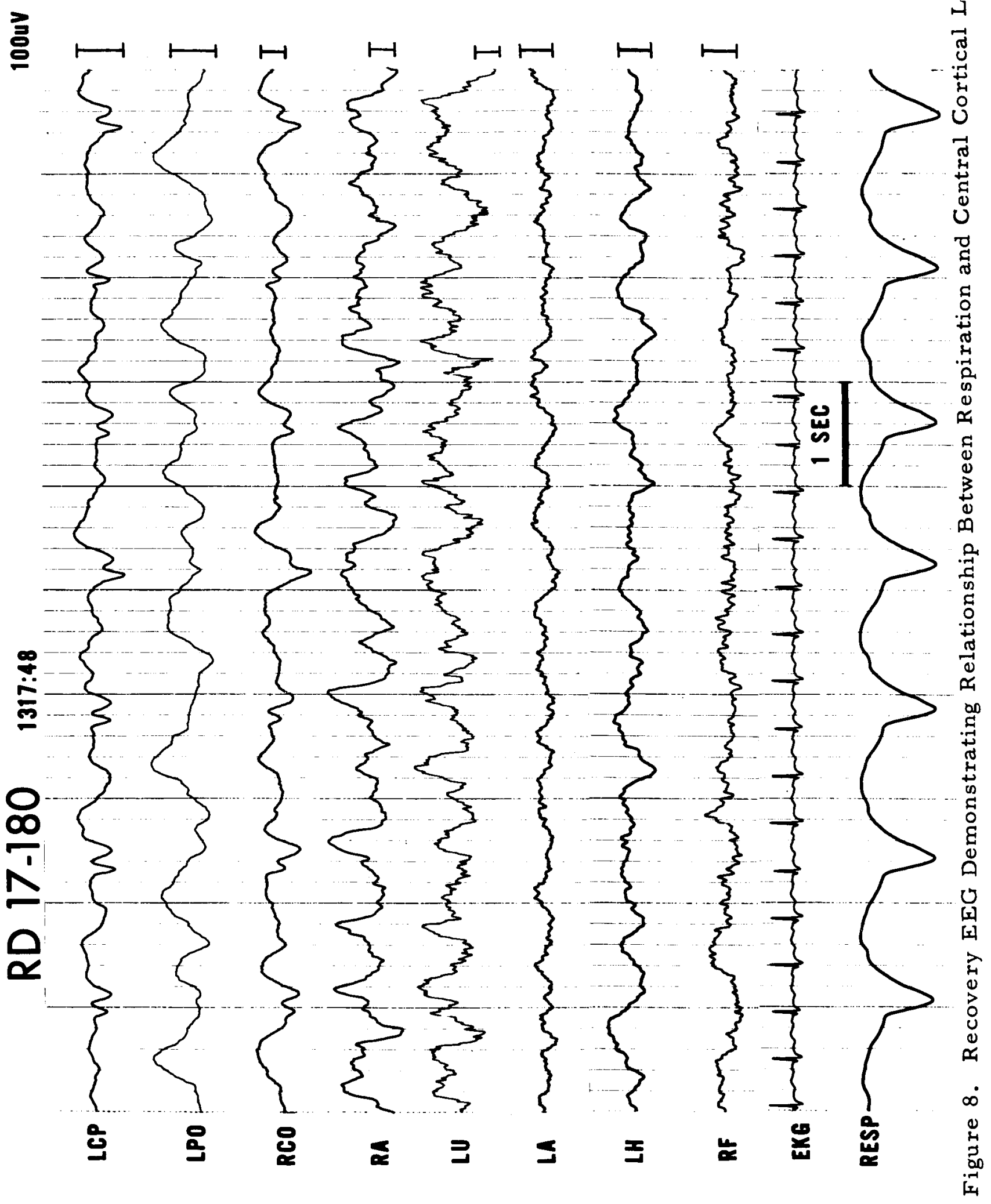




\section{N. Centrum Medianum Stimulation}

The normal averaged evoked responses recorded from the right centro-occipital cortex and right amygdala to stimulation of the right $\mathrm{N}$. Cm., as well as the changes induced by rapid decompression and subsequent recovery, are illustrated in Figures 9 and 10. The presence of direct pathways to both cortex and amygdala is suggested by the very short latency $n_{1}$ component in the cortical response and the $p_{1}$ component in the amygdala response. At $\mathrm{RD}+30$ seconds the early components are reduced in the cortical response, and the later components, if present at all, are obscured by artifact. The amygdala response at this time shows a significant reduction in the early components and a loss of secondary components.

At $R D+120$ seconds there is only a suggestion of $n_{1}$ in the cortical response, and the amygdala response is flat. The EEG is electrically silent at this time, with some EMG artifact in the cortical leads.

At $R D+5$ minutes the short latency components are beginning to recover, and by $R D+14$ minutes they are prominent. Slower secondary components have partially recovered by $R D+38$ minutes, by which time the EEG is near normal subcortically, while retaining some cortical slow activity. The response has returned to normal, and is nearly indistinguishable from the pre$R D$ response by $R D+92 \cdot$ minutes.

\section{EEG Computer Analysis}

Selected epochs of the EEG record from RD 17/180 were analysed using power spectral density (PSD) techniques developed for use with EEG data by Walter et al. at UCLA $(4,5,6,7)$. The taped EEG data were digitized, and the PSD was computed on the basis of a Fourier transformation performed on the output from a series of digital filters, giving power with one cycle resolution from zero to 28 c.p.s.

Figure 11 demonstrates the changes in power for different frequencies during recovery from $R D$. These changes in power may be compared to the range of power during normal pre-RD periods. Samples of the normal pre-RD EEG record have been used to compute limits for each frequency, and the experimental 
Note: Average evoked responses (AER) recorded from the right centro-occipital cortex to 20 stimuli delivered to the right centromedian are recorded in the left hand column with the corresponding time referred to rapid decompression (RD) time. Sample EEG

tracings during the stimulations a re in the right hand column.

100 iN calibration refers to the EEG tracings only.

AER RC-O Cx.<smiles>[R6]P=[R]</smiles>

$\mathrm{RD}+30 \mathrm{sEC}$

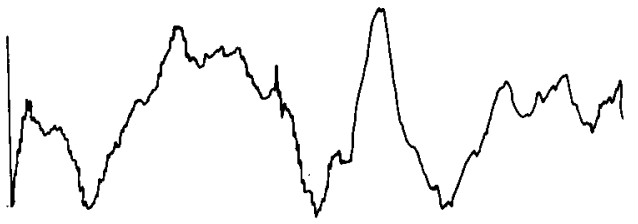

$R D+120$ SEC.

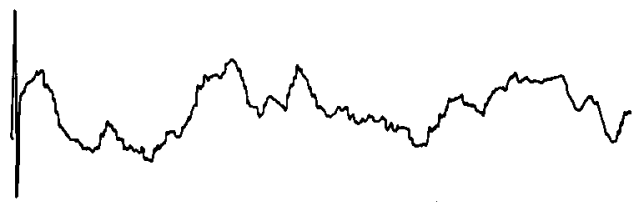

$R D+5$ MIN

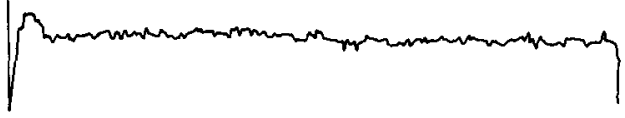

$R D+14$ mIN.

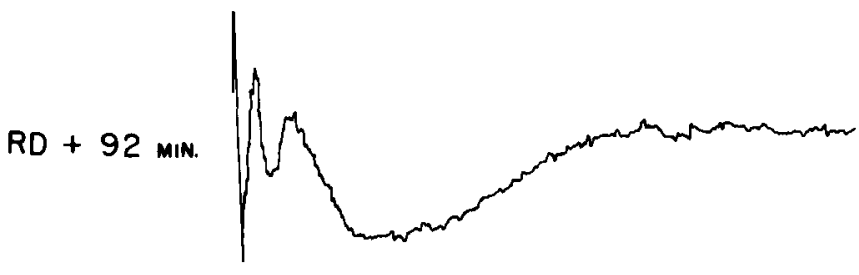

EEG RC-O Cx.
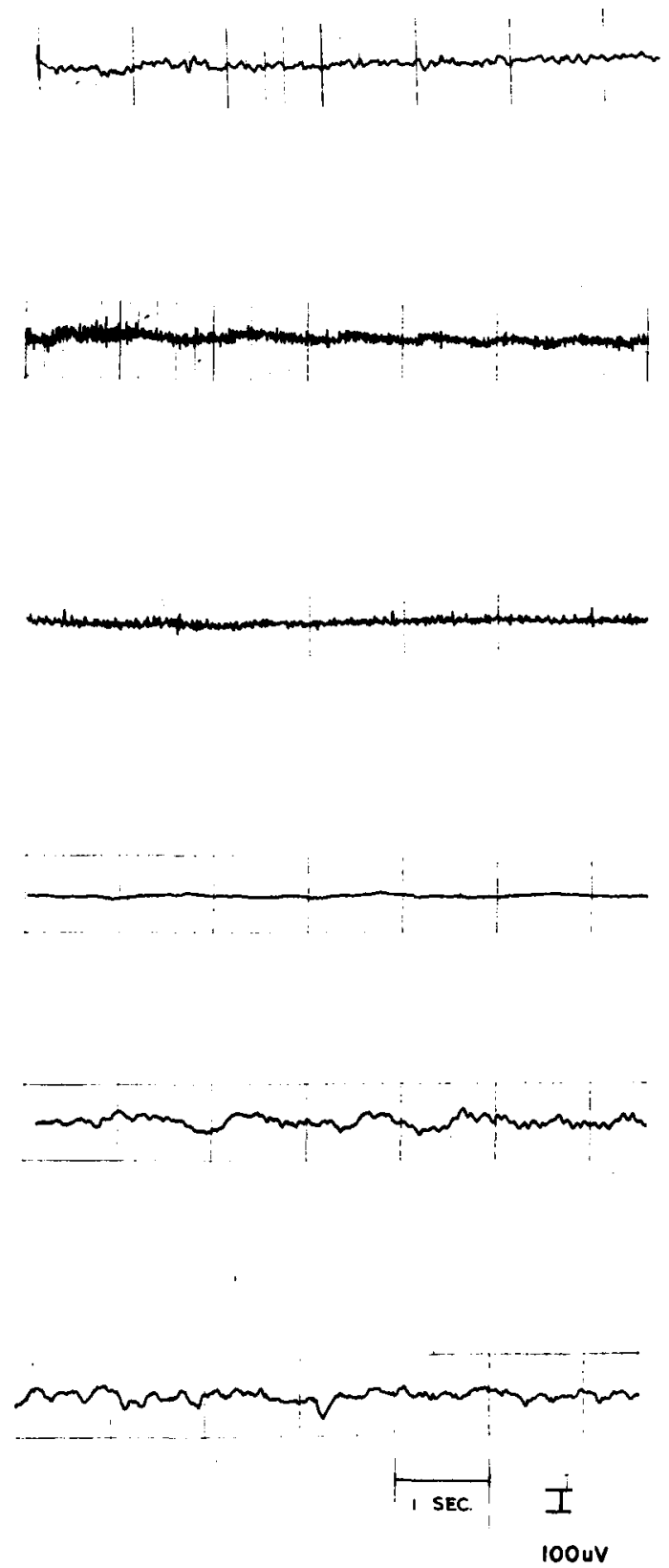

5 MSEC.

Figure 9. Average Evoked Responses Recorded from the Right Centro-Occipital Cortex 
AER LAmg.

PRE-RD
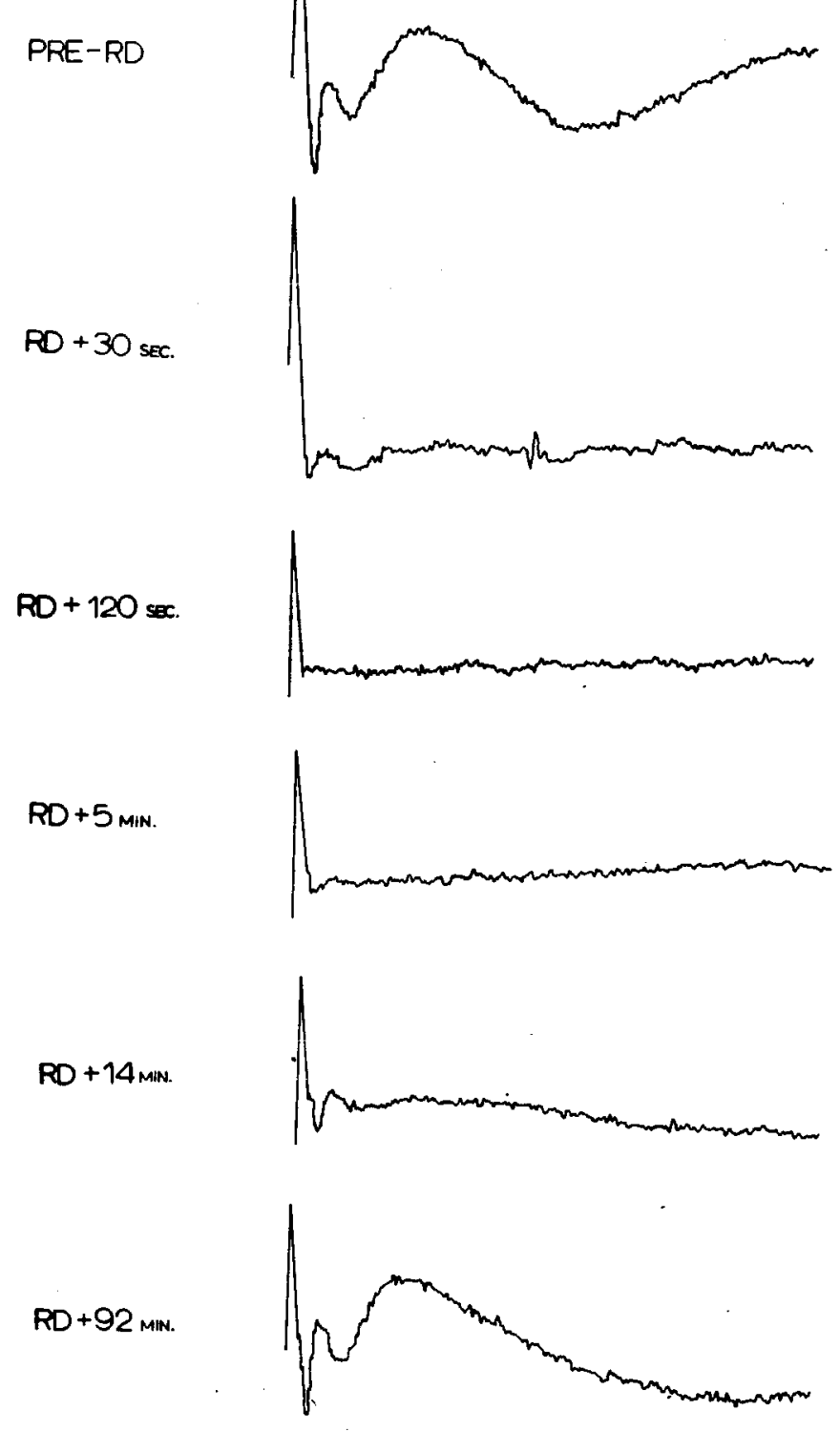

$$
\underset{5 \text { MSEC }}{1}
$$

EEG LAmg.
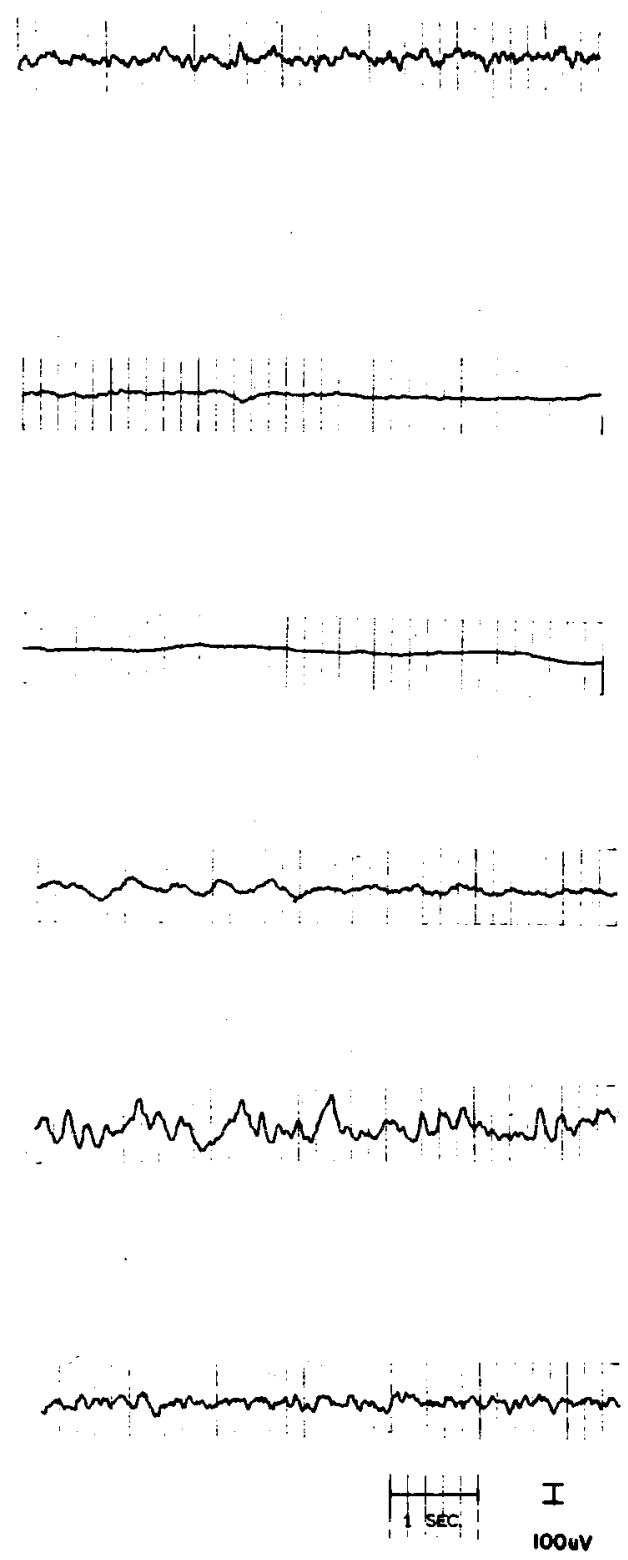

Figure 10. Average Evoked Responses from the Left Amygdala 
u
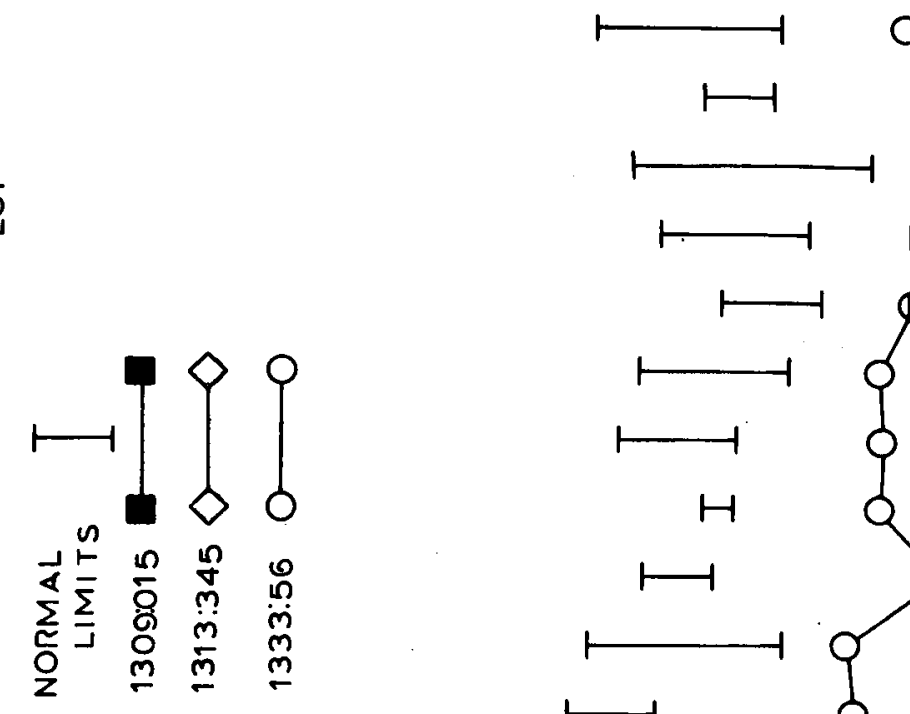

热

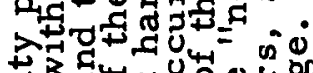
至 $3 c^{4}$

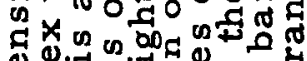

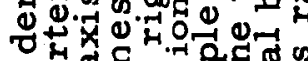

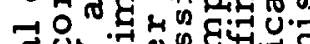
UD O

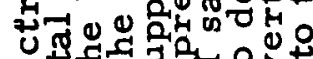

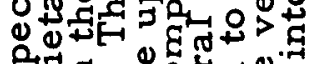
कम दू

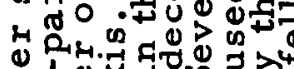

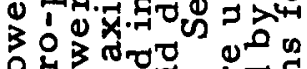
우 1. C्र

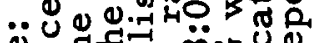
¡ 之热出

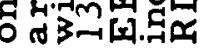


epochs deviate ase a function of the time of the sample. For example, the solid squares represent a 10-second epoch taken approximately I minute after decompression. There has been a tremendous reduction in power with only remnants of physiological electrical activity some of which represents EMG activity. The diamonds represent an epoch taken 2 minutes after recompression. It is notable that there is even less power than before and certainly would coincide with a clinical evaluation of the EEG as reflecting "electrical silence." The circles are just prior to the first behavioral response to a meaningful stimulus. As can be seen, the cortex is high in delta, normal in theta and low in all other frequency ranges. In other words, in terms of power the cortex has returned to approximately normal in the low frequency ranges prior to the first response.

Figures 12 and 13 represent the same epochs as Figure 11 except for electrodes in the amygdalae and hitppo-... campus, respectively. The solid squares for both have the same significant depression noted at the level of the cortex. However, in the epoch represented by the diamonds ( two minutes following recompression), the amygdalae has nearly recovered and is virtually normal in the delta and theta ranges while still a little low in the higher frequencies. The hippocampus during this same epoch has returned to pre-RD limits in all frequencies except theta which is slightly suppressed. In the epoch represented by the circles the amygdalae is high in power for delta and theta and normal in other ranges. The hippocampus during this same epoch is high in theta and alpha and normal in all other frequencies.

Descriptive statements of the auto-spectra were also investigated. These statements permit the description of the EEG and PSD curves across a total file. In other words, relationships can be demonstrated as a function of the time of the epoch sampled. These measures included statements of the average frequency in terms of power $(\bar{F})$, and a measure of variability of the modal frequency (B.W. or "bandwidth"). When these two measures are plotted against each other, they demonstrate the stability of the predominant frequency. 


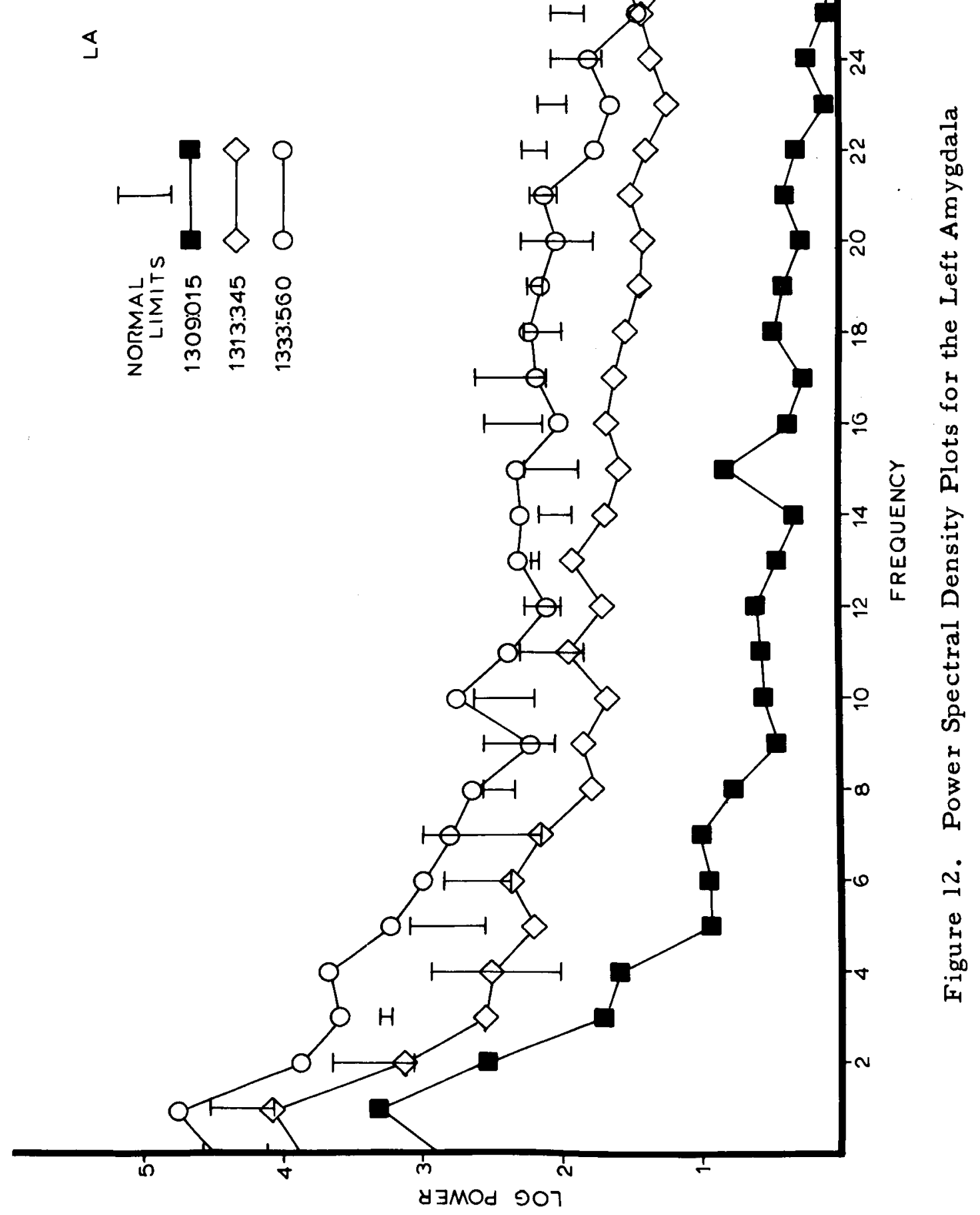




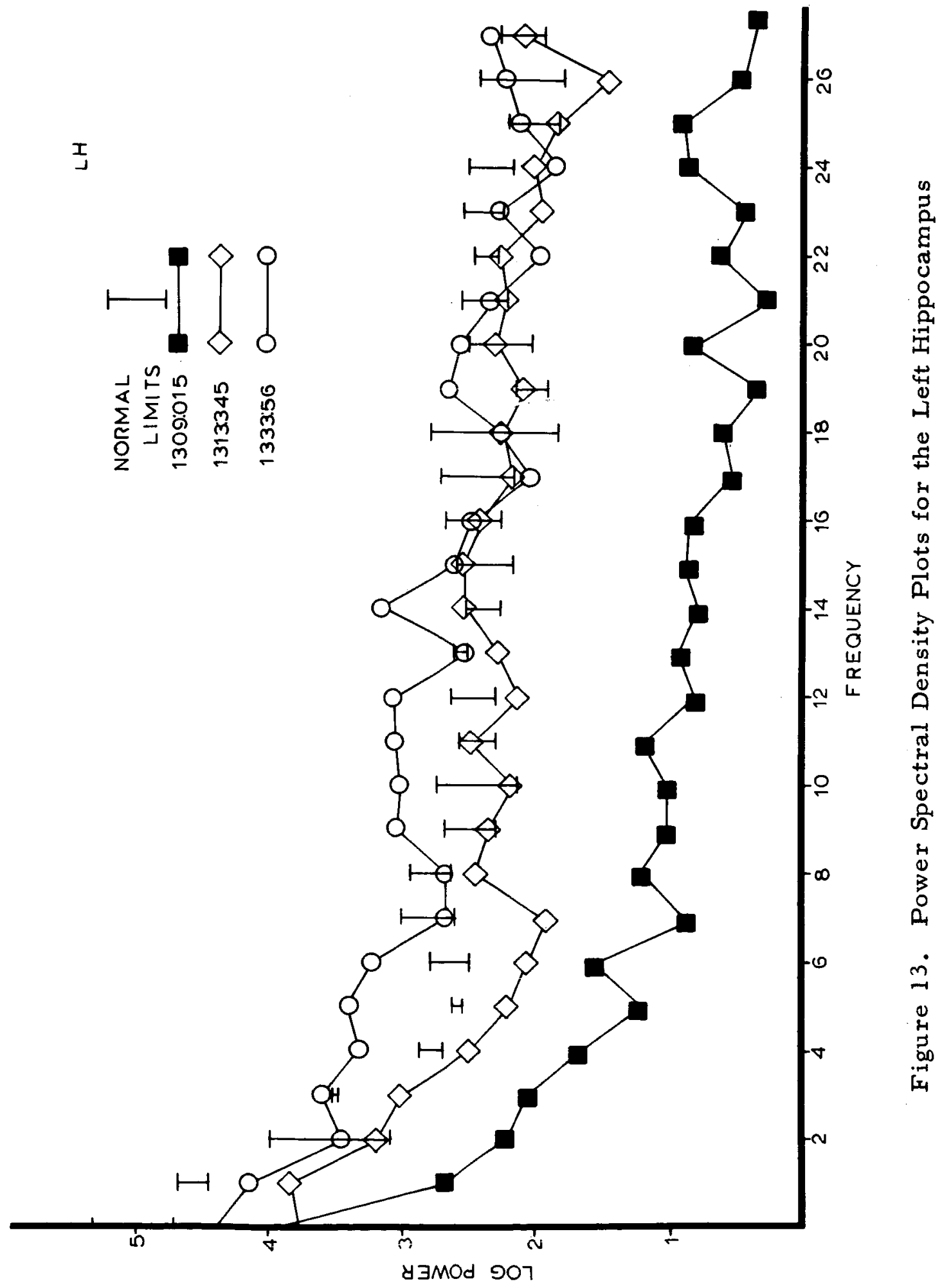


Figure 14 illustrates B.W. as a function of $\bar{F}$ for the left centro-parietal cortex. The PSD analys is of 10-second epoch samples of EEG from various stages of sleep (awake, Stages II, III, IV and paradoxical or REM) was also included with the Pre-RD samples to estimate the normal limits of stability. PSD epochs representing 10 -second samples following recompression but prior to the first meaningful behavioral response are enclosed by the cross-hatched areas. Figure 15 displays the same information for the left hippocampus. The differences in the patterns of stability and pattern of recovery among various structures are demonstrated by the comparison of these two figures.

\section{DISCUSSION AND CONCLUSIONS}

$R$ apid decompression entails both a sudden reduction of ambient pressure, in this case to a near vacuum, and the associated anoxia.

The loss of pressure permits the possibility of evolved gas bubble formation in the tissues as well as vaporization of body fluids or ebullism, and alveolar $\mathrm{Po}_{2}$ falls to levels below the venous $\mathrm{Po}_{2}$.

In dogs intrathoracic pressure rises with rapid decompression to levels in the vicinity of $60 \mathrm{~mm}$. Hg. Postcaval pressure measurements reflect a similiar rise, which may continue to increase to levels in the vicinity of $100 \mathrm{~mm}$. $\mathrm{Hg} \mathrm{(8)}$. Cerebral spinal fluid (CSF) pressure has been found to reflect changes in intrathoracic pressure (9), and should also be significantly influenced by venous pressure. Therefore, assuming patency of the CSF system, a pressure of from $60-100 \mathrm{~mm}$. $\mathrm{Hg}$. would be expected with decompression. This is above the vapor pressure of water, and would be expected to decrease the likelihood of ebullism with embolism although gas evolution with bubble formation would still be possible. Certainly none of the chimpanzees involved in the $R D$ experiments have demonstrated neurological sequalae suggestive of embolic phenomena.

Previous work in dogs $(10,11)$ strongly suggests that within a few seconds after RD to pressures below the vapor pressure of water, blood circulation stops, although the EKG 


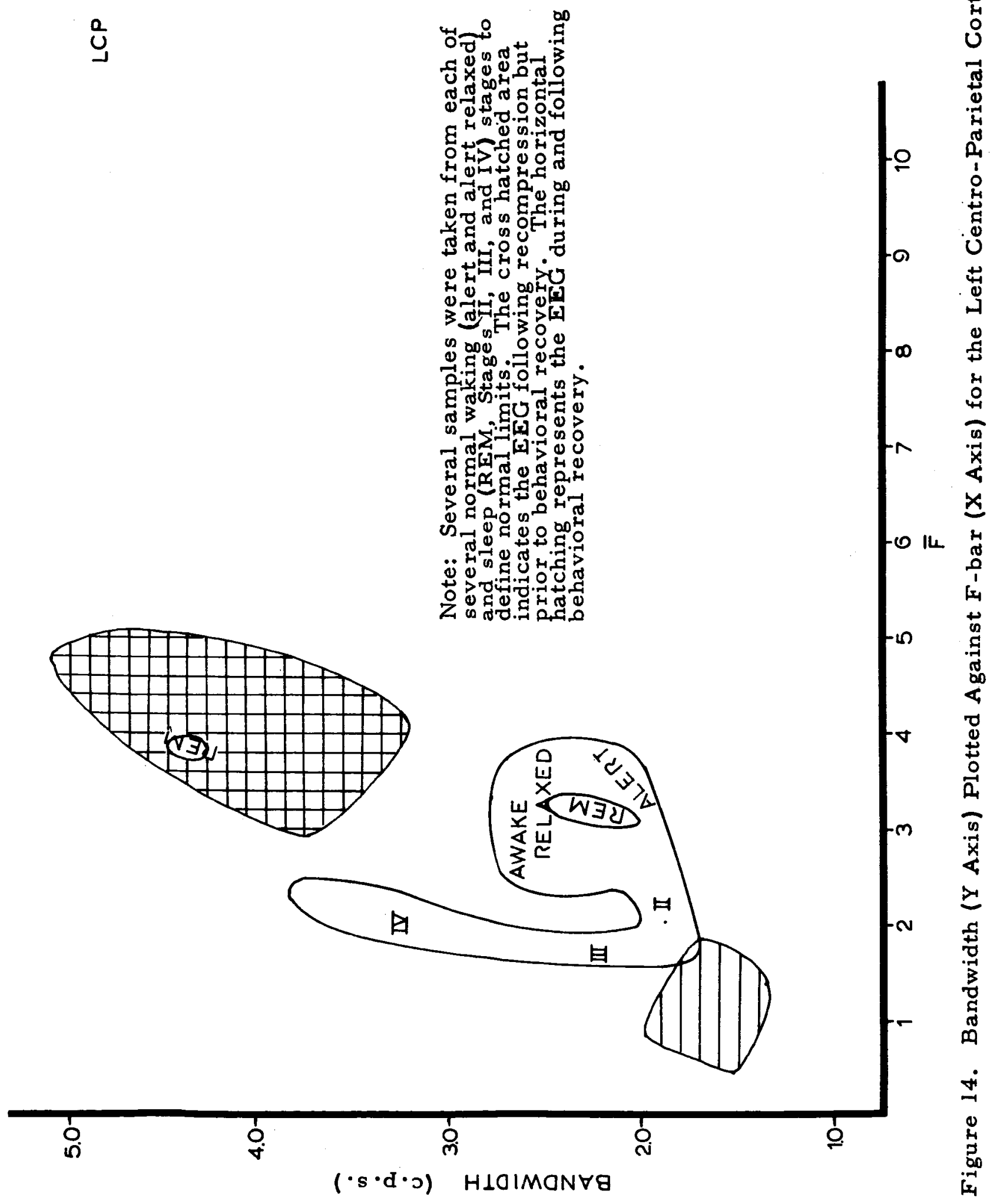




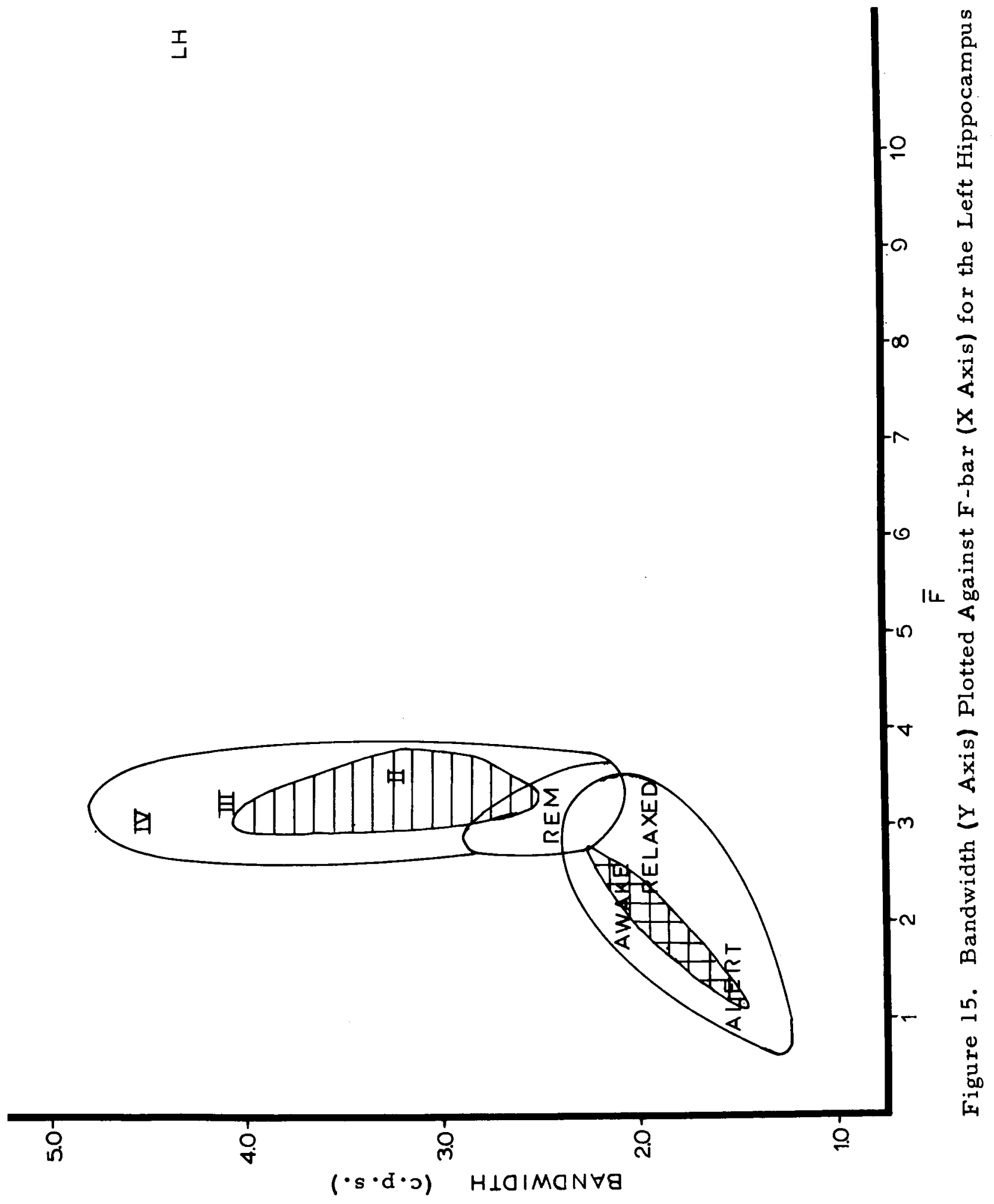


complexes continue. One explanation of cessation of flow is that intracardiac bubble formation precludes effective pumping action of the heart. This circulation arrested, the $\mathrm{O}_{2}$ content of the static blood in the tissues, including the central nervous system (CNS), would be available for metabolic needs. The effects, therefore, would be primarily due to ischemia, or stagnant anoxia, rather than just anoxia alone.

Ischemia, under normal pressure conditions, is known to be a more malignant process than anoxia, and irreversible cellular damage occurs faster with ischemia than with anoxia (12). Schneidler (12) feels that complete revival of the brain without lasting damage is possible after $3-1 / 2$ to 4 minutes of ischemia, although revival time with resultant damage may be possible up to 8 to 10 minutes, revival here being limited by cardiac insufficiency which develops with prolonged ischemia of the heart. In the present case, however, circulatory arrest and the resulting ischemia may be a survival enhancing factor, considering the severely abnormal environment the blood would be exposed to in passage through the lungs.

With the rapid and extensive expansion of gas during a $\mathrm{RD}$ the ambient temperature drop is correspondingly large. In the chimpanzee the skin temperature drops from 1.7 to $2.0^{\circ} \mathrm{C}$, but we cannot extrapolate to internal temperature changes on the basis of these data. Pratt (8) has, however, found postcaval temperature drops of from 1.5 to $7.7^{\circ} \mathrm{C}$ beginning 2 to 10 seconds post $R D$ in decompressions lasting 60 seconds. It is possible, therefore, that brain temperature drops at least slightly following rapid decompression, thus decreasing the metabolic rate and decreasing the rate of consumption of that $\mathrm{O}_{2}$ remaining in the tissues, and decreasing the rate of substrate utilization during the anerobic metabolism which follows oxygen exhaustion. The magnitude of the temperature drop would of course be related to blood volume flow, and early cessation of flow would diminish the change in temperature. Rosomoff (13) has found a decrease in cerebral metabolism of 6 percent per degree centigrade reduction in brain temperature, and Schneider (12) has noted that hypothermia increases revival time of brain in ischemia. Indeed, in dogs under conditions of profound hypothermia, neuropathological changes resulting from circulatory arrest were felt to be reversible if circulation was restored within 45 minutes (14). 
The EKG response to rapid decompression is remarkably reproducible, with a pronounced tachycardia terminating at approximately the same time in all animals as illustrated in Figure 1. With the multiplicity of physiological changes taking place during this period, those responsible for the change in rate would be difficult to separate. If, however, circulation stops in the chimpanzee as it does in the dog, it would probably stop at a time very close to that at which the heart rate slows so dramatically, and the cessation of coronary circulation may be causally related to the ensuing bradycardia.

It is of interest to note that the two animals that developed ventricular tachycardia (RD 12/90 and 16/90), one of whom progressed to ventricular fibrillation and death, both had pre-decompression normal heart rates significantly higher and more variable than the remainder of the animals. This raises the question of whether a higher level of activity in the sympathetic or another regulatory system might increase cardiac sensitivity to anoxia with resultant arrhythmias. Studies along this line could possibly result in metabolic or hormonal determinations relating to the likelihood of cardiac arrhythmia being associated with decompression, which could be used in a predictive manner.

Although a great deal of movement occurs at the time of decompression, it seems unlikely that this alone could account for the extensive pen deflection noted in the EEG record at RD, as movements of equal magnitude in the laboratory, although inducing some movement artifact especially in cortical leads, were not followed by pen displacement of the same degree. Frank (15), recording the electroencephalogram of dogs during rapid decompression, mentioned the great pen displacement that occurs with decompression, which in his study seemed to occur . 25 second earlier in the posterior leads. No such time variation was noted in the present study. Pen deflections of this nature could be related to sudden alterations in intracerebral tissue impedance, but such measurements have not been made.

In the present case, cortical electrical silence preceded subcortical silence and subcortical recovery preceded cortical recovery. This has been reported to occur in cats subjected to anoxia (16), and is in keeping with the concept of phylogenetically newer structures being more sensitive to the effects of anoxia than are older structures. 
The slow reticular formation rhythm that was time-locked to the EKG during decompression, and when other areas were silent, is very similar to that described by Sugar (16) as being recorded from the medulla of cats after the cerebral circulation had been tied off. Sugar felt that in cats the activity could reflect venous pulsation. If indeed circulation stops during decompression, this activity would not be related to flow. A possible venous pressure wave associated with cardiac contraction, even though there may be no effective flow, cannot be excluded however. It is also possible that this activity represents continued activity of this phylogenetically old structure in the face of electrical silence in higher structures such as the rhinencephalon and cortex.

With stimulation of the N. Cm. there was a complete loss of the amygdala response, and a loss of all but an $n_{1}$ residual of the cortical response. In monkeys undergoing rapid decompression from $200 \mathrm{~mm}$. $\mathrm{Hg}$ to 30 to $90 \mathrm{~mm}$. Hg, the striate response to geniculate stimulation persisted for from 3 to 5 minutes, although spontaneous cortical electrical activity ceased at about 29 seconds (17). Certainly in the present case the environmental extremes were greater, and whether a residual cortical response would have been present at 180 seconds is not known. If the persistence of the $n_{1}$ wave in the cortex is real, it might suggest that the afferent volley continues to arrive at the cortex which is itself unable to respond to the stimulation. Thalamocortical projections may not be responding in a physiological manner, however, and a cortical afferent volley may represent only aberrent axonal propagation from thalamic areas. The complete loss of the amygdala response, which due to the apparently greater resistance of the amygdala to an anoxic stress of this sort as measured by spontaneous activity would be expected to outlast the cortical response, tends to support the latter possibility.

Although the computer analysis of EEG data from this experiment has not yet been completed, those results which are available are being included for the purpose of illustrating the basic feasibility of using this type of analysis, and what might be expected to derive from it.

The power spectra computed for various structures permits a rapid evaluation of relative power in the various frequency ranges and as in Figures 11, 12, and 13, clearly demonstrates what ranges have returned to normal and in what 
order structures return to normal. A contour map type of spectral display has been used to show this type of information and will be applied to the present data in the near future.

Plotting bandwidth against F-bar (Figs. 14 and 15) clearly separates different behavioral states, in this case stages of sleep and progressive recovery from unconsciousness with return of behavioral functioning. As the total power in each structure returns, recovery appears to proceed through a similar pattern, following a progression like that seen from deep (Stage IV) sleep through light (Stage II) sleep to awake and alert in the normal animal.

With regard to the normal functioning of the structures recorded during varying states of alertness and sleep, the hippocampus is inversely related to the other structures, and this same inverse relationship holds during recovery from RD, again measured by bandwidth as a function of $F$-bar. This would support the hypothesis that informational organization as measured by these variables may be of more than one type, and would suggest that phylogenetic development may be a significant variable in determining the type of informational organization utilized by a particular structure.

Differences were seen in the apparent amount of organization during recovery. The hippocampus appeared to maintain the majority of its plotted points within normal limits (i.e., the limits encountered in the normal sleep and waking record) while the cortex, and to a lesser degree the amygdala and uncus, ranged further outside normal limits. Among the structures recorded, the hippocampus also returned to normal first. This would support the hypothesis that phylogenetically older structures possess a greater degree of internal organization, are less dependent upon integration and processing of information by lower centers, and exhibit less disruption of informational or ganization when function is disrupted by a stress of this sort. Differences of organization and information processing as a function of cortical phylogenetic and cytoarchitectural differences, the hippocampus representing archicortex, the uncus palecortex, and the cortex, neocortex, may well be reflected in these data. If at each higher stage of organization or phylogenetic age incoming information can be modified before transmission to a higher level, and the input 
to higher levels is in part a function of processing at lower levels as is generally thought to be the case in the central nervous system, the higher structures will be the most seriously disrupted and the last to return to normal, which is what was found in this case.

The final step in the analysis employing PSD data will be an attempt to predict recovery at least at the ordinal level, using variables defined and described above. This prediction will subsequently be tested in future RD experiments.

The return of the normal cortical average evoked response to N.Cm. stimulation parallels an increase in cortical bandwidth and F-bar, suggesting that these measures may also contain information relevant to cortical excitability.

The follow-up EEGs will be submitted for computer analysis. Since the animals performance on the behavioral program 6 weeks post RD was slightly but significantly poorer than baseline, there would seem to be an effect caused by decompression. In addition, the animal was noted to be more irritable and hyperactive than normal for several months following decompression. It would therefore appear that, in combination with the performance decrement, one might hypothesize a mild organic residual. Although not mentioned in other studies, symptoms of this nature would probably not be noticed unless actively looked for. Another area in which early organic changes may well become apparent is that of social behavior. This area has not been studied, and it is not known if experiencing a rapid decompression with a resultant mild cortical impairment might alter social behavior in a significant manner. Certainly from the standpoint of extrapolation to man, such information would be most important as relatively mild changes such as increased irritability, hyperactivity, or mild changes in the direction of thoseassoeiated with loss of cortical tis sue could have a pronounced effect on the micro-society of a space vehicle, especially if the person exhibiting such changes gave no other gross evidence of CNS damage. Although none of the animals in the previous or present series of RDs have shown any evidence of a delayed deleterious effect, the possible development of delayed postanoxic encephalopathy as a complication of rapid decompression should be kept in mind. Described as a complication of anoxia 
in humans, the insidious nature of its development could well be overlooked in animal experimentation. Patients subjected to coma producing anoxia from a variety of causes exhibit apparently complete intellectual and neurological recovery from the initial insult. After an apparently normal period of from 2 to 10 days, and possibly as long as several weeks, psychological symptoms such as withdrawal irritability, confusion, or excitement are noted, to be shortly followed by progressive neurological deterioration usually leading to death. Cerebral hemispheric demyelination without significant neuronal damage has been the consistent pathological abnormality, and the pathogenesis is unknown. Death is not the inevitable outcome, however, and recovery may be complete (18). 


\section{REFERENCES}

1. Koestler, A. G. "The Effect on the Chimpanzee of Rapid Decompression to a Near Vacuum." NASA Contractor Report CR-329, 1965.

2. Stephens, L. M., J. L. Hartman, O. F. Lewis, A. G. Koestler and J. M. Rhodes. Section II. "Physiology in the Effect on the Chimpanzee of Rapid Decompression to a Near Vacuum." A. Koestler, Ed., NASA CR-329, 1965

3. Cooper, Ray. Personal communication.

4. Rhodes, J. M. , M. L. Reite, D. Brown, and W. R. Adey. "Cortical Subcortical Relationships of the Chimpanzee During Different Phases of Sleep." IN: Neurophysiologie des Etats de Sommeil, J. Jouvet, Ed. , Editions du Centre National do la Recherche Scientifique, Paris, pp. 451-473, 1965.

5. Walter, D. O. "Spectral Analysis for Electroencephalograms: Mathematical Determination of Neurophysiological Relationships from Records of Limited Duration. " Exp. Neurol. 8: 155-181 1963.

6. Walter, D. O. and W. R. Adey. "Spectral Analys is of Electroencephalograms Recorded during Learning in the Cat, Before and After Subthalamic Lesions." Exp. Neurol. 7:481-501, 1963.

7. Walter, D. O., J. M. Rhodes, D. Brown and W. R. Adey. "Comprehensive Spectral Analysis of Human EEG Generators in Posterior Cerebral Regions." EEG and Clin. Neurophysiol. 20: $224-237,1966$.

8. Pratt, A. J. "Cardiovascular and Respiratory Sequalae of Anesthetized Dogs Upon Rapid Decompression to a Near Vacuum." 657 lst ARI, Holloman AFB. N. M. (In Press)

9. Whitehorn, W. V., A. Lein, A. Edelmann and F. A. Hitchcock. "The Effect of Explosive Decompression on Cerebrospinal Fluid Pressure." Amer. J. Physiol. 148: 253-258, 1947. 
10. Frỳe, S. A., Jr. "Circulatory Arrest in Dogs as Shown by $\mathrm{X}$-ray Studies Following Explosive Decompression to $30 \mathrm{~mm}$. hg." Studies in Explosive Decompression WADC Tech Report 53-191 December 1953.

11. Whitehorn, W. V. "Circulatory Responses to Exposure to Barometric Pressure of $30 \mathrm{~mm}$. Hg." Fed. Prov. 7: 133, 1948 (No. 267).

12. Schneider, M. "Survival and Revival of the Brain in Anoxia and Ischemia" IN: Cerebral Anoxia and the Electroencephalogram, Gastaut, H. and Meyer, J., Ed. Chas. Thomas, Springfield, Ill., Chap 13, pp. 134-143, 1961.

13. Rosomoff, H. L. "Protective Effects of Hypothermia Against Pathological Processes of the Nervous System." Ann N. Y. Acad. Sci. 80 (2): 475-486, 1959.

14. Miller, D. R., M.A.S. Hallaba, A. T. Steegmann. "Effect of Profound Hypothermia with Circulatory Arrest in Dogs." Annals of Surgery 161:272-285, Feb. 1965.

15. Frank, G. B. "The Effects of Explosive Decompression on the Elect roencephalograms of Dogs. " Studies in Explosive Decompression WADC Tech Report 53-191, December 1953.

16. Sugar, O., and R. W. Gerard. "Anoxia and Brain Potentials." J. Neurophysiology, 1:558-572, 1938.

17. Luft, U. C. and W. K. Noell. "Anoxic Survival Time of Cerebral Activity in Sudden Exposure to High Altitudes." Am. J. Physiol. 171:745. Dec. 1953 (Abstract).

18. Plum, F., J. B. Posner and R. F. Hain. "Delayed Neurological Deterioration after Anoxia." Arch. Int. Med.

$110: 18-25,1962$. 


\title{
SECTION III
}

\section{CLINICAL EVALUATION}

Donald C. Van Riper, Captain, VC, USAF Phillip W. Day, Captain, VC, USAF

\author{
Veterinary Division \\ 657 1st Aeromedical Research Laboratory \\ Aerospace Medical Division \\ Air Force Systems Command \\ Holloman Air Force Base, New Mexico
}





\section{INTRODUCTION}

During the continuation of the decompression effort it was the responsibility of the Veterinary Division of the 657 Ist Aeromedical Research Laboratory, Holloman AFB, New Mexico, to provide healthy subjects according to the criteria described in detail in the publication entitled "Effect on the Chimpanzee of Rapid Decompression to a Near Vacuum," edited by Alfred G. Koestler, NASA CR-329, November 1965. However, some changes in procedure developed: Based on data collected during the first series of nine decompressions, it was decided to omit postdecompression laboratory analyses since no major variations in hematology or blood chemistry values had been found. Because of interfering substances in the urine samples collected in metabolic cages, steriod values were not determined; however, modification of procedures are now being developed to permit analysis of samples at a later date.

\section{CLINICAL EVALUATION}

Four days prior to decompression all experimental subjects underwent a physical examination. This examination included measurement of pulse rate, respiration rate, temperature, body weight, and blood pressure. Roentgenograms (PA, lateral, in a vertical position) of the chest and the abdomen were taken. Palpation, auscultation, and percussion of the thorax was performed and blood chemistry and hematology data were determined. All values were within normal ranges for chimpanzees, with the exception of Subject No. 170. This subject displayed an elevated blood pressure (systolic and diastolic) and electrocardiograms as well as $\mathrm{X}$-ray pictures showed the heart to be displaced toward the left of the chest, but it was decided to continue with the test to determine the effects of rapid decompression to a near vacuum on a subject of questionable fitness.

Post-decompression examinations followed immediately after subjects were removed from the decompression chamber. All subjects appeared to be somewhat subdued and dehydrated weight loss ranged from 250 to 800 grams. The subjects consumed large amounts of fluid and showed good appetites when food and water were presented. Clinical values were within 
normal ranges for chimpanzees during the immediate postdecompression examination; however, Subjects No. 172 and No. 156 showed slight neutrophelia 24 and 48 hours respectively post-decompression. Male subjects showed tenderness in the area of the scrotum and swelling of the penal sheath. Subject No. 170 expired during exposure to near vacuum. A detailed necropsy report is presented in Section $I$. 


\section{SECTION IV}

\section{PHYSICAL ENVIRONMENT}

Thomas L. Dobson, B.S. M.E.

Fredrick C. Segesman, 1 Lt. USAF

Environmental Test Branch Central Inertial Guidance Test Facility Air Force Missile Development Center Air Force Systems Command Holloman Air Force Base, New Mexico 


\section{ACKNOW LEDGEMENTS}

Gerald D. Downard, SSgt., USAF

Thomas L. Smith, SSgt., USAF

Jasper E. Burrell, SSgt., USAF

Herman P. Smith, TSgt., USAF

Delore Martell

Charles E. Nichols

Atwell N. Rumsey
Chamber Operation

Chamber Operation

Instrumentation

Chamber Operation

Instrume ntation

Chamber Maintenance

Engineering Assistance 
A modified closed environmental system chamber ( see Section I for description) was connected by a pneumatic decompression valve to an 84.9 cubic meter tank and a 48 cubic meter "Stratosphere Chamber." With the decompression chamber at $179 \mathrm{~mm}$. $\mathrm{Hg}$ and both parasitic tanks at approximately 200 microns, the resultant initial pressure amounted to approximately $2 \mathrm{~mm}$. Hg. after decompression.

A liquid nitrogen $\left(\mathrm{LN}_{2}\right)$ coil was piaced into the first vacuum tank covering the opening of the decompression valve. The coil was manufactured from finned refrigeration tubing. Thirty minutes before a scheduled decompression, liquid nitrogen was pumped through the system, which brought the temperature of the coil to approximateiy $-190^{\circ} \mathrm{C}\left(83^{\circ} \mathrm{K}\right)$. The liquid nitrogen system was designed to trap condensible outgassing during and following decompression and to maintain pressure variations during decompression below $.2 \mathrm{~mm}$. Ifg.

Recompression to $179 \mathrm{~mm}$. $\mathrm{Hg}$ in 30 seconds was accomplished with bottled oxygen through a regulator adjusted to $1.552 \mathrm{~mm}$. $\mathrm{H}_{\mathrm{B}}$. Five-second emergency recompression was constantly available through an oxygen bottle $(25,860 \mathrm{~mm}$. $\mathrm{Hg}$ pressure) connected directly to the system. The life support sub-system was separated from the decompression chamber 5 seconds prior to decompression, and flow was resumed immediately after the chamber was recompressed to $179 \mathrm{~mm}$. $\mathrm{Hg}$.

The chamber instrumentation system was augmented for the special conditions of this experiment. In addition to the system oxygen analyzer-recorder, three Brown stripchart recorders were installed. A dual-pen recorder charted chamber wall and air temperatures which were sensed by copper-constantan thermocouples. A single-pen unit recorded pressures from 1 to $660 \mathrm{~mm}$. $\mathrm{Hg}$, sensed by a Statham $646.5 \mathrm{~mm}$. Hg strain-gauge pressure transducer through a bridge circuit. The third recorder was used for accurate pressure readings between 1 and $2 \mathrm{~mm}$. $\mathrm{Hg}$ which was sensed by a Pirani tube through a CEC Autovac gauge. A fourth unit was installed to record relative humidity as sensed by a Honeywell Q457A lithium chloride sensor. 
Nine decompression tests were completed between 1 April 1965 and 31 August 1966. The environmental conditions for these tests are recapitulated in the following table. Temperature, relative humidity, and percent oxygen values are averages of 15-minute readings. 


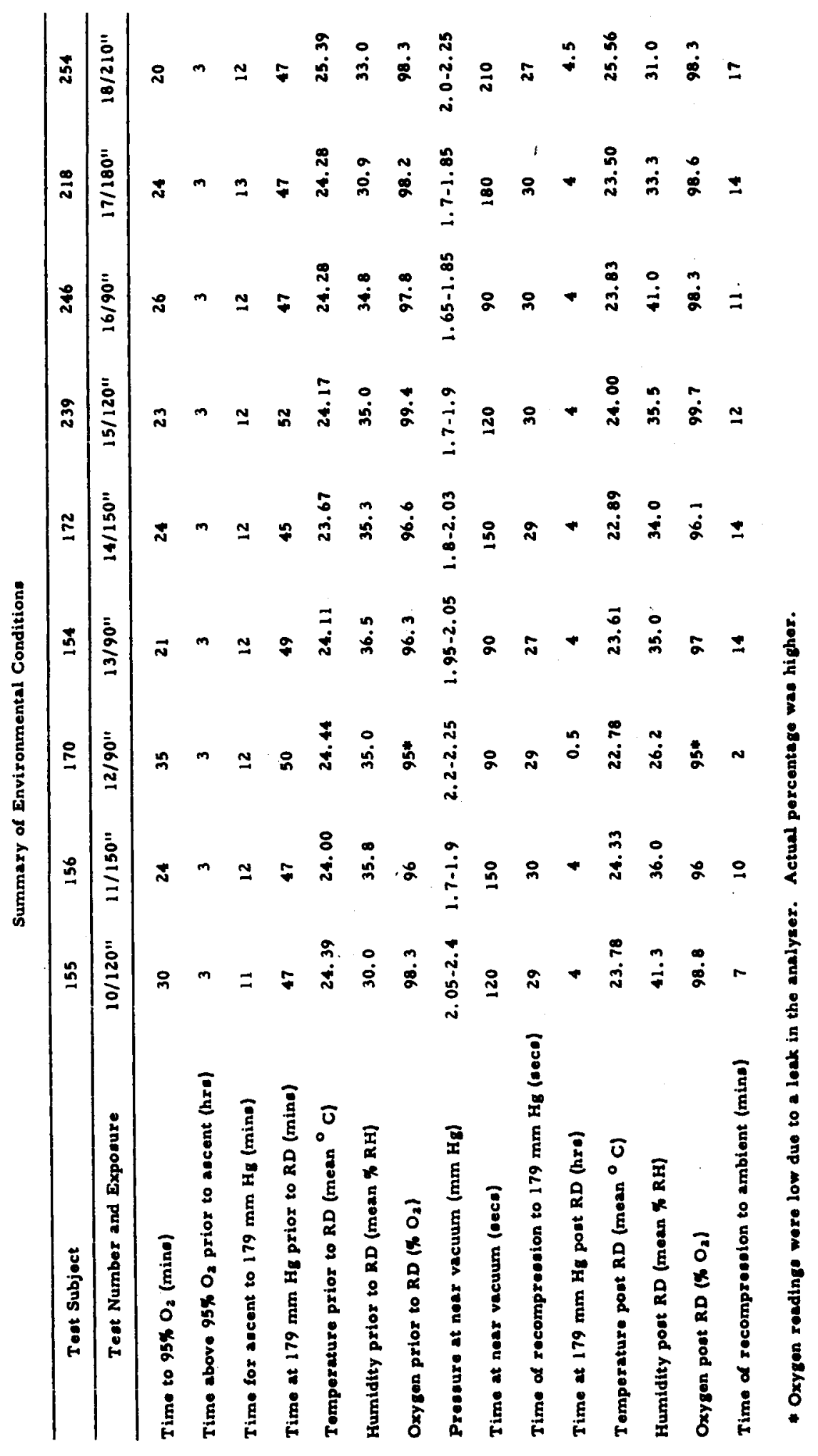


Unclassified

Security Classification

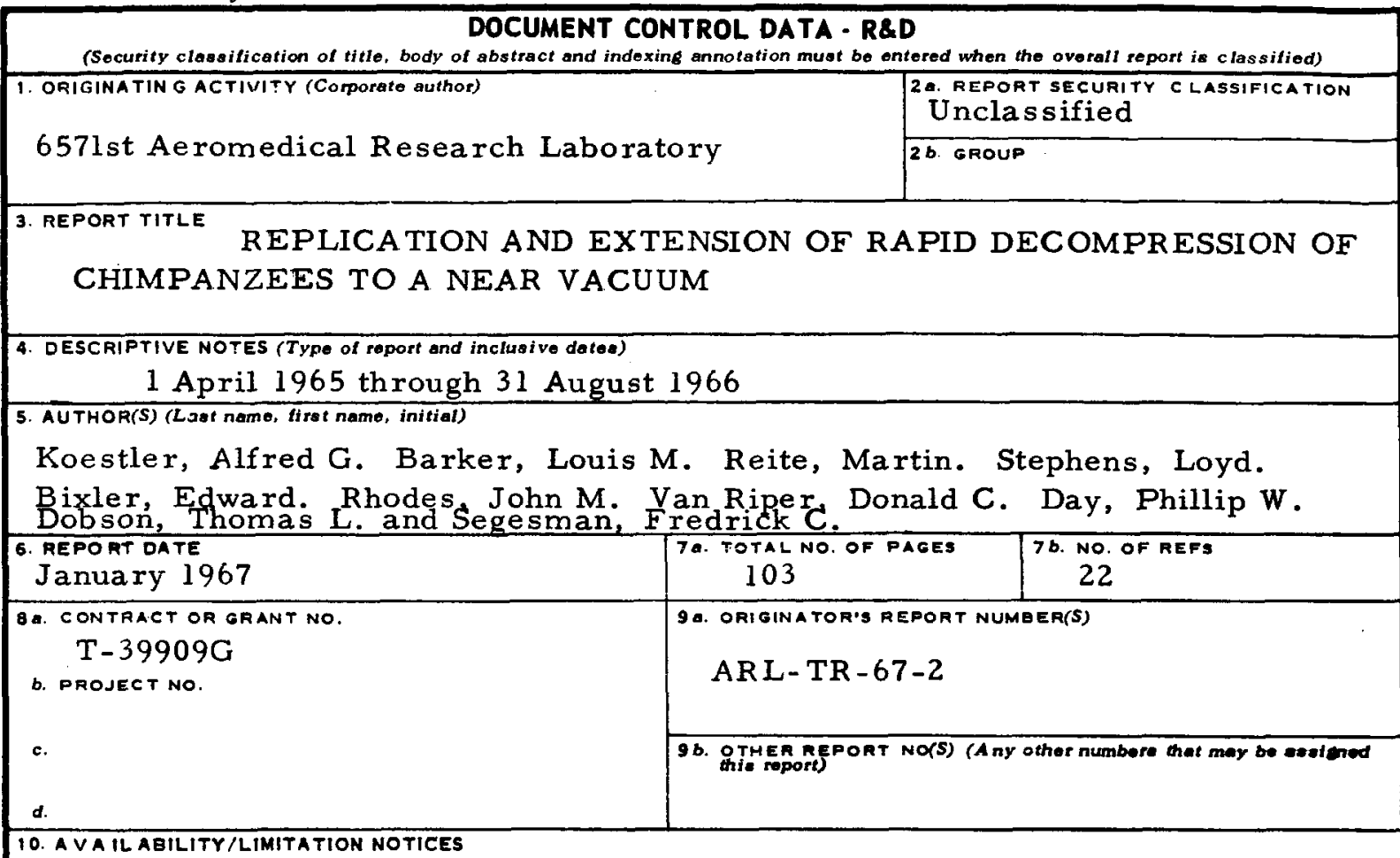

Distribution of this document is unlimited.

11. SUPPL EMENTARY NOTES

12. SPONSORING MILITARY ACTIVITY

6571st Aeromedical Research Laboratory

Holloman AFB, NMex 88330

13. Agstract Nine chimpanzees were decompressed from $179 \mathrm{~mm}$. Hg (breathing $100 \%$ oxvgen) to less than $2 \mathrm{~mm}$. $\mathrm{Hg}$ in .8 second and remained at this altitude from 90 to 210 seconds. After recompression with 100 percent oxygen to $179 \mathrm{~mm}$. $\mathrm{Hg}$, , the subjects were maintained at this pressure environment for 4 hours post decom pression. Results of these tests, which were of replicatory nature, have substantiated previous findings that chimpanzees can survive sudden exposure to a near vacuum and recove $x$ within 4 hours to once again satisfactorily perform complex behavioral schedules on which they had had extensive training. One subject of questionable fitness expired following a 90-second exposure to a near vacuum. ECG, respiration, and skin temperature were recorded as a standard procedure from all subjects, only two of which were instrumented for EEG. All subjects demonstrated tachycardia immediately following decompression which was regularily followed by a rather sudden bradycardia. There was an initial drop in skin temperature immediately after decompression with an ensuing gradual fall resulting in a total decrease of 1.7 to $2.0^{\circ} \mathrm{C}$. Visual inspection of the EEG as well as power spectral density compute $r$ analysis indicated the expected greater subcortical resistance to anoxia when compared to cortical responses. Evoked responses to stimulation of subcortical areas were used as indicators of excitability 
Unclassified

Security Classification

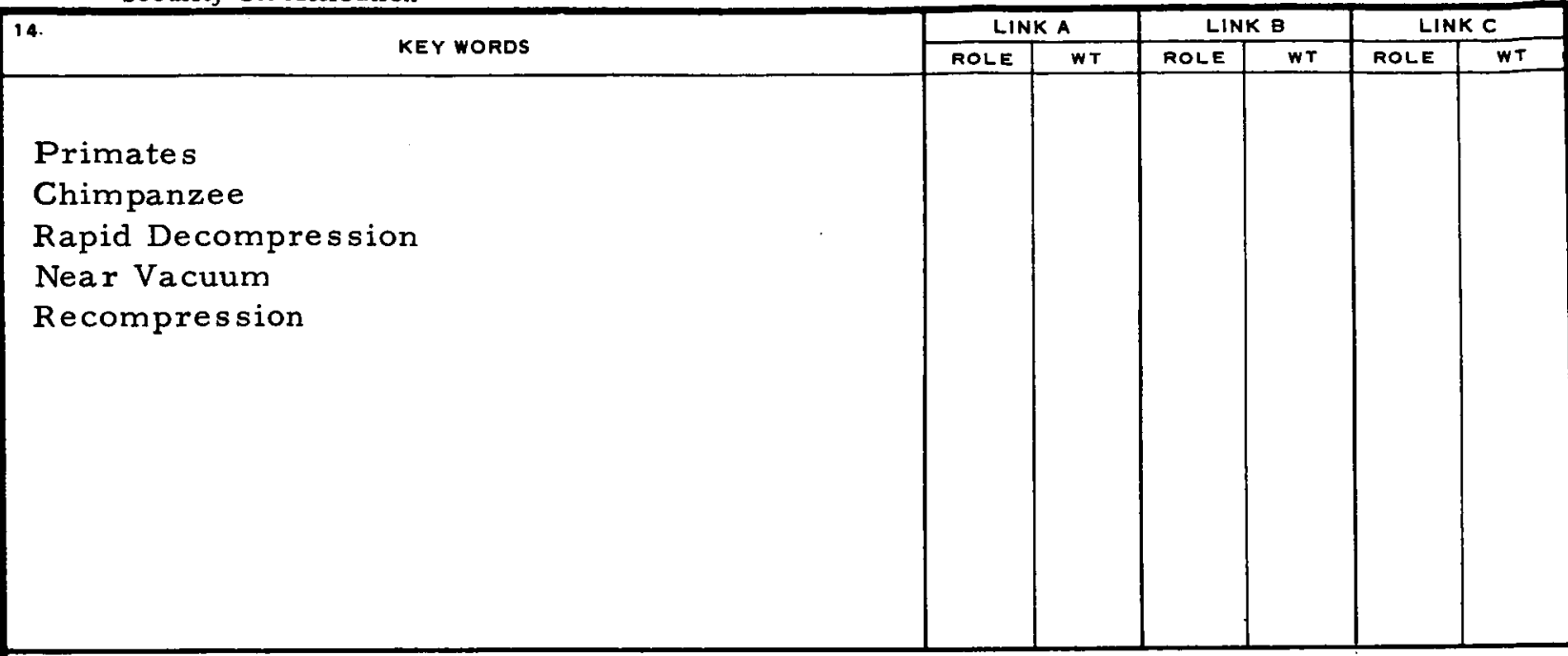

1. ORIGINATING ACTIVITY: Enter the name and address of the contractor, subcontractor, grantee, Department of Defense activity or other organization (corporate suthor) issuing the report.

2a. REPORT SECURTY CLASSIFICATION: Enter the overall security classification of the report. Indicate whether "Restricted Data" is included. Marking is to be in accordance with appropriate security regulations.

2b. GROUP: Automatic downgrading is specified in DoD Directive 5200.10 and Armed Forces Industrial Manual. Enter the group number. Also, when applicable, show that optional markings have been used for Group 3 and Group 4 as authorized.

3. REPORT TITLE: Enter the complete report title in all capital letters. Titles in all cases should be unclassified. If a meaningful title cannot be selected without classification, show title classification in all capitals in parenthesis immediately following the title.

4. DESCRIPTIVE NOTES: If appropriate, enter the type of report, e.g., interim, progress, summary, annual, or final. Give the inclusive dates when a specific reporting period is covered.

5. AUTHOR(S): Enter the name(s) of author(s) as shown on or in the report. Enter last name, fir st name, middle initial. If military, show rank and branch of service. The name of the principal aiathor is an absolute minimum requirement.

6. REPORT DAT $=$ Enter the date of the report as day, month, year; or month, year. If more than one date appears on the report, use date of publication.

7a. TOTAL NUMBER OF PAGES: The total page count should follow normal pagination procedures, i.e., enter the number of pages containing information.

7b. NUMBER OF REFERENCES Enter the total number of references cited in the report.

8a. CONTRACT OR GRANT NUMBER: It appropriate, enter the applicable number of the contract or grant under which the report was written.

8b, \&c, \& 8d. PROJECT NUMBER: Enter the appropriate military department identification, such as project number, subproject number, system numbers, task number, etc.

9 a. ORIGINATOR'S REPORT NUMBER(S): Enter the official report number by which the document will be Ident ified and controlled by the originating activity. This number must be unique to this report.

9b. OTHER REPORT NUMBER(S): If the report has been assigned any other report numbers (either by the originator or by the sponsor), also enter this number(s).

10. AVAILABILITY/LIMITATION NOTICES: Enter any limitations on further dissemination of the report, other than those imposed by security classification, using standard statements such as:

(1) "Qualified requesters may obtain copies of this report from DDC."

(2) "Foreign announcement and dissemination of this report by DDC is not authorized."

(3) “U. S. Government agencies may obtain copies of this report directly from DDC. Other qualified DDC users shall request through

(4) "U. S. military agencies may obtain copies of this report directly from DDC Other qualified users shall request through

(5) "All distribution of this report is controlled Qualified DDC users shall request through - "

If the report has been furnished to the Office of Technical Services, Department of Commerce, for sale to the public, indicate this fact and enter the price, if known

11. SUPPLEMENTARY NOTES: Use for additional explanatory notes.

12. SPONSU! ING MILITARY ACTIVITY: Enter the name of the departmental praject office or laboratory sponsoring (paying for) the research and development. Include address.

13. ABSTRACT: Enter an abstract giving a brief and factual summary of the document indicative of the report, even though it may also appear elsewhere in the body of the technical report. If additional space is required, a continuation sheet shall be attached.

It is highly desirable that the abstract of classified reports be unclassified. Each paragraph of the abstract shall end with an indication of the military security classification of the information in the paragraph, represented as $(T S),(S),(C)$, or $(U)$.

There is no limitation on the length of the abstract. However, the suggested length is from 150 to 225 words.

14. KEY WORDS: Key words are technically meaningful terms or short phrases that characterize a report and may be used as index entries for cataloging the report. Key words must be selected so that no security classification is required. Identifiers, such as equipment model designation, trade name, military project code name, geographic location, may be used as key words but will be followed by an indication of technical context. The assignment of links, rules, and weights is optional. 


\title{
February 1967
}

\author{
ERRATA
}

ARL-TR-67-2. $\frac{\text { Replication and Extension of Rapid Decompression }}{\text { of Chimpanzees to a Near Vacuum, dated January } 1967 .}$

Change: Attach the following explanatory note to Figure 15, Page 86.

Note: The horizontal lined area represents the EEG following recompression but prior to behavioral recovery. The cross hatched area represents the EEG during and following behavioral recovery.

6571st Aeromedical Research Laboratory

Aerospace Medical Division

Air Force Systems Command

Holloman Air Force Base, New Mexico 